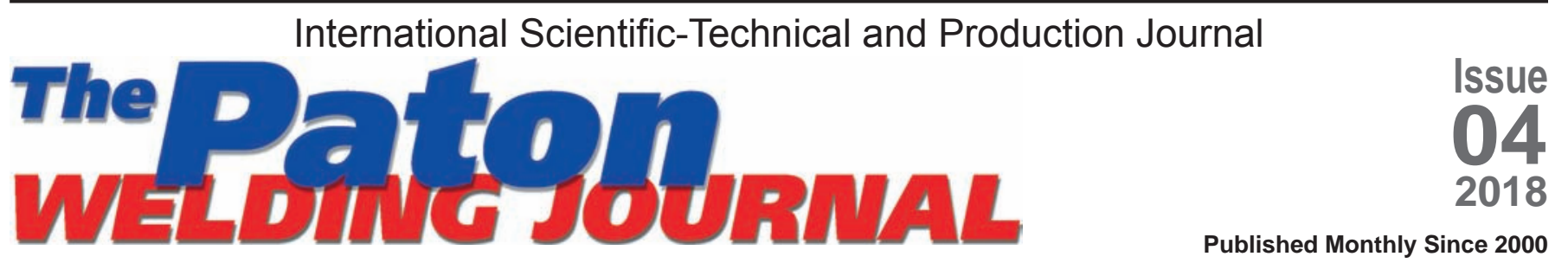

English translation of the monthly «Avtomaticheskaya Svarka» (Automatic Welding) journal published in Russian since 1948

\section{EDITORIAL BOARD \\ Editor-in-Chief B.E. Paton}

Scientists of PWI, Kyiv S.I. Kuchuk-Yatsenko (vice-chief ed.), V.N. Lipodaev (vice-chief ed.), Yu.S. Borisov, G.M. Grigorenko, A.T. Zelnichenko, V.V. Knysh,

I.V. Krivtsun, Yu.N. Lankin, L.M. Lobanov, V.D. Poznyakov, I.A. Ryabtsev, K.A. Yushchenko

Scientists of Ukrainian Universities V.V. Dmitrik, NTU «KhPI», Kharkov V.V. Kvasnitsky, NTUU «KPI», Kyiv

E.P. Chvertko, NTUU «KPl», Kyiv

Foreign Scientists

N.P. Alyoshin

N.E. Bauman MSTU, Moscow, Russia Guan Qiao

Beijing Aeronautical Institute, China M. Zinigrad

Ariel University, Israel V.I. Lysak

Volgograd STU, Russia Ya. Pilarczyk

Welding Institute, Gliwice, Poland U. Reisgen

Welding and Joining Institute, Aachen, Germany G.A. Turichin

St. Petersburg SPU, Russia

Founders

E.O. Paton Electric Welding Institute, NASU

International Association «Welding» Publisher

International Association «Welding» Translators

A.A. Fomin, O.S. Kurochko, I.N. Kutianova Editor

N.G. Khomenko

Electron galley

D.I. Sereda, T.Yu. Snegiryova Address

E.O. Paton Electric Welding Institute,

International Association «Welding»

11 Kazimir Malevich Str. (former Bozhenko Str.), 03150, Kyiv, Ukraine

Tel.: (38044) 20060 16, 2008277

Fax: (38044) 2008277,2008145

E-mail: journal@paton.kiev.ua

www.patonpublishinghouse.com

State Registration Certificate

KV 4790 of 09.01 .2001

ISSN 0957-798X

DOI: http://dx.doi.org/10.15407/tpwj Subscriptions

$\$ 348,12$ issues per year

air postage and packaging included. Back issues available.

All rights reserved.

This publication and each of the articles contained

herein are protected by copyright

Permission to reproduce material contained in this

journal must be obtained in writing from the Publisher.

\section{CONTENTS}

Interview with A.N. Kovalchuk, Director of PSJC

«Kharkiv Mashinostroitelnii Zavod «Svet Shakhtyora»

\section{SCIENTIFIC AND TECHNICAL}

Kvasnytskyi V.V., Kvasnytskyi V.F., Dong Chunlin, Matviienko M.V. and Yermolayev G.V. Stressed state of welded and brazed assemblies from similar materials with a soft interlayer under axial loading

Anoshin V.A., Ilyushenko V.M. and Lukyanchenko E.P. Effect of main impurities on formation of cracks in welding of copper-nickel alloys and surfacing of monel on steel

Kavunichenko A.V., Shvets V.I. and Antipin E.V. Peculiarities of flash-butt

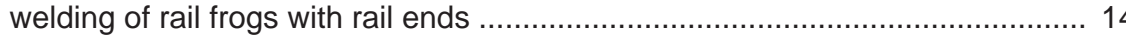

Vakulenko I.O. and Plitchenko S.O. Determination of parameters of friction stir welding mode of aluminum-based alloy

\section{INDUSTRIAL}

Cheprasov D.P., Kuznetsov Yu.A. and Lednikov E.A. Automatic submerged-arc welding of bridge spans of high-quality steels 10KhSNDA and 15KhSNDA in field

Makhlin N.M., Vodolazsky V.E., Popov A.E., Korotynsky A.E. and Lavrov S.I.

Selection of welding technology in manufacture and restoration repair of spirals of high-pressure heaters of NPP power units

Voronchuk A.P., Zhudra A.P., Petrov A.V. and Fedosenko V.V. Influence of surfacing modes using flux-cored strips on chemical composition and hardness of deposited metal

Kuskov Yu.M., Soloviov V.G., Osechkov P.P. and Zhdanov V.A. Application of non-conducting consumable billets at electroslag surfacing in currentsupplying mould

\section{NEWS}

Visit of Specialists of the Lanzhou University of Technology (PRC)

to the PWI

\section{INFORMATION}

Method of Assessment of Metal State of WWER-1000 Reactor Welded Body

Developed in the PWI

Equipment for Production of 3D Metallic Parts using Plasma-Arc Technology

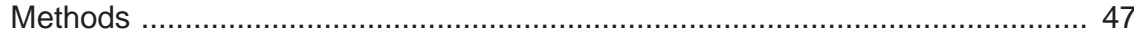

Reverse Polarity Plasma-Air Cutting ….............................................. 48

Unit for Plasma-Arc Wire Spraying of Coatings ......................................... 48 


\section{INTERVIEW WITH A.N. KOVALCHUK, DIRECTOR OF PSJC «KHARKIV MASHINOSTROITELNII ZAVOD «SVET SHAKHTYORA»}

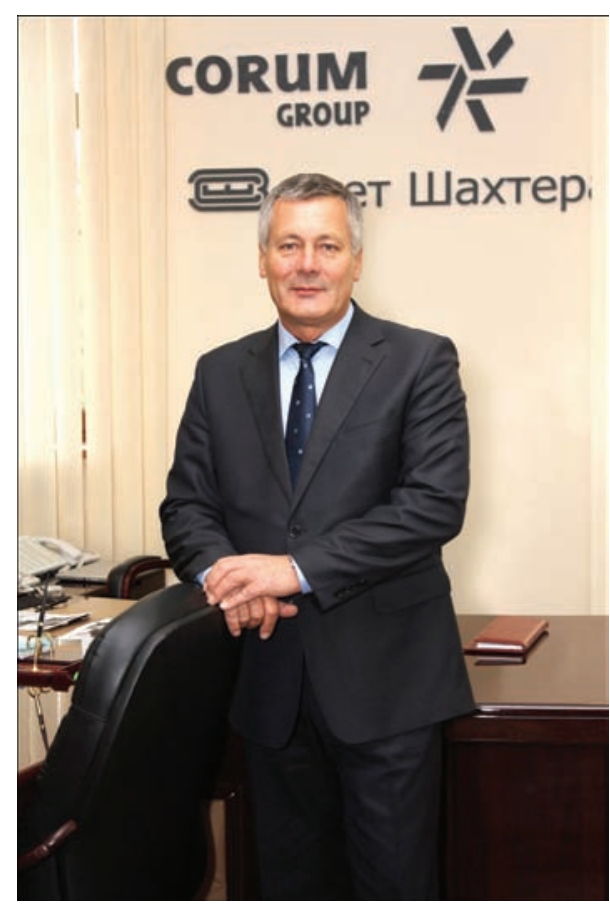

PJSC «Svet Shakhtyora» is a structural unit of CORUM GROUP Company, producing equipment for mining industry: scraper conveyors and reloaders, cleaning and tunneling combines, mine substations, mine crushers, safety hydraulic clutches, head explosion proof battery lights, and methane analyzers.

Products are operated at different mining and climatic conditions in coal, shale and potassium mines.

Products are certified in keeping with the requirements of DSTU ISO 90010-2001.

Mr. Kovalchuk, your company has been successfully developing during the last three years. It increases the output of mining equipment, where welded structures make up a considerable proportion. Under the conditions, when the market of independent Ukraine has declined, how can you explain intensive development of your company?

Yes, indeed, internal market of mining equipment in Ukraine is limited, and the share of sales in the internal market has decreased. The issue of entering foreign markets became more acute, so that individual approach to each order, promptness of its fulfillment and constant communication with users are becoming ever more important.

Despite all the difficulties, we increased the range of products manufactured by our company; mastered production of cleaning and tunneling combines, and stable-hole complexes. We also started manufacturing products, earlier untypical for us, namely explosion-proof transformer substations. We are working in the field of high-potential developing plow dredging that will allow us even more expanding the niche occupied by us in mining equipment manufacturing.

During 2017, our plant manufactured 17 conveyors of different type, 15 cleaning and tunneling combines, 50 transformer substations, a large volume of spare parts for mining equipment; export accounted for $18 \%$ of product output.

Quality, reliability and safety of our products are confirmed by the respective certificates that make them competitive in supplying both the domestic and foreign markets.

Reconstruction of production facilities has been performed under your leadership. What has been done to ensure manufacturing competitive products?

One of major investments into the equipment of «Svet Shakhtyora» plant in 2014-2017 was purchase of wire EDM machine tool Mitsubishi MV2400S+ and processing center DOOSAN DBC160 (South Korea) with Fanuk 31i-B control system (Japan). The cost of introduction of 
these projects was 4.5 and 25 mln hryvnias, respectively.

With purchasing and putting into operation modern high-efficient equipment, the enterprise was able to master new technology of processing complex surfaces, improve the quality of manufactured products, reduce enterprise dependence on outsourching, as well as create new workplaces for operators of CNC machine tools, programmers, technologists.

High-performance tools of proven manufacturers, namely Walter (Germany), Sandvik (Sweden), Taegu Tec and Korloy (South Korea), etc. are used for operation of modern equipment.

\section{Alongside EDM machine tools, what other modern welding equipment is used?}

«Svet Shakhtyora» enterprise uses equipment for automatic submerged-arc surfacing of crane wheels. Replacement of semi-automatic welding by automatic and robotic welding in fabrication of some structures of mining equipment is planned.

The achievements of your company are related to the conducted personnel policy. It is known that young people are eager to work at your company. What are the working conditions at your enterprise? What is the personnel policy?

Our philosophy is extremely simple — work so today, as to secure your future. And we are successful in many respects here. We are known, we give an opportunity to everyone who wants to get a decent, highly paid, stable job in Kharkiv.

We pay salaries in time and do not have debts. In 2017 we increased piece-rate tariffs for the basic production piece-workers by $40 \%$ in order to achieve a competitive salary level in the labour market. For additional motivation, salaries of other personnel categories were also increased. On the whole, average salary in 2017 was increased by $35 \%$ from 2016 level, and was equal to 9000 hryvnias.

\section{How do you solve the issues of personnel training and development?}

At the enterprise one can have professional training and retraining, and get a second profession on the job, and become a qualified professional. Due to internal resources of the enterprise 309 employees were trained, 87 workers got a related profession and 108 persons learned new professions. Total cost of investment into education and vocational training of enterprise workers for 2017 amounted to 469,544 hryvnias.

We have a mentoring system allowing newly hired employees to adapt to the workplace. Special attention is paid to young specialists. Special-purpose courses are always conducted that enable employees to develop and improve their professional level. Each employee is able to realize his potential and build a promising career.

How much attention is paid to the social sphere at the enterprise?

Our company employees are provided with an almost full social package. This, primarily, is $100 \%$ medical insurance. We

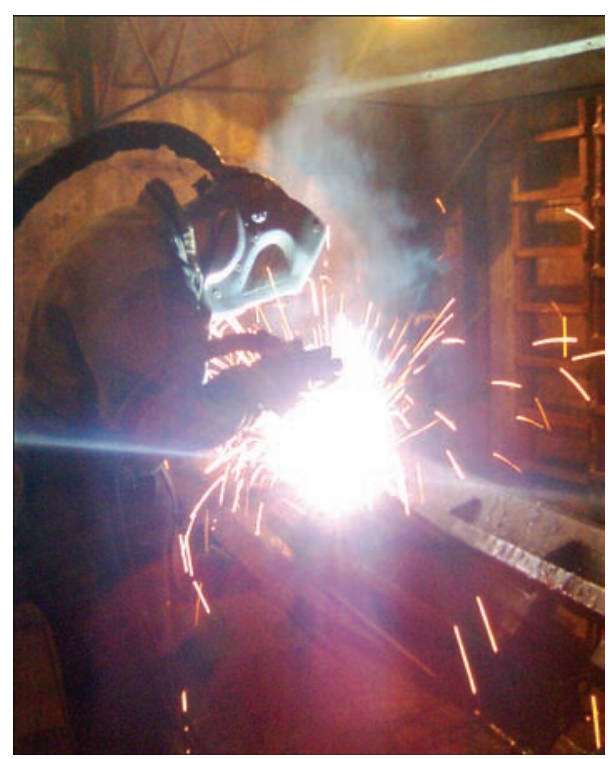




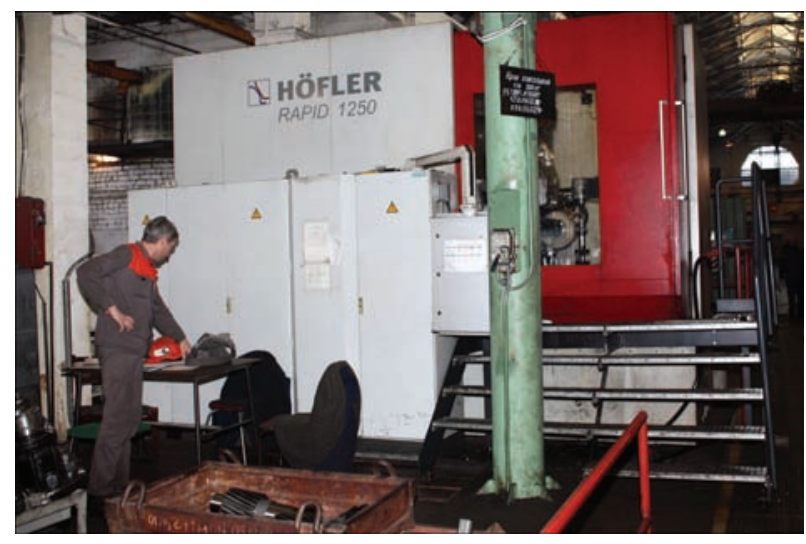

have organized free transportation of employees by buses from the metro to work; there is a dining room and a buffet, where workers can have a full dinner.

The enterprise management provides sponsor and charitable assistance to school and preschool institutions. Every year we congratulate the first-graders of our employees on the Day of Knowledge, we give them portfolios and stationery as a start to a new life stage.

Plant management and trade union committee take care of the rest of plant workers and their families. Employees have the opportunity to stay in holiday hotels, health centers, and children — at children's health camps.

Fans of football, volleyball, darts and other sports take part in sports events organized by the enterprise.

Corporate culture at our enterprise is supported by various events timed to the holidays: Day of the Machine Builder, Company Day, Knowledge Day, New Year, etc.

A youth organization was created at «Svet Shakhtyora» enterprise, which conducts intensive sports and cultural activities, and which all the interested persons can always join. In addition to fulfillment of basic guarantees, compensations and privileges provided by the Legislation and the Collective Agreement, the enterprise has a compensatory housing policy, according to which workers receive compensation payments to cover accommodation rent.

Thus, we have successfully established ourselves in the market, while maintaining the best traditions and formed new methods of work. We boldly demonstrate the ability to meet time challenges, to adopt and implement ambitious strategic objectives.

Mr. Kovalchuk, your company has expanded the geography of equipment supplies. To which countries do you supply your equipment? How do you see the company when compared with similar enterprises in the EU, China, and the USA?

In addition to the domestic market of Ukraine, CORUM GROUP Company supplies mining equipment for coal mines in Kazakhstan, and Poland, potassium mines in Belarus and shale mines in Estonia.

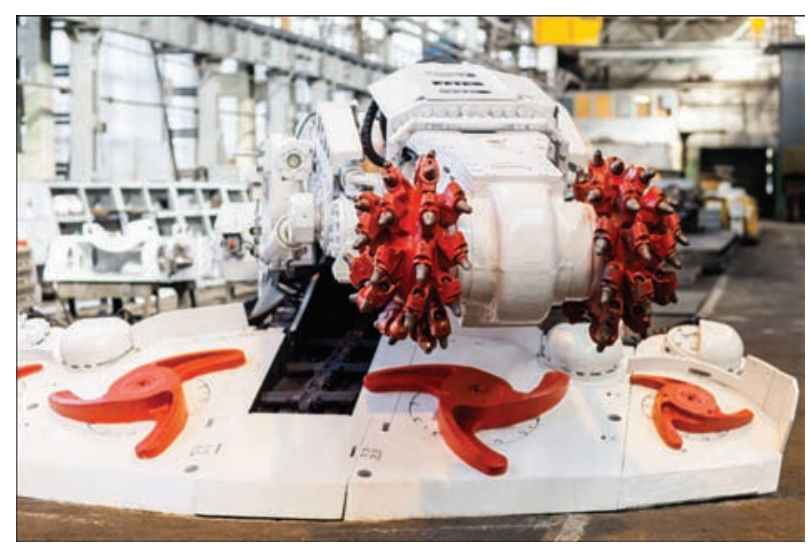

We are working to enter the markets of Bulgaria, Turkey, Romania, and Bosnia.

The market for mining equipment is now highly competitive. To be a competitive enterprise at the level of producers from the EU, the USA and China we have to perform a tremendous amount of work.

This is due not only to the high technical level of the equipment supplied, which must comply with the requirements of the European safety direc- 
tives, harmonized standards of the EU, China and the USA, but also with logistics of delivery, and organization of service maintenance of the equipment during operation. These high requirements should be also transferred to the domestic market for its retention under the conditions of severe competition with foreign producers.

It is known that manufacturing competitive products requires scientific support. Do you plan to cooperate with the PWI, NTU «KhPI» and other organizations?

Production of competitive mining equipment requires application of modern wear-resistant thermally strengthened materials of both domestic and foreign manufacturers. Accordingly, for their successful application, it is necessary to use modern technologies that provide quality welded joints. In most cases, such information can be found in scientific papers of specialized publications, such as «Avtomaticheskaya Svarka» and «Svarshchik». When the necessary information is not there, we seek advice directly from PWI specialists.

Our company actively cooperates with various educational institutions of the city. We provide production and technological practice training at the facilities of PJSC «Svet Shakhtyora». In 2017 we had 282 students pass practical training at our enterprise, who were supervised by the staff members from high-level skilled workers.

Our company also cooperates with the National Technical University «Kharkiv Polytechnic Institute» (NTU «KhPI»). Students of the Department of Welding conduct pre-diploma practical work at our enterprise, study materials and equipment for fabrication of metal structures, i.e. get «hands-on» experience of welding production.

\section{What makes your equipment competitive?}

A long-term operational experience of the enterprise served as a basis for formation of a highly skilled group of managers and technical specialists who solve any tasks related to design, production, implementation, and service support of mining equipment.

The main components of competitiveness of mining equipment, produced by the machine-building plant «Svet Shakhtyora», are the minimum production time, product quality at the level of the European competitive price, warranty coverage, service support for the manufactured products, as well as the availability of consignment warehouses, that enables supplying equipment to the customer in a short time, and performing its maintenance.

Your enterprise can serve as an example of effective development of production. What are the main principles of organization of company production under modern conditions?

Modern market dictates its conditions and now, in order to effectively develop, it is necessary to have a flexible production, which allows mastering new products types in the shortest term.

At the enterprise, introduction of electronic document circulation and straight-through design is going on, which allows accelerating the processes of development and approval of the design and technological documentation, as well as finished product output.

Special attention is paid to improving the skills of employees, and development and support of rationalization and inventive activities. Financial interest of the team in the timely release of quality products is supported.

One of the main principles also is investing in modern high-efficient and energy-efficient equipment, as well as application of modern materials and tools in production, that enables manufacturing products within the terms, required by the customer.

Interview was recorded by V.V. Dmitrik 


\title{
STRESSED STATE OF WELDED AND BRAZED ASSEMBLIES FROM SIMILAR MATERIALS WITH A SOFT INTERLAYER UNDER AXIAL LOADING
}

\author{
V.V. KVASNYTSKYI ${ }^{1,3}$, V.F. KVASNYTSKYI ${ }^{2}$, DONG CHUNLIN ${ }^{3}$, \\ M.V. MATVIIENKO ${ }^{2}$ and G.V. YERMOLAYEV ${ }^{2}$ \\ ${ }^{1}$ NTUU «Igor Sikorskii Kyiv Polytechnic Institute» \\ 37 Pobedy Prosp., 03056, Kyiv, Ukraine. E-mail: kvas69@ukr.net \\ ${ }^{2}$ Admiral Makarov National University of Shipbuilding \\ 9 Heroiv Ukrainy Prosp., 54025, Mykolaiv, Ukraine. E-mail: welding @nuos.edu.ua \\ ${ }^{3}$ China-Ukraine E.O. Paton Institute of Welding \\ Guangzhou, P.R.China. E-mail: dchunlin@163.com
}

\begin{abstract}
Computer modeling method was used to study the stressed state in assemblies, manufactured by diffusion welding and brazing, under the impact of axial load. Cylindrical assemblies from steel with a copper interlayer are considered under loading above the copper yield point. It is shown that formation of a complex stressed state resulted in the level of equivalent stresses decreasing in the interlayer compared to the applied axial load, and increasing in a small zone of base metal near the outer surface at the butt joint with the interlayer that causes the effect of hardening (unloading) of the interlayer and softening (overloading) of base metal. Quantitative dependencies of the degree of interlayer hardening and base metal softening on more load magnitude were derived. It is found that at the elastoplastic stage of assembly loading base metal softening is external pronounced, than at the elastic stage. Degree of interlayer hardening at the elastic stage of its work does not depend on the magnitude of external load, and at the elastoplastic stage it is increased in proportion to the load. 9 Ref., 5 Figures.
\end{abstract}

Ke y w or d s : welded and brazed assemblies, soft interlayer, computer modeling, stressed state, force loading

New composite materials and assemblies that cannot be joined by fusion welding are ever wider applied in modern engineering. In these cases brazing or solid-phase welding, for instance vacuum diffusion welding (VDW), is used. At VDW interlayers are often used for formation of guaranteed contact of the surfaces being joined over the entire area. Copper, aluminium and nickel are used as interlayers. Brazed seam often is an interlayer in brazing.

Stressed state and performance of joints with a soft interlayer were studied in works [1-3], but the capabilities of analytical methods are limited. They do not allow taking into account all the features of the materials, loading types and structural factors, including the kinetics of formation of the stressed state (SS).

Modern computer equipment and developed program packages open up broad possibilities for such studies. In this work SS modeling was performed with application of ANSYS program package, based on finite element method, which we also applied in previous work [4-7].

In [6] it was established that in assemblies with a soft interlayer at loading by axial load SS in the joint zone becomes volumetric, equivalent stresses in interlayer material are reduced, and in the stronger base material they increase, on the contrary, i.e. so-called effect of soft interlayer hardening [1-3] is manifested, which is associated with joint SS. Here just one vari- ant was modeled, when applied load (40 MPa) is close to the yield point (38 MPa) of interlayer material.

The objective of this work was studying SS of welded and brazed assemblies from similar materials with a soft interlayer at uniaxial compressive loading, at which axial stresses from applied load noticeably exceed interlayer material yield point, both during joint formation and when working in tension.

An interlayer is called soft, when its yield point is lower than that of base metal $\left(\sigma_{T_{\mathrm{int}}}<\sigma_{T_{\mathrm{BM}}}\right)$.

SSS of cylindrical assemblies at joining similar material (steel + steel) through a soft copper interlayer $50 \mu \mathrm{m}$ thick (relative thickness $s / d=0.0025$ ) was studied.

In view of sample asymmetry relative to interlayer mid-thickness, SS of the upper half of the sample was modelled with appropiate assembly fastening on the model lower edge.

Model dimensions were as follows: cylinder of diameter $d=20 \mathrm{~mm}$, and height $h=20 \mathrm{~mm}$, half of interlayer thickness $s / 2=25 \mu \mathrm{m}$. Figure 1 gives the schematic of splitting into finite elements (FE) of the model as a whole and region adjacent to the interlayer.

Properties of the materials being joined and the interlayer: steel with modulus of elasticity $E=$ $=2 \cdot 10^{5} \mathrm{MPa}$, yield point $-250 \mathrm{MPa}$, Poisson's ratio - 0.3 , modulus of hardening at plastic deformation $-2 \cdot 10^{3} \mathrm{MPa}$; copper with modulus of elasticity $E=1 \cdot 10^{5} \mathrm{MPa}$, yield point $-100 \mathrm{MPa}$, Poisson's 

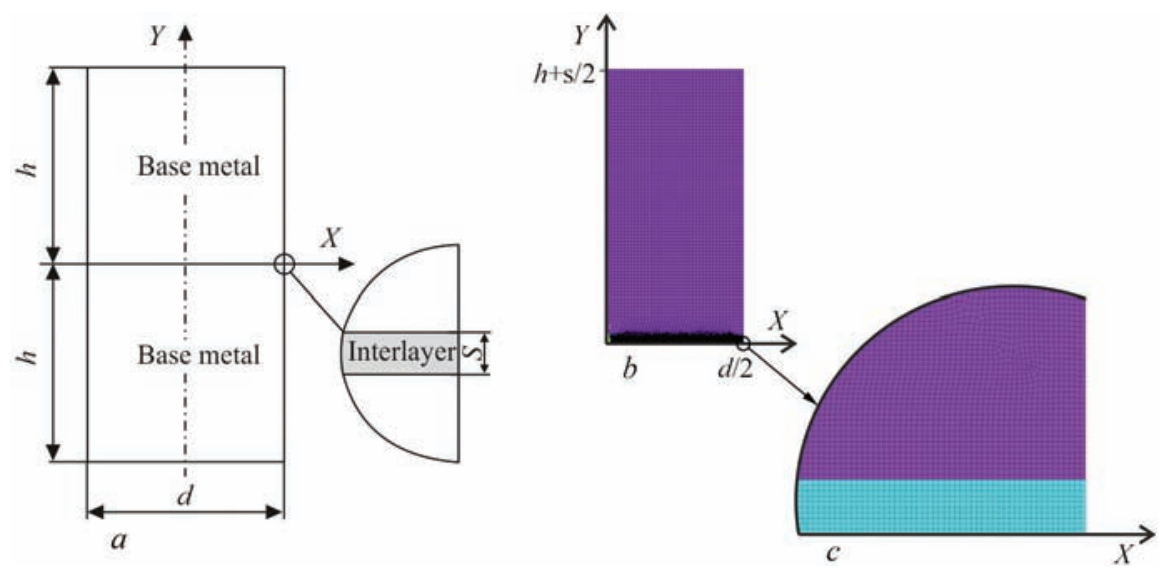

Figure 1. General view of the sample with the interlayer $(a)$, section of axisymmetric finite element model $(b)$ and zone of interlayer mating with the metal being joined (c)

ratio - 0.34; modulus of hardening at plastic deformation $-1 \cdot 10^{3} \mathrm{MPa}$.

Model was loaded by axial compressive load, the value of stress from which changed from 100 up to 200 $\mathrm{MPa}$, i.e. maximum stresses exceeded the interlayer yield point up to two times, so that the process of interlayer material deformation occurred both at the elastic and plastic stages. At replacement of compression (during joint formation) by tension (in operation) the signs of stresses and strains will change for reverse ones without the change of their values and nature of distribution.

SS influence on mechanical properties of materials in the joint zone was assessed using stress stiffness factor equal to the ratio of stresses $\sigma_{\mathrm{y}}$ applied to the assembly to equivalent stresses $\sigma_{\text {eq. }}$ in this material: $K_{\text {stif }}=\sigma_{y} / \sigma_{\text {eq }}$ [8]. The magnitude of this factor determines the effect of softening (equivalent stresses exceed applied load, $K_{\text {stif }}>1$ ) or hardening (equivalent stresses below the applied ones, $K_{\text {stif }}<1$ ) of material in a particular narrow zone of the assembly, compared to linear stressed state, in which standard mechanical testing of material for strength is conducted. At $K_{\text {stif }}<1$, strength, i.e. ability to resist plastic deformation, decreases and its ductility, i.e. ability to plastically deform without fracture, increases. At $K_{\text {stif }}>1$, contrarily, strength increases and ductility decreases.

Analysis of the fields of all the components and equivalent stresses in the assemblies at axial loading showed that alongside axial stresses all the other components, namely radial, circumferential normal and tangential stresses are manifested in the small zone of the joint, namely, in the interlayer material and adjacent base metal regions, of the width of about two thicknesses of the interlayer, i.e. SS becomes volumetric. As a result, in this zone of the assembly equivalent stresses differ from applied axial stresses $\sigma_{y}$, exceeding them in the base metal, and decreasing in interlayer material. Here, at increase of the load the nature of the fields practically does not change, just the stress level rises in proportion to the load.

Analysis of equivalent stress curves (Figure 2), determining material behaviour at loading (purely elas- tic or elastoplastic deformation), showed that practically constant stress level is preserved both in the materials being joined, and in the interlayer on greater part of its length (up to 80-90\%).

Here, equivalent stresses are equal to applied load in base metal (Figure 2, a, b), and in the interlayer they change from 71 up to $100 \mathrm{MPa}$ (elastic loading) at load change from 100 up to $130 \mathrm{MPa}$, and remain practically unchanged at the yield point level (about $100 \mathrm{MPa}$ ) at the load from 140 up to $200 \mathrm{MPa}$ (elastoplastic loading) (Figure 2, $b, d$ ).

In the immediate vicinity from the butt joint edge, they somewhat increase both in the base metal, and in the interlayer material at the elastic stage of its work. The width of increased stress zone is not higher than $1-2 \mathrm{~mm}$ (10-20\% of sample radius). This leads to a change of stress stiffness factor $K_{\text {stif }}$ in this region, and somewhat changes the effect of softening or hardening, compared to the linear stressed state.

For analysis and comparison with stronger interlayers having a higher yield point, the notion of «interlayer overloading coefficient» was used, which is equal to the ratio of stresses from applied axial load to interlayer yield point $K_{\text {over }}=\sigma_{1} / \sigma_{y_{\text {inf }}}$. In our case, at elastic loading of the interlayer it changeed in the range from $1.0(100 \mathrm{MPa}$ loading) to $1.3(130 \mathrm{MPa})$, and at elastoplastic loading from 1.4 (140 MPa) to 2.0 (200 MPa).

With load increase from 100 to $130 \mathrm{MPa}$ (degree of interlayer overloading from 1.0 to 1.3 ) maximum equivalent stresses in the base metal near the butt joint edge increase from 108 to $141 \mathrm{MPa}$ (Figure 2, a) by the linear law. Coefficient of softening (stress stiffness factor) of base metal near the butt joint edge here remains practically unchanged at the level of about 0.92 , respectively.

At further increase of load from 140 to $200 \mathrm{MPa}$, when plastic deformations develop in the interlayer, maximum stresses, similar to elastic loading, increase from 155 up to $241 \mathrm{MPa}$ (Figure 2,c) also practically by a linear law, which is described by equation $\sigma_{\mathrm{eq}}=$ $=141 \mathrm{~K}_{\text {over }}$ differing somewhat from elastic stage $\sigma_{\text {eq }}=$ $=110 K_{\text {over }}^{\text {over }}-2$. Accordingly, reduction of stress stiff- 

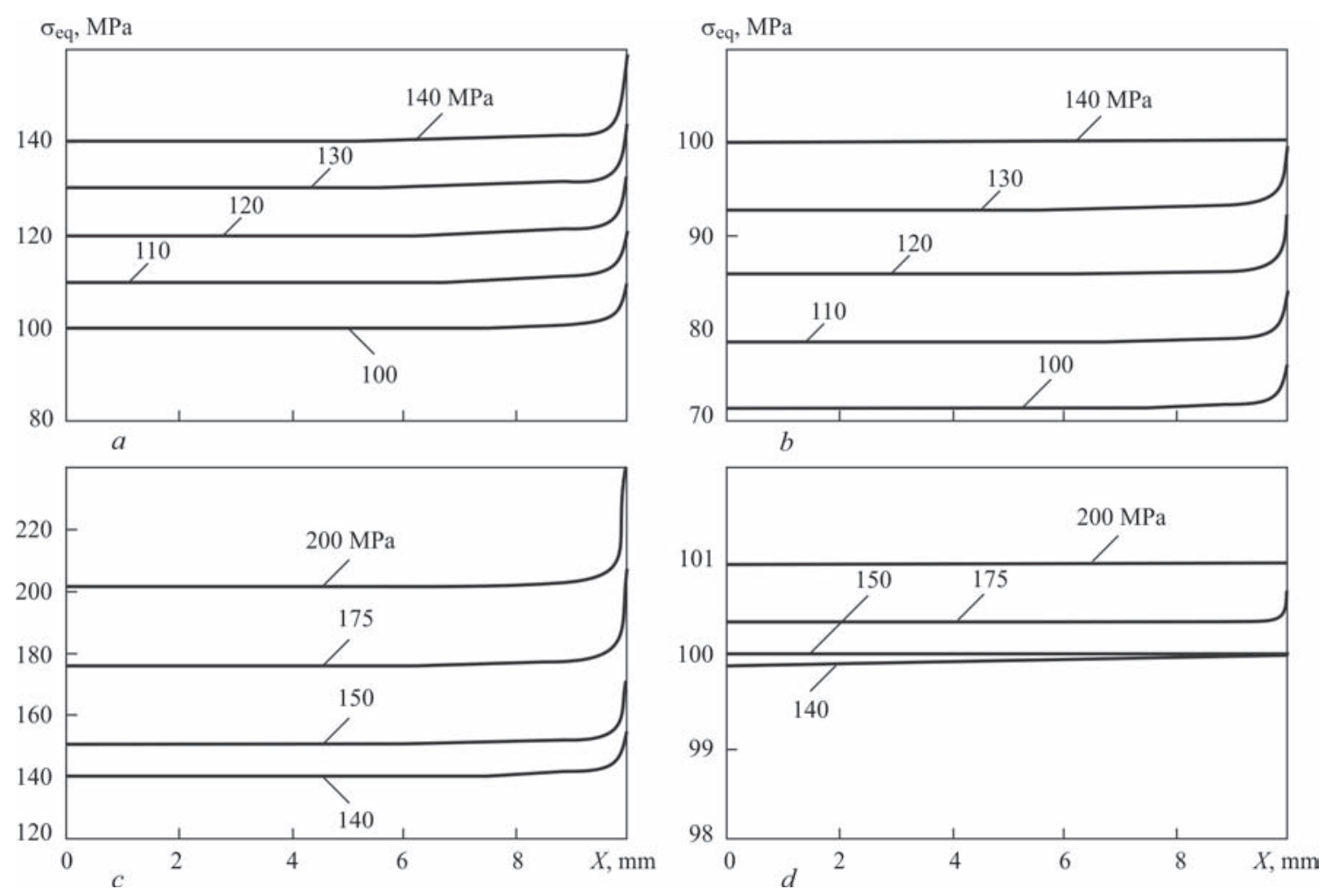

Figure 2. Curves of equivalent stresses in the butt joint on steel $(a, c)$ and in the interlayer $(b, d)$ at different axial loads

ness factor in the base metal at butt joint edge from 0.90 at $140 \mathrm{MPa}$ load, causing plastic deformations in the interlayer, to 0.83 at the pressure of $200 \mathrm{MPa}$.

Lowering of stressed state stiffness causes the effect of softening of base metal at the assembly surface, expressed in that the maximum equivalent stresses at butt joint edge exceed those from applied axial load.

Thus, while at the elastic stage of soft interlayer deformation, stress stiffness factor, and degree of base metal softening, accordingly, depend only on the ratio of modules of elasticity and Poisson's ratios of base metal and interlayer, and do not depend on the magnitude of applied axial load, at the plastic stage dependence on the degree of interlayer overloading is also manifested.

For convenience of comparison of the two loading stages, Figure 3 gives the dependence of softening coefficient in the entire loading range, including the elastic

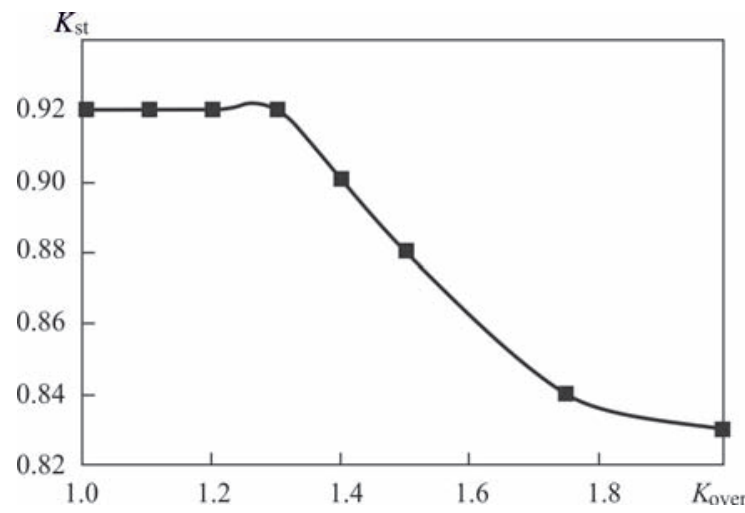

Figure 3. Dependence of softening coefficient and stress stiffness factor $K_{\text {stif }}$ respectively of base metal near the butt joint edge on degree of soft interlayer overloading $K_{\text {over }}$

and plastic stages of interlayer work, with the change of the extent of interlayer overloading from 1.0 up to 2.0.

One can clearly see from Figure 3 that in the second (elastoplastic) stage of assembly loading base metal softening is more pronounced, that is attributable to noticeable increase of Poisson's ratio (up to 0.5 ) and small coefficient of interlayer material hardening at its plastic deformation. Moreover, while at the elastic stage base metal softening is determined only by the ratio of base metal and interlayer properties, at the plastic stage it depends also on the magnitude of load (degree of interlayer overloading).

In interlayer material equivalent stresses (Figure 2, b) remain constant at the level below the yield point $(100 \mathrm{MPa})$, somewhat increasing at the edge only at up to $130 \mathrm{MPa}$ load. At load increase from 100 up to $130 \mathrm{MPa}$, equivalent stresses in the interlayer increase linearly from 71 up to $93 \mathrm{MPa}$ on greater part of its length and from 75 up to $98 \mathrm{MPa}$ on the edge (Figure $2, b$ ). At the load from 140 up to $200 \mathrm{MPa}$, equivalent stresses in the interlayer on the entire length of the butt joint, including the edge, remain on the same level, close to interlayer yield point (100 MPa). This confirms that interlayer material with the yield point of $100 \mathrm{MPa}$, is hardened due to increase of stressed state stiffness at the elastic stage, and it starts plastically deforming only at the load above $130 \mathrm{MPa}$.

Coefficient of interlayer hardening (stressed state stiffness) changes accordingly. At the load from 100 up to $130 \mathrm{MPa}$, it remains practically constant at the level of 1.4 on greater part of the butt joint and of 1.33 near its edge. At the load above $140 \mathrm{MPa}$, it, un- 
like elastic loading, grows linearly, and reaches the value of 1.97 at $200 \mathrm{MPa}$. Its dependence on the degree of interlayer overloading in this load range is linear, and is described by equation of regression $K_{\text {stif }}=$ $=0.98 K_{\text {over }}+0.03$, i.e. stress stiffness factor (hardening coefficient) of the interlayer is practically equal to its overloading degree $\left(K_{\text {stif }}=K_{\text {over }}\right)$ (Figure 4).

Analysis of the curves of tangential stresses along the butt joint showed that they are equal to zero on greater part of the butt joint (about $95 \%$ ), appearing and increasing up to $12-17 \mathrm{MPa}$ only near its edge, at the distance of about two thicknesses of the interlayer (about $0.1 \mathrm{~mm}$ ) from the outer surface. This is indicative of low effectiveness of purely force loading from the viewpoint of activation of the process of plastic deformation and joint formation by the traditional technology of diffusion welding.

Nature of axial stress distribution along the assembly generatrix (outer surface) is practically the same at all the loading variants. They are nonuniformly distributed along the assembly generatrix (outer surface) near the interlayer, in a zone of the width of up to two thicknesses of the interlayer, changing in the range of 70 to $120 \mathrm{MPa}$ in the interlayer and $100-170 \mathrm{MPa}$ in the base metal at elastic loading of the interlayer (see Figure 5, a) and 85-120 and 140-255 MPa at elastoplastic loading, respectively (Figure 5,b). Here, the peak (maximum) of axial stresses, noticeably exceeding the level of stresses from the applied external load, is located in the base metal in the immediate vicinity of the butt joint with the interlayer.

This is indicative of the fact that in the case of sufficient hardening of the soft interlayer, fracture can run through the stronger base metal at the butt joint with the interlayer, where softening (lowering of the yield point) of the material being joined is combined with an increase of axial stresses. In keeping with experimental data derived on Armco-iron samples brazed using copper, given in [9], at copper interlayer thickness of about $0.05 \mathrm{~mm}$, fracture at tensile testing ran through iron at up to $325-350 \mathrm{MPa}$ stresses in the assembly that is more than 1.5 times higher than copper yield point.

The established general regularities of SS formation in assemblies with a soft interlayer, expressed in increase

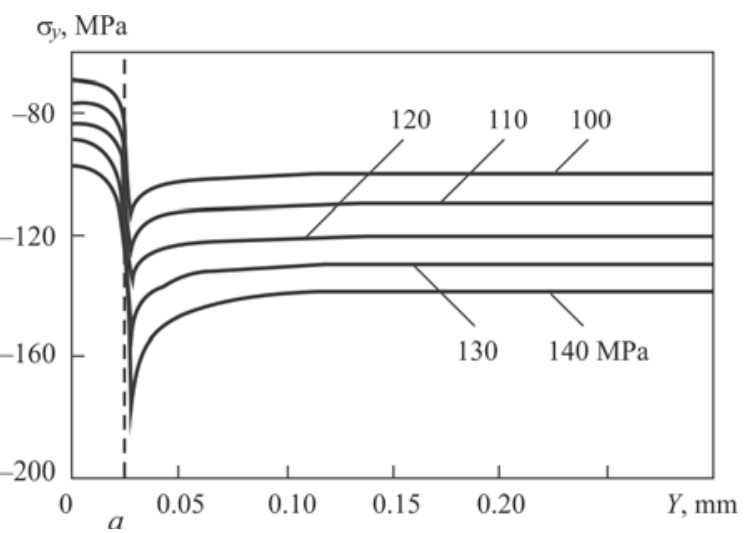

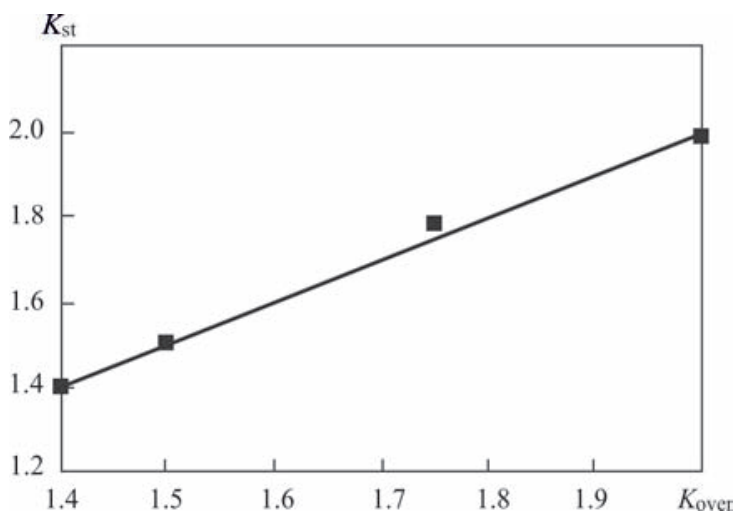

Figure 4. Dependence of hardening coefficient (stress stiffness factor $K_{\text {stif }}$ ) of the interlayer on the degree of «soft» interlayer overloading $K_{\text {over }}$

of stressed state stiffness, soft interlayer hardening, decrease of SS stiffness in base metal near the interlayer and its strength lowering (softening), are preserved both at elastic and at plastic loading in a broad load range.

A variant of the interlayer with a higher yield point of $150 \mathrm{MPa}$ was also considered, in order to determine the influence of the level of interlayer yield point on the established regularities.

Axial load of $150 \mathrm{MPa}$, i.e. equal to interlayer yield point, 200 and $250 \mathrm{MPa}$, exceeding interlayer yield point (degree of overload), 1.33 and 1.67 times, respectively, was applied.

Analysis of equivalent stress curves along the butt joint under such loading conditions and their comparison with the previous variant of the assembly (interlayer yield point of $100 \mathrm{MPa}$ ) showed that the shape of the curves is preserved both in the base material, and in the interlayer. Equivalent stresses do not change in the base material on greater part of the butt joint, remaining on the level of stresses from the applied load. At the butt joint edge they rise up to 163,220 and $295 \mathrm{MPa}$ at 150 , 200 and $250 \mathrm{MPa}$ loading, respectively. Stress stiffness factors remain on 1.0 level in the base metal on greater part of the butt joint, and at the butt joint edge at $150 \mathrm{MPa}$ loading (degree of interlayer overloading $K_{\text {over }}=1.0$ ) base metal stress stiffness factor $K_{\text {stif }}=\sigma_{\mathrm{y}}$ ' $\sigma_{\text {eq }}=150 / 163=0.92$ that fully coincides with the variant of the assembly with $100 \mathrm{MPa}$ yield point at the

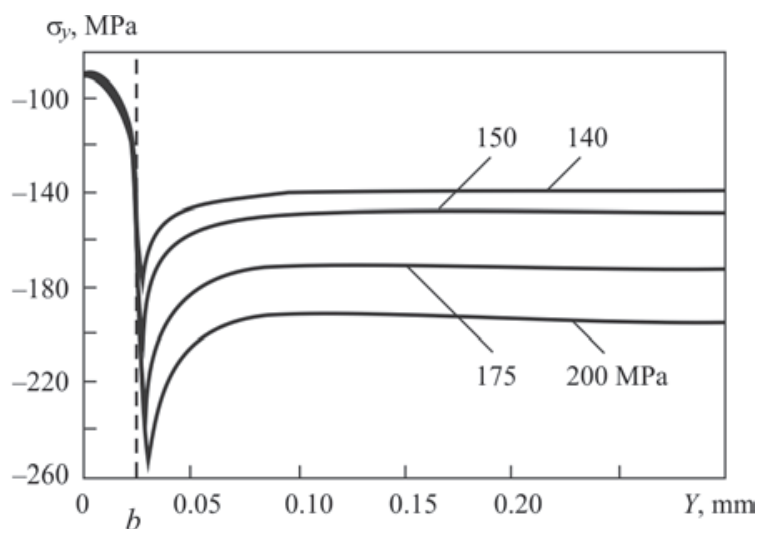

Figure 5. Curves of axial stresses near the generatrix at axial loads of 100-130 MPa (a) and 140-200 MPa (b) 
same overload level. Similar results were obtained also at overloads of 200 and $250 \mathrm{MPa}$.

In the interlayer, equivalent stresses also remain constant on greater part of the butt joint on the level below the yield point (107 and $143 \mathrm{MPa}$ ) at the degree of interlayer overloading of 1.0 and 1.33 and on yield point level $(150 \mathrm{MPa})$ at interlayer overloading degree of 1.67 .

At $150 \mathrm{MPa}$ load (degree of interlayer overloading $K_{\text {over }}=1.0$ ), stress stiffness factor of the interlayer $K_{\text {stif }}^{\text {over }}=150 / 107=1.40$ that practically coincides with 1.41 result, obtained for an assembly with an interlayer with $100 \mathrm{MPa}$ yield point. The pattern is similar also at 200 and $250 \mathrm{MPa}$ loads, at which $K_{\text {stif }}=$ $=200 / 143=1.40$ and $K_{\mathrm{st}}=250 / 150=1.67$, respectively, that fully coincides with the results obtained for the assembly with an interlayer with $100 \mathrm{MPa}$ yield point.

At butt joint edge at a small degree of interlayer overloading (overloading degree of 1.0 and 1.33), when the interlayer is elastically deformed, equivalent stresses rise to 113 and $150 \mathrm{MPa}$, and stress stiffness factor increases to $K_{\text {stif }}=150 / 113=1.33$ and $K_{\text {stif }}=$ $=200 / 150=1.33$, accordingly, that also completely coincides with the elastic stage of the work of interlayer with yield point of $100 \mathrm{MPa}$.

One should bear in mind that the derived regularities remain in force only under the condition of base metal working at the elastic stage. For this purpose, it should have the yield point above the maximum axial load applied to the assembly. The required degree of excess depends on the degree of soft interlayer overloading and corresponding coefficient of base metal softening. By the data of this work at the degree of interlayer overloading equal to 2.0 , base metal softening coefficient is equal to 0.83 , i.e. base metal yield point should be higher than 200/0.83 =241 MPa to ensure its elastic work, i.e. it should be not less than 2.4 times higher than interlayer yield point (100 MPa). At greater load plastic deformations develop in the base metal, and their influence on assemblies SS requires a separate study.

Thus, at quantitative assessment of the behaviour of assemblies with soft interlayers with different yield point values at different levels of axial loads, it is convenient to apply the notion of the degree of interlayer overloading, which is equal to the ratio of the value of axial load to interlayer material yield point $\left(K_{\text {over }}=\sigma_{\mathrm{y}} / \sigma_{\mathrm{y}_{\mathrm{int}}}\right)$.

At sufficiently high base material yield point, exceeding the level of stresses from applied load, when just the soft interlayer undergoes elastoplastic deformation, the derived regularities of base metal softening and soft interlayer hardening remain in force both at the elastic and at the plastic stages of interlayer material work at different levels of its yield point and applied axial load.

\section{Conclusions}

1. At loading of the assembly with a soft interlayer volumetric SS forms in the interlayer material and in the small zone of base metal, adjacent to the interlayer near its edge. This accounts for the change of the parameters of metal strength and ductility, determined under the conditions of linear stressed state, i.e. hardening or softening of base metal and interlayer.

2. It is found that stress stiffness factor, determining the degree of hardening or softening of the interlayer and base metal, is constant in the interlayer material at the elastic stage, and is equal to 1.35 for the assumed variants of combination of elastic properties. At the plastic stage $K_{\text {stif }}$ grows linearly, reaching the value of 1.97 at the load two times higher than the interlayer material yield point at standard testing.

3. Coefficient of base metal softening near the edge of the butt joint with the interlayer depends not only on interlayer properties, but also on the degree of its overload. For the considered variants it gradually, from 0.925 at elastic deformation of the interlayer, approaches 0.83 at increase of its overload coefficient to 2.0.

4. Maximum axial stresses, noticeably exceeding the level of stresses from applied external load, arise on assembly generatrix in the base metal in the immediate vicinity of the butt joint with the interlayer. In the case of sufficient hardening of the soft interlayer, fracture may run through stronger base metal, where softening of the material being joined is combined with increase of axial stresses.

1. Bakshi, O.A., Shron, R.Z. (1962) Strength at static tension of welded joints with soft interlayer. Svarochn. Proizvodstvo, 5, 6-10 [in Russian].

2. Bakshi, O.A., Kachanov, L.M. (1965) On stress state of plastic interlayer at axisymmetric deformation. Izv. AN SSSR. Mekhanika, 2, 134-137 [in Russian].

3. Bakshi, O.A., Shron, R.Z. (1971) On calculated evaluation of strength of welded joints with soft interlayer. Svarochn. Proizvodstvo, 3, 3-5 [in Russian].

4. Makhnenko, V.I., Kvasnytskyi, V.V., Yermolayev, G.V. (2009) Stress-strain state in diffusion welding of materials with different physico-mechanical properties. In: Proc. of 4th Int. Conf. on Mathematical Modeling and Information Technologies in Welding and Related Processes (27-30 May 2008, Katsiveli, Ukraine). Ed. by V.I. Makhnenko. Kiev, PWI, 95-102.

5. Makhnenko, V.I., Kvasnytskyi,V.V. (2009) Peculiarities of formation of stress-strain state in diffusion bonds between dissimilar materials. The Paton Welding J., 8, 7-11.

6. Kolesar, I.A., Yermolayev, G.V. (2014) Stress-strain state at force and temperature loading of assemblies from dissimilar steels with soft interlayer. Ibid., 8, 21-25.

7. Yermolayev, G.V., Martynenko, V.A., Olekseenko, S.V. et al. (2017) Effect of the rigid interlayer thickness on the stressstrain of metal-graphite assemblies under thermal loading. Strength of Materials, 49(3), 422-428.

8. Kopelman, L.A. (2010) Fundamentals of strength theory of welded structures: Manual. 2nd Ed. St.-Petersburg, Lan [in Russian].

9. Yermolayev, G.V., Kvasnytskyi, V.V., Kvasnytskyi, V.F. et al. (2015) Brazing of materials. Ed. by V.F. Khorunov et al. Mykolayiv, NUK [in Ukrainian]. 


\title{
EFFECT OF MAIN IMPURITIES ON FORMATION OF CRACKS IN WELDING OF COPPER-NICKEL ALLOYS AND SURFACING OF MONEL ON STEEL
}

\author{
V.A. ANOSHIN, V.M. ILYUSHENKO and E.P. LUKYANCHENKO \\ E.O. Paton Electric Welding Institute of the NAS of Ukraine \\ 11 Kazimir Malevich Str., 03150, Kyiv, Ukraine. E-mail: office@paton.kiev.ua
}

\begin{abstract}
Effect of main impurities on formation of cracks in welding of copper-nickel alloys, including in welding and surfacing of monel on steel, was investigated. Methods of optical metallography and electron-fractography analysis determined that the cracks have intercrystalline and solidification nature. Emission X-ray spectrum analysis determined significant (27 times) enrichment of gray surface of cracks forming in monel welding. It is shown that oxygen intensifies detrimental effect of sulfur in monel surfacing in contrast to welding of low-carbon steel. Carried theoretical calculations of significant saturation of boundaries of grains with detrimental impurities at small coefficient of distribution are of interest for explaining the reason of solidification crack formation on other nickel alloys. 6 Ref., 1 Table, 4 Figures.
\end{abstract}

Keywords : copper-nickel alloys, detrimental impurities, solidification cracks

Copper-nickel alloys having improved mechanical properties and high corrosion resistance are widely used in marine shipbuilding and chemical machine building for manufacture of parts operating in different aggressive media. Complexly alloyed copper-nickel alloys containing additives of such elements as aluminum, iron and manganese are very perspective. In this connection the problem of investigation of these alloys weldability is relevant.

Present work is continuation of investigations on evaluation of impurities effect on copper weldability [1], in particular, applicable to copper-nickel alloys as well as nickel-copper alloy monel.

Preliminary evaluation of weldability of pilot alloys MNZh5-1; MNAZhMts6-1.5-1; MNZhMtsA
13-1.5-3-1 was carried on procedure developed at the E.O. Paton Electric Welding Institute using LTPM or «fish skeleton» specimens [1].

Electron-fractography and metallographic analyses of crack surface showed their intercrystalline and solidification nature (Figure 1).

Figure 2 presents a crack on fused grain boundaries in near-weld zone of MNZhMtsA 13-1.5-3-1 alloy. The method of emission X-ray spectrum analysis determined that the crack surfaces have 3-5 times more detrimental impurities (lead, phosphorus, bismuth). Pilot ingots with their different content were cast to evaluate effect of these impurities on MNZh5-1 alloy weldability. The specimens for evaluation of alloys

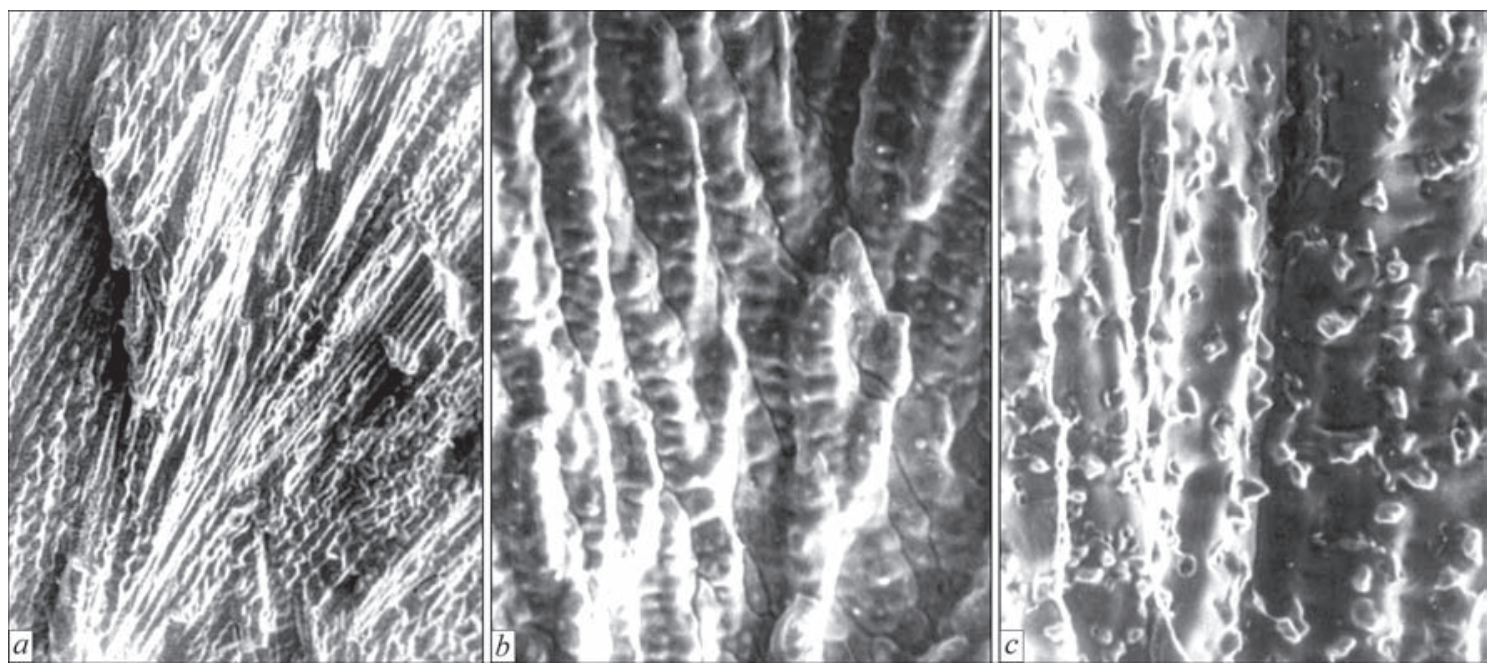

Figure 1. Intercrystalline $(a, \times 150)$ and solidification $(b, \times 800, c, \times 1200)$ nature of cracks in monel welding 


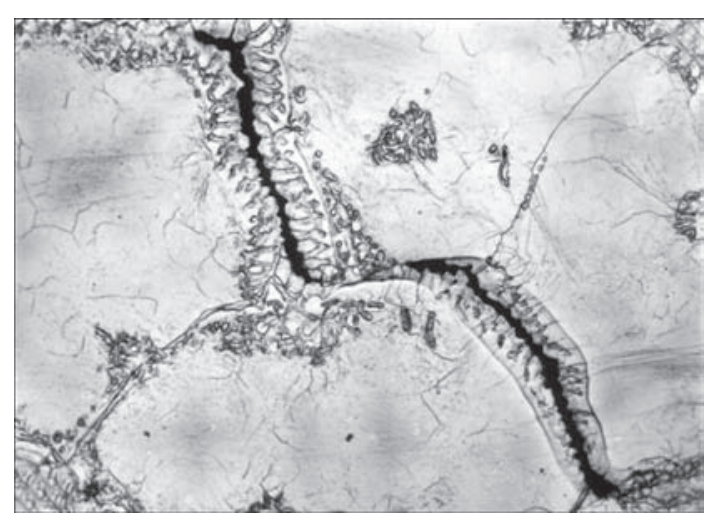

Figure 2. Crack on fused grain boundaries in near-weld zone of MNZhMtsA13-1.5-3-1 alloy

susceptibility to crack formation were cut out from these ingots. Figure 3 represents the dependence of $K_{\text {cr }}$ index for pilot alloy containing different concentrations of bismuth, lead and phosphorus.

Susceptibility to crack formation in welding and surfacing of NMZhMTs28-2.5-1.5 grade monel on steel was also investigated. Welding of monel specimens was carried out in argon medium with nonconsumable electrode using the procedure indicated above. Surfacing was made on low-carbon steel of $20 \mathrm{~mm}$ thickness under AN-26S flux using standard $3 \mathrm{~mm}$ diameter wire of NMZhMTs28-2.5-1.5 grade. It is determined that crack nature is the same as for copper-nickel alloys. The surface of cracks is mostly enriched with sulfur (in 27 times). Carried calculations on Smith formula* [2] (the results are given in the Table) also indicate significant enrichment of grain boundaries with impurities in comparison with initial concentration of $C_{0}$ (for example, sulfur with $K_{\mathrm{o}} \approx 0.005$ for monel).

It should be noted that there is an increase of crack formation susceptibility in surfacing of monel on steel under oxidized flux AN-18. Therefore, the experiments were carried out on investigation of common effect of oxygen and sulfur on crack formation

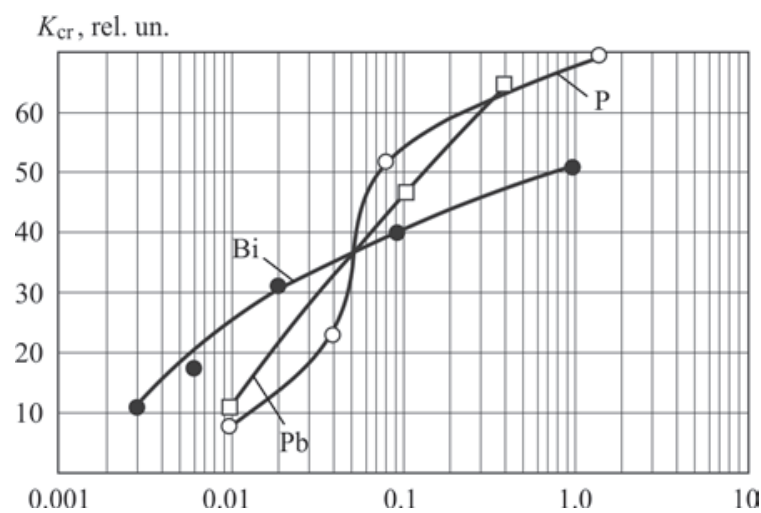

Figure 3. Dependence of index $K_{\mathrm{cr}}$ for alloy MNZh5-1 on bismuth, lead and phosphorus concentration in it

using V.V. Podgaetsky procedure [4]. Figure 4 shows the examination results of joint effect of oxygen and sulfur on crack formation in surfacing of monel on steel. As can be seen from obtained data, increase of oxygen content in weld reduces critical content of sulfur, at which cracks appear in the welds. At high concentrations of oxygen and small concentrations of sulfur there are microcracks, which do not propagate due to small amount of sulfur in the weld metal. Taking into account that copper and nickel at solidification temperature have more chemical affinity to sulfur than iron, appearance of sulfides $\mathrm{Cu}_{2} \mathrm{~S}$ and $\mathrm{Ni}_{3} \mathrm{~S}_{2}$ in monel surfacing are more probable. They form the eutectic with melting temperature $728{ }^{\circ} \mathrm{C}$ or ternary eutectic of $\mathrm{Ni}-\mathrm{Cu}-\mathrm{S}$ system. Introduction of oxygen promotes more decrease of eutectic temperature and, apparently, rises surface activity of sulfur in contrast to low-carbon steel, where, as is known [4], oxygen reduces detrimental effect of sulfur on solidification crack formation.

Phosphorus has the same effect as sulfur. Typical intercrystalline cracks appear at more than $0.045 \%$ phosphorus content in the weld in surfacing on steel as well as monel welding.

Relative segregation of impurities in different distance $X_{2}$ from grain boundary in depending on distribution coefficient

\begin{tabular}{|c|c|c|c|c|c|c|c|c|c|c|c|c|}
\hline \multirow{4}{*}{$v_{\mathrm{cr}}, \mathrm{cm} / \mathrm{s}$} & \multicolumn{12}{|c|}{$C_{\mathrm{cr}}\left(X_{2}\right) / C_{\mathrm{o}}$} \\
\hline & \multicolumn{3}{|c|}{$K=0.1$} & \multicolumn{3}{|c|}{$K=0.02$} & \multicolumn{3}{|c|}{$K=0.005$} & \multicolumn{3}{|c|}{$K=0.001$} \\
\hline & \multicolumn{12}{|c|}{$X_{2}, \mathrm{~cm}$} \\
\hline & $10^{-5}$ & $5 \cdot 10^{-5}$ & $10^{-4}$ & $10^{-5}$ & $5 \cdot 10^{-5}$ & $10^{-4}$ & $10^{-5}$ & $5 \cdot 10^{-5}$ & $10^{-4}$ & $10^{-5}$ & $5 \cdot 10^{-5}$ & $10^{-4}$ \\
\hline 0.01 & 256.0 & 60.0 & 32.0 & 437.0 & 90.5 & 46.0 & 480.0 & 97.0 & 49.0 & 497.0 & 100.0 & 50.0 \\
\hline 0.05 & 60.0 & 14. & 8.0 & 90.5 & 19.0 & 10.0 & 97.0 & 20.0 & 10.0 & 100.0 & 20.3 & 10.3 \\
\hline 0.1 & 32.0 & 8.0 & 4.0 & 46.0 & 10.0 & 5.0 & 49.0 & 10.0 & 5.3 & 50.0 & 10.3 & 5.3 \\
\hline 0.5 & 8.0 & 2.0 & 1.3 & 10.0 & 2.3 & 1.4 & 10.0 & 2.3 & 1.4 & 10.3 & 2.4 & 1.4 \\
\hline 1.0 & 4.0 & 1.3 & 1.0 & 5.0 & 1.4 & 1.0 & 5.3 & 1.4 & 1.0 & 5.3 & 1.4 & 1.0 \\
\hline
\end{tabular}

*It is necessary to note that Smith formula, given in the text of work [2], has a mistake: instead of $(2 n-1)$ coefficient it should be $(2 n+1)$. This mistake was automatically transferred into N.N. Prokhorov works [3, page 377] et al. At the same time in appendix to work [2] the formula is written correctly. 
In welding of nickel alloy (INCONEL 690) the solidification cracks also appear due to formation of intragranular liquid layers [5], in our opinion, also saturated with sulfur due to small coefficient $K^{\mathrm{S}}{ }_{\mathrm{o}} \approx 0.001$ in nickel. Thus, the results of carried experiments show that studied elements rise welds susceptibility to crack formation in welding of copper-nickel alloys and monel. As the surface active elements they decrease deformation capability of solidified metal [6], and, as a result, due to appearance of effect of adsorption decrease of ductility and strength, promote formation of solidification cracks.

\section{Conclusions}

1. Investigated was an effect of main impurities (lead, phosphorus and bismuth) on susceptibility of copper-nickel alloys to formation of hot cracks, their intercrystalline nature was determined. Significant enrichment by sulfur (in 27 times) of crack surface in monel welding was shown.

2. It is determined that oxygen in welding and surfacing of monel in contrast to low-carbon steel intensifies detrimental effect of sulfur.

3. It is proved that detrimental impurities the same as in copper welding promote formation of solidification cracks due to the fact of being surface active elements and manifestation of effect of adsorption decrease of ductility and strength.

1. Anoshin, V.A., Ilyushenko, V.M., Bondarenko, A.N. et al. (2014) Integrated evaluation of effect of main impurities on weldability of copper. The Paton Welding J., 11, 24-27.

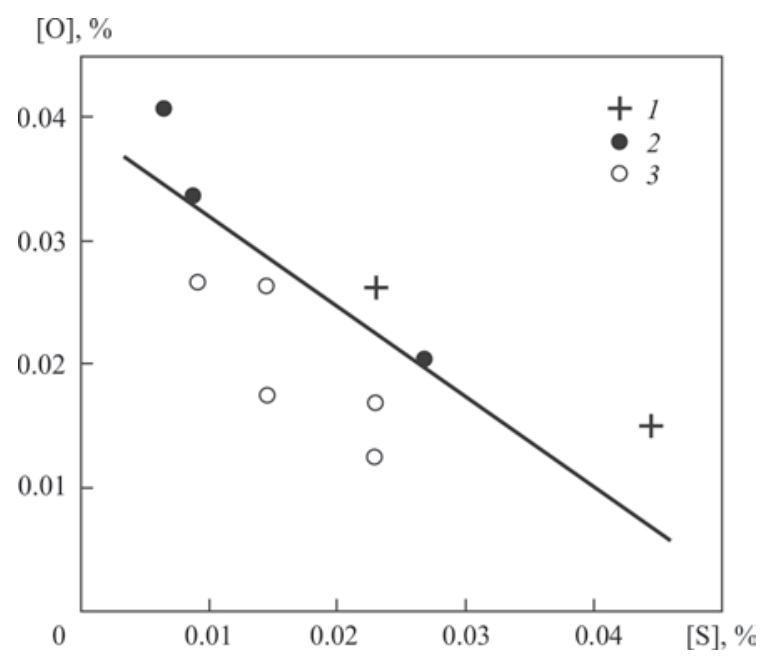

Figure 4. Joint effect of sulfur and oxygen content in weld metal on formation of cracks in deposition of monel on steel: 1 cracks; 2 - microcracks; 3 - no cracks

2. Smith, V.G., Tiller, W.A., Rutter, G.W. (1955) A mathematical analysis of solute redistribution during solidification. Canad. J. Phys., 33(12), 723-745.

3. Prokhorov, N.N. (1968) Physical processes in metals during welding. Vol. 1: Elements of physics of metals and solidification process. Moscow, Metallurgiya [in Russian].

4. Podgaetsky, V.V., Parfesso, G.I. (1977) Cracks of sulfide origin in welding of steel. Kiev, Naukova Dumka [in Russian].

5. Yushchenko, K.A., Savchenko, V.S., Chervyakov, N.O. et al. (2011) Comparative evaluation of sensitivity of welded joints on alloy Inconel 690 to hot cracking. The Paton Welding J., 11, 2-7.

6. Anoshin, V.A., Gurevich, S.M., Ilyushenko, V.M., Baranova, V.N. et al. (1981) Effect of surface-active elements on deformation capacity of nickel and monel. Avtomatich. Svarka, 7, 46-48 [in Russian]. 


\title{
PECULIARITIES OF FLASH-BUTT WELDING OF RAIL FROGS WITH RAIL ENDS
}

\author{
A.V. KAVUNICHENKO, V.I. SHVETS and E.V. ANTIPIN \\ E.O. Paton Electric Welding Institute of the NAS of Ukraine \\ 11 Kazimir Malevich Str., 03150, Kyiv, Ukraine. E-mail: office@paton.kiev.ua
}

\begin{abstract}
Producing of quality welded joints of rail frogs of steel 110G13L with rail ends without an intermediate insert is still an urgent problem. The results of investigations of formation of welded joints of rail steel M76 with steel 110G13L made by the flash-butt welding without an austenitic insert. are presented. It was shown that in the near-contact layer of rail steel, the high-alloy unstable austenite, fringed with carbides, is formed. It was established that localization of internal stresses and the presence of embrittling structures are the cause of a low deflection at the required fracture force of welded joints. 7 Ref., 2 Tables, 9 Figures.
\end{abstract}

Keywords : flash-butt welding, steel 110G13L, rail steel M76, microstructure, heat treatment, nonmetallic inclusions, internal stresses, mechanical properties, carbides, unstable austenite

At the enterprises of the railways of Ukraine, a large number of railway frogs are used, which are joined with a rail by bolts.

At the E.O. Paton Electric Welding Institute the technology of flash-butt welding of railway frogs, made of steel 110G13L with rail ends (steel M76) through an intermediate insert was developed using a pulse flashing [1]. The developed technology envisages the use of an intermediate austenitic insert of a standard production in the joints without a subsequent heat treatment [2].

At the same time, the attempts are still made to produce a quality joint of railway frogs from 110G13L steel with rail ends directly (without an intermediate insert).

The aim of this work is to investigate the peculiar features of formation and properties of joints of rail steel with steel $110 \mathrm{G} 13 \mathrm{~L}$ without an intermediate insert by using the flash-butt welding (FBW).

The welding of a pilot batch was carried out on castings of steel $110 \mathrm{G} 13 \mathrm{~L}$ in the form of a rail profile R65 and rail steel (Table 1) using the technology developed at the E.O. Paton Electric Welding Institute [3]. The parameters of the welding process varied in wide ranges:

- duration of welding process is $60-120 \mathrm{~s}$;

- allowance for welding is $24 \pm 1-30 \pm 1 \mathrm{~mm}$;

- final speed of forcing is $1.0-1.4 \mathrm{~mm} / \mathrm{s}$;
- upsetting value is $10-14 \mathrm{~mm}$.

The metallographic examinations and analysis of chemical heterogeneity of joints metal were carried out in the optical microscope «Neophot-32» and in the microanalyzer SX-50 of the «Camebax» Company.

The carried out examinations showed that microstructures of the joints of rail steel with steel 110G13L have a similar nature. Therefore, for discussion, the joint was selected, produced at the following mode:

- duration of welding process is $75 \mathrm{~s}$;

- allowance for welding is $26 \pm 1 \mathrm{~mm}$;

- final speed of forcing is $1.2 \mathrm{~mm} / \mathrm{s}$;

- upsetting value is $12 \mathrm{~mm}$.

During analysis of the microstructure the following sections of a joint were selected for discussion: HAZ of rail steel, HAZ of steel 110G13L, transition zone at the contact boundary.

In the HAZ metal of rail steel (similar to the homogeneous joint), the microstructure of hardening sorbite is preserved. The effect of welding heat is pronounced by an increase in size of primary austenite grains at approaching the joint line.

In contrast to rail steel, the steel $110 \mathrm{G} 13 \mathrm{~L}$ is thermally unstable [4].

In the temperature range of $400-700{ }^{\circ} \mathrm{C}$, already at the short-time heating, a decay of austenite by the reaction $\gamma \rightarrow \gamma_{\text {depl }}+(\mathrm{Fe}, \mathrm{Mn})_{3} \mathrm{C}$ is possible. In its turn, the austenite, depleted with carbon and manganese,

Table 1. Chemical composition of steels (wt.\%) and their melting range

\begin{tabular}{|c|c|c|c|c|c|c|c|}
\hline Steel & $\mathrm{Mn}$ & $\mathrm{Si}$ & $\mathrm{C}$ & $\mathrm{P}$ & $\mathrm{S}$ & $\mathrm{Cu}$ & $T_{\text {sol }}-T_{\text {liqq }},{ }^{\circ} \mathrm{C}$ \\
\hline M76 & 0.81 & 0.029 & 0.724 & 0.007 & 0.014 & - & $1380-1470$ \\
\hline 110G13L & 14.1 & - & 1.2 & 0.03 & 0.002 & - & $1330-1375$ \\
\hline
\end{tabular}




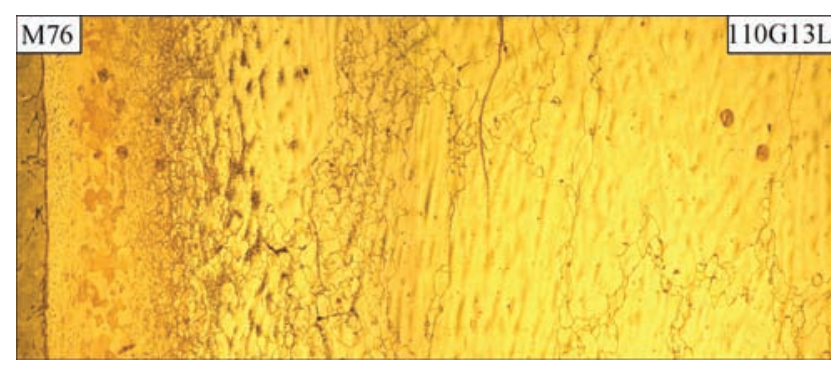

Figure 1. Microstructure $(\times 50)$ of joint of steel $110 \mathrm{G} 13 \mathrm{~L}$ with steel M76

can further decay with the formation of troostite-sorbite structures [5].

In the joint, the precipitation of carbides is observed in the region at a distance of about $1 \mathrm{~mm}$ from the joint (Figure 1). The carbides are precipitated along the grain boundaries. In the middle part of the marked section, the development of the process leads to the formation of a solid carbide network (Figure 2, $b$ ). The appearance of acicular carbides of crystallographic orientation, growing from the boundary, is possible. It should be noted that in the area of carbides region the fine globular formations are observed, the nature of which requires additional investigations.

The austenite layer of a polyhedral structure, which is formed under the conditions of homogenization annealing, is adjacent to the joint line. In the near-contact zone, a partial melting of grain sub-boundaries is possible in this layer (Figure 2, $a$ ).

The formation of the transition zone at the contact boundary with rail steel occurs as a result of solid-liquid interaction with the melt of steel $110 \mathrm{G} 13 \mathrm{~L}$, the melting interval of which is significantly lower (see Table 1).

During analysis of microstructure of the transition zone, it was established that in rail steel at a depth of 2-3 $\mathrm{mm}$ from the joint line between the blocks of grains (Figure 3) a structural component of light color is formed (conventionally called the interblock struc-

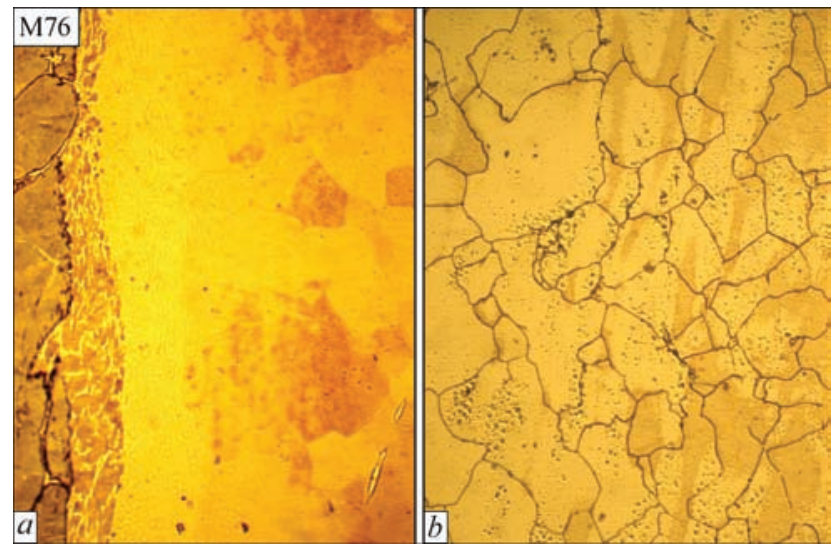

Figure 2. Microstructure $(\times 200)$ of the characteristic sections of the HAZ metal of steel 110G13L: $a$ - near-contact layer with partial melting of grain sub-boundaries; $b$ - carbide network along the grain boundaries

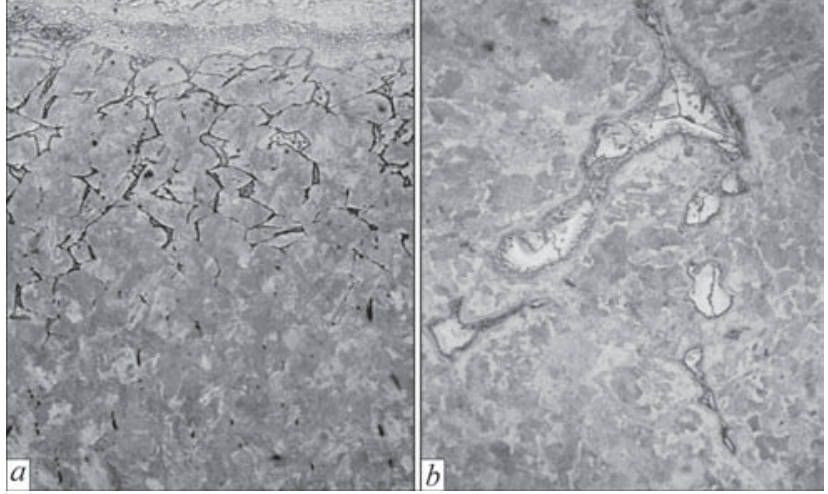

Figure 3. ISC in rail steel M76: $a-\times 50 ; b-\times 400$

tural component - ISC). Within the ISC, the presence of nonmetallic inclusions, eutectic colonies, is possible.

According to the results of the X-ray spectral microanalysis, the base of ISC consists of iron, containing in wt.\%: 4-8 Mn and 0.9-2.4 C. The microhardness of ISC of about $H V 0.2-2570$ corresponds to the microhardness of high-alloy unstable austenite. The trend of the carbon distribution curve gives assumption that the ISC is fringed with carbides, presumably (Fe, Mn) ${ }_{3} \mathrm{C}$ (Figure 4).

It is supposed that the formation of ISC occurs at the first stage of concentration melting of metal around the nonmetallic inclusions, located mainly along the grain boundaries (in the systems $\mathrm{Fe}-\mathrm{Mn}-\mathrm{S}, \mathrm{Fe}-\mathrm{P}$, $\mathrm{Fe}-\mathrm{Mn}-\mathrm{P}, \mathrm{Fe}-\mathrm{Cr}-\mathrm{Ni}-\mathrm{Ti}-\mathrm{C}$ there are eutectics with $T_{\text {e }}$ about $1000{ }^{\circ} \mathrm{C}$ ). Then the processes of diffusion transfer to the melt of the base metal elements with higher solubility in the liquid phase (carbon, manganese) and mass transfer of the melt from the boundary along the fused grains follow.

In the joint transition zone a layer is adjoined to rail steel, which includes the dark color formation of

Chemical composition of microvolumes of ISC, wt.\% (see Figure 4)

\begin{tabular}{|c|c|c|c|c|c|c|c|}
\hline No. & $\mathrm{Si}$ & $\mathrm{Cr}$ & $\mathrm{Ti}$ & $\mathrm{Ni}$ & $\mathrm{Fe}$ & $\mathrm{Mn}$ & $\mathrm{C}$ \\
\hline 1 & 0.486 & 0.095 & 0.000 & 0.004 & 92.882 & 4.088 & 2.438 \\
\hline 2 & 0.589 & 0.096 & 0.006 & 0.000 & 92.998 & 4.382 & 1.979 \\
\hline 3 & 0.512 & 0.080 & 0.026 & 0.014 & 93.768 & 3.813 & 1.736 \\
\hline 4 & 0.473 & 0.142 & 0.058 & 0.004 & 89.686 & 8.721 & 0.911 \\
\hline
\end{tabular}

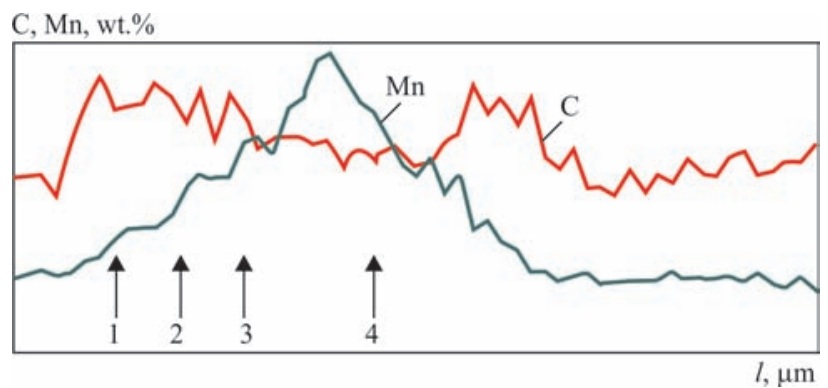

Figure 4. Distribution of carbon and manganese in ISC. Results of analysis of chemical composition of metal microvolumes within ISC 


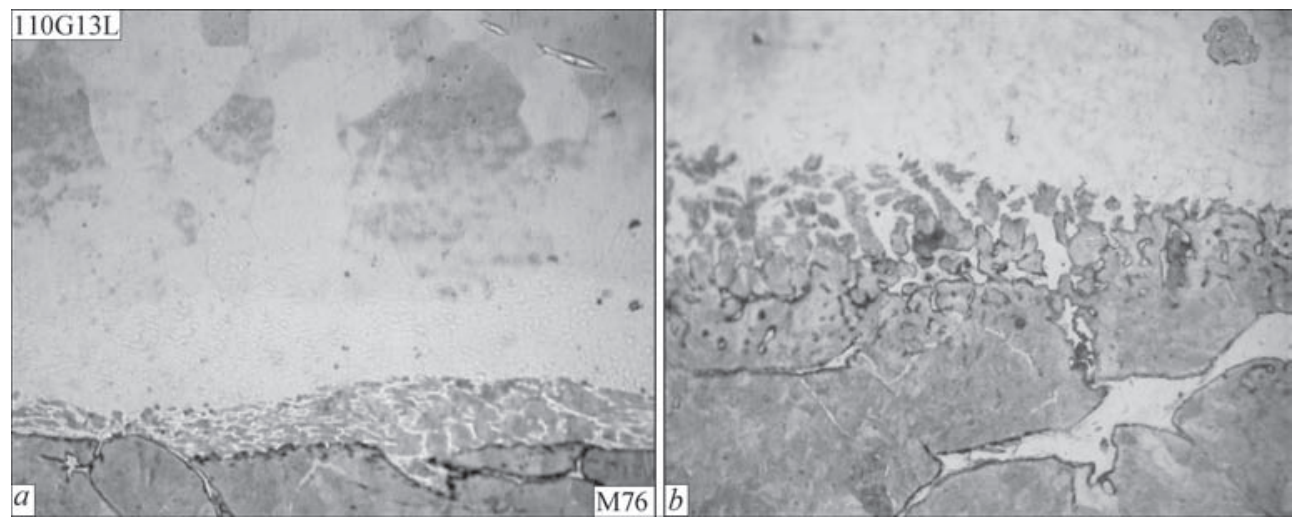

Figure 5. Microstructure of transition zone at the contact boundary of rail steel M76 and Hadfield steel: $a-\times 200 ; b-\times 400$

irregular shape, which in some cases is acicular. The appearance of this layer is not regular (Figure 5).

According to the results of X-ray spectral microanalysis (Figure 6), the concentration of manganese and carbon varies stepwise in the region of the transition zone without the layer. The width of diffusion zones in both steels amounted to about $5 \mu \mathrm{m}$ (Figure $6, b$ ).

In the region with the layer, on the curve of manganese distribution a step of about $65 \mu \mathrm{m}$ width (Figure $6, a$ ) with an intermediate value of manganese concentration of $3.5-4.5 \mathrm{wt} . \%$ is observed. The con-

Chemical composition of layer microvolumes having fragments with the hardening structure of iron-carbon steels, wt.\%

\begin{tabular}{|c|c|c|c|c|c|c|c|}
\hline No. & $\mathrm{Si}$ & $\mathrm{Cr}$ & $\mathrm{Ti}$ & $\mathrm{Ni}$ & $\mathrm{Fe}$ & $\mathrm{Mn}$ & $\mathrm{C}$ \\
\hline 1 & 0.453 & 0.056 & 0.025 & 0.000 & 94.882 & 3.877 & 0.707 \\
\hline 2 & 0.553 & 0.063 & 0.028 & 0.042 & 94.996 & 4.123 & 0.796 \\
\hline 3 & 0.445 & 0.062 & 0.027 & 0.007 & 94.275 & 4.879 & 0.620 \\
\hline 4 & 0.456 & 0.046 & 0.016 & 0.028 & 90.301 & 4.433 & 4.664 \\
\hline
\end{tabular}

C, Mn, wt. \%

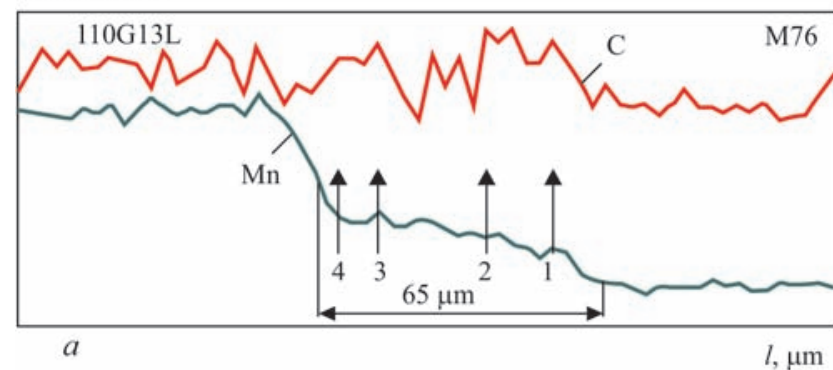

C, $\mathrm{Si}, \mathrm{Mn}$, wt. $\%$

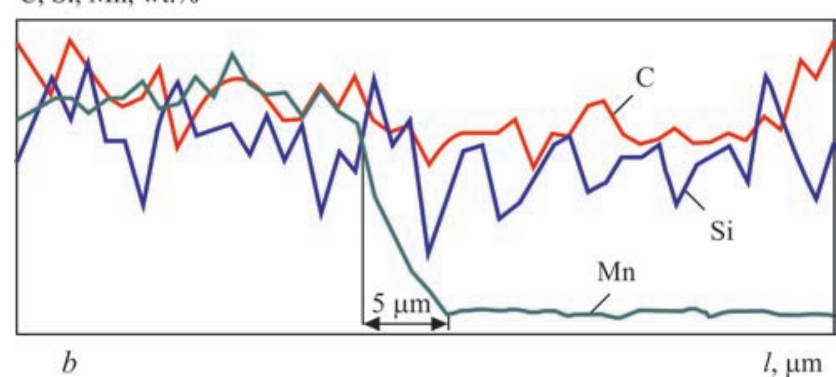

Figure 6. Distribution of elements in the transition zone of a joint of rail steel M76 and Hadfield steel in the region: $a$ - with acicular phase; $b$ - without acicular phase

centration of carbon in this case is at the level of that of steel 110G13L.

Obviously, the layer was formed as a result of partial dissolution of rail steel and the subsequent crystallization of excessive phases on residual particles. In the case when the melt with particles is almost completely squeezed out during upsetting (or only the frontal dissolution of rail steel takes place), the layer is absent. In this case the joint is formed similarly to the joints produced during solid-phase interaction.

The strength characteristics of such a welded joint are low. The fracture occurs in the near-contact layer of rail steel at a distance of up to $2 \mathrm{~mm}$ from the joint line. The ISC inclusions, fringed by carbides, as well as boundaries of grain blocks with carbide precipitations are critical for the strength under the conditions of high postweld stresses due to a large difference in the coefficient of thermal expansion (CTE) of steels being joined.

The ability of transformation of non-desirable structural components with the use of heat treatment was considered. The effect of annealing was studied at the following modes:

1. $T=350{ }^{\circ} \mathrm{C}, 3 \mathrm{~h}$, oil cooling (tempering);

2. $\mathrm{T}=850^{\circ} \mathrm{C}, 3 \mathrm{~h}$, oil cooling (normalization);

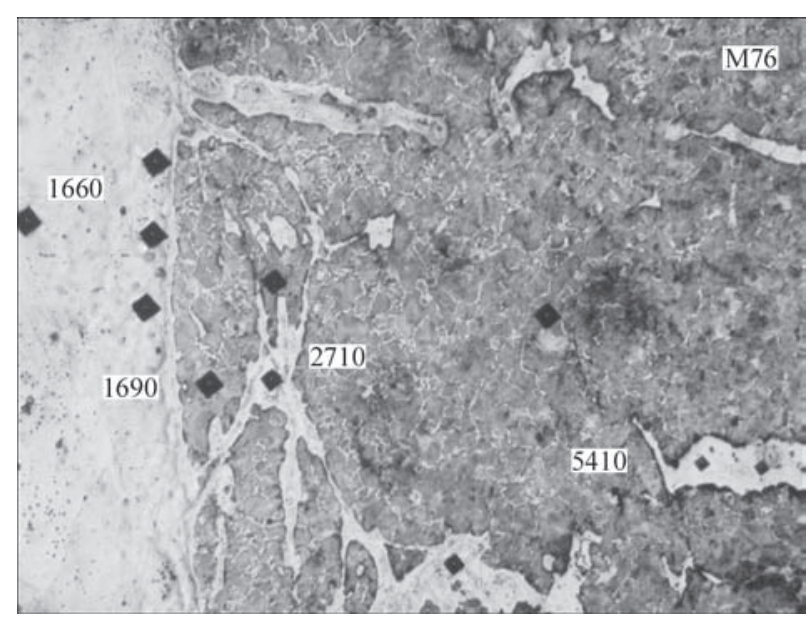

Figure 7. Microstructure $(\times 400)$ and distribution of microhardness in the joint of rail steel M76 and Hadfield steel after annealing by the mode: $T=850^{\circ} \mathrm{C}, \tau=3 \mathrm{~h}$, oil cooling 


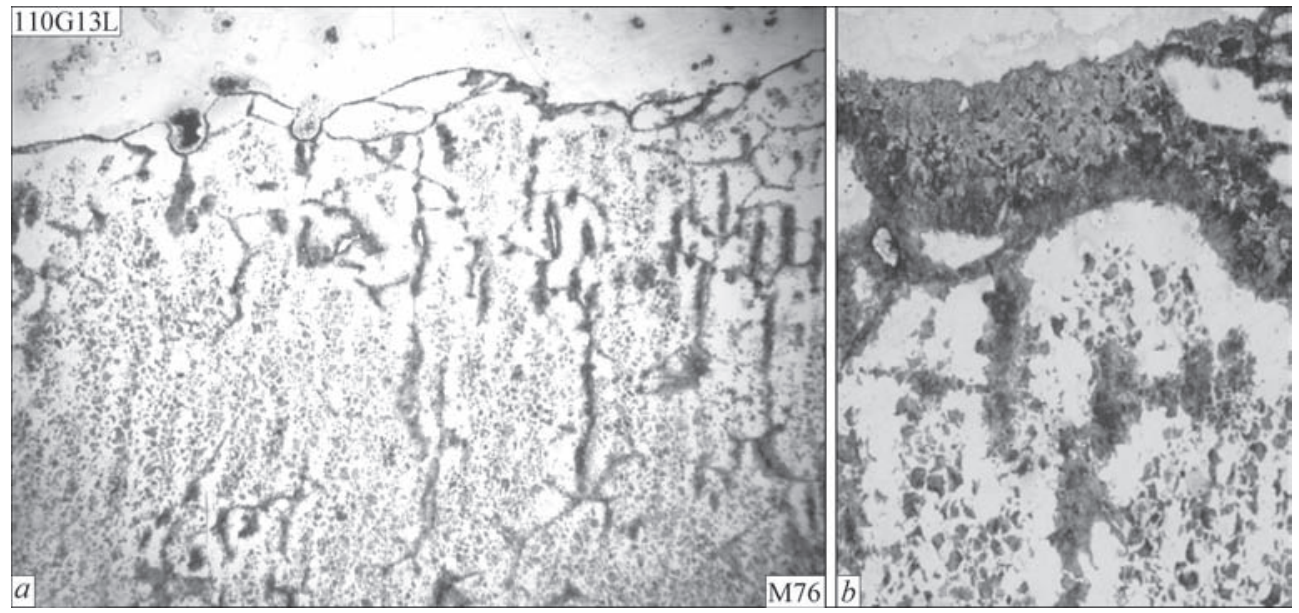

Figure 8. Microstructure of welded joint of rail steel with steel 110G13L after annealing by the mode 3: $a-\times 50 ; b-\times 400$

3. $T=1000{ }^{\circ} \mathrm{C}, 3 \mathrm{~h}$, oil cooling (homogenizing annealing).

Annealing by the mode 1 affects the change in the hardness of structural components. The hardness of ISC (HV 0.5-3810) and the hardness in the areas with dark formations in the layer along rail steel (HV $0.5-5430)$ is increased. The microhardness of steel $110 \mathrm{G} 13 \mathrm{~L}$ and rail steel properly in the near-contact zone decreased and amounted to HV 0.5-1600-2000 and HV 0.5-1800-2000, respectively.

After recrystallization by the mode 2, the dark formations in the layer along the contact boundary of rail steel as well as the fringing of carbides at the ISC boundary with the base metal, disappear in the microstructure of the transition zone. In this case, the hardness of ISC increases to HV 0.5-5500 (Figure 7). Apparently, on the one hand, the observed changes are caused by the dissolution of carbides in the austenite matrix at the temperatures higher than $\mathrm{A}_{3}$ point, and on the other hand, by the formation of martensite in the metastable austenite of ISC. The microstructure of rail steel in the near-contact zone represents refined pearlite colonies with a ferrite fringing and microhardness of $H V 0.5-1830$, which is lower than that at a distance of $4 \mathrm{~mm}$ from the contact boundary $H V 0.5-2600$. The values of microhardness in the near-contact zone of Hadfield steel are in the range of HV 0.5-1600-1750.

The results of homogenizing annealing of the joint by the mode 3 are of interest. As is seen (Figure 8), after heat treatment, ISC are completely or partially transformed into pearlite with microhardness of HV 0.5-1850-2310. The observed residual regions of ISC, surrounded by pearlite, preserve the microhardness of high-alloy austenite of HV 0.5-3220-4390.

It should be noted that microhardness of austenitic grains of steel 110G13L after homogenizing annealing remains at the same level ( $H V$ 0.5-2440-3200) with a significant reduction in the microhardness of rail steel (HV 0.5-1190).

The homogenizing annealing appears to be promising for eliminating undesired structural components formed in rail steel. However, the capabilities of postweld heat treatment are limited by carbide formation in steel $110 \mathrm{G} 13 \mathrm{~L}$, occurring in the temperature range of $250-950{ }^{\circ} \mathrm{C}$. To preserve the properties of steel $110 \mathrm{G} 13 \mathrm{~L}$, the quenching from the homogenizing temperatures is required. This may cause the formation of martensite in rail steel, which, in its turn, is unacceptable.

In connection with the fact that the fracture of welded joints during tests on static bending occurs at relatively small deflection, the investigations were carried out to determine residual stresses in welded joints which can reduce the deformability, as well as the fatigue strength of the welded joint. To calculate
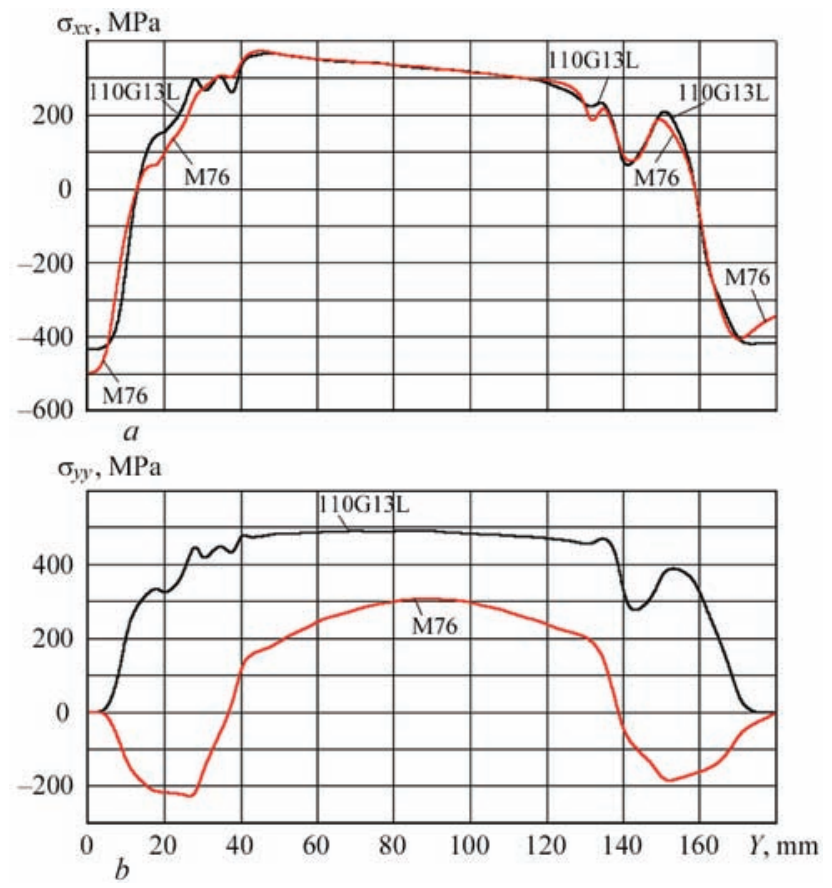

Figure 9. Distribution of residual stresses $\sigma_{x x}(a)$ and $\sigma_{y y}(b)$ along the joint at a distance $x=2.5 \mathrm{~mm}(\mathrm{M} 76)$ and $x=-2.5 \mathrm{~mm}(110 \mathrm{G} 13 \mathrm{~L})$ 
Table 2. Results of tests of welded specimens on static bending (R65 profile)

\begin{tabular}{|c|c|c|}
\hline No. of specimen & Fracture force, $\mathrm{kN}$ & Deflection, $\mathrm{mm}$ \\
\hline 1 & 1000 & 12 \\
\hline 2 & 900 & 13 \\
\hline 3 & 980 & 17 \\
\hline 4 & 1050 & 19 \\
\hline 5 & 1000 & 19 \\
\hline 6 & 800 & 11 \\
\hline 7 & 1000 & 12 \\
\hline 8 & 1100 & 15 \\
\hline 9 & 1100 & 13 \\
\hline 10 & 900 & 12 \\
\hline 11 & 1150 & 17 \\
\hline
\end{tabular}

the stressed state, an algorithm for numerical solution of the problem of non-isothermal plastic flow with the Mises yield criterion was used.

The analysis of the calculation data of residual stresses, presented in Figure 9 for joints of steel 110G13L with rail steel showed that the beginning of crack formation in the transition zone of a joint in the web of the rail profile is determined by the presence of tensile residual stresses $\sigma_{x x}$, the values of which are the highest ones in the wall near the transition to the flange.

The use of welding modes with increased specific powers led to decrease in the level of residual stresses in welded joint, which made it possible to produce full-profile welded joints which did not fracture spontaneously. The testing of welded joints of full-profile specimens on static transverse bending at a certain destructive force did not demonstrate stable results by deflection (the deflection is in the range of 8-19 $\mathrm{mm}$, see Table 2), which does not meet the requirements of the Ukrainian and European standards [6, 7].

\section{Conclusions}

1. In the transition zone of the joint of steel 110G13L with rail steel, produced by FBW, the structural components of the intermediate chemical composition are formed.

2. In the near-contact layer of rail steel, the socalled interblock structural component (ISC) is formed, representing a high-alloy unstable austenite, fringed by carbides.
3. In the transition zone along the boundary of rail steel, the layers with products of dissolution of rail steel and the subsequent crystallization of carbides on them are formed.

4. The formation of cracks in the fusion zone along the joint can be related to the presence of residual tensile stresses $\sigma_{x x}$ whose values are the highest ones in the wall near the transition to the flange.

5. The localization of internal stresses in the weld due to a large difference in CTE of the steels joined (almost 2 times) and the presence of embrittling structural components are the cause of the joint low strength.

6. The use of postweld heat treatment is problematic as far as there is no coincidence between the permissible modes of heat treatment for rail steel and steel $110 \mathrm{G} 13 \mathrm{~L}$.

7. The technological measures preventing the formation of the mentioned defects should be aimed at increasing the resistance of the fusion zone material to occurrence of the corresponding cracks; from these positions, the use of an intermediate austenitic insert containing nickel is one of the effective technological means in this direction.

1. Kuchuk-Yatsenko, S.I., Shvets, V.I., Gordan, G.N. et al. (2006) Features of formation of structure of joints of rail steel M76 to steel 110G13L made by flash-butt welding. The Paton Welding J., 1, 2-8.

2. Kuchuk-Yatsenko, S.I., Shvets, Yu.V., Dumchev, E.A. et al. (2005) Flash-butt welding of railway frogs with rail ends using an intermediate insert. Ibid., 1, 2-4.

3. Kuchuk-Yatsenko, S.I., Didkovsky, O.V., Bogorsky, M.V. et al. (2002) Method of flash-butt welding. Ukraine, Pat. 46820. Int. Cl. B23K 11/04 [in Ukrainian].

4. Gruzin, P.L., Grigorkin, V.I., Moskaleva, L.N., Mural, V.V. (1969) Transformations in austenitic manganese steel. Metallovedenie i Termich. Obrab. Metallov, 1, 5-9 [in Russian].

5. Tkachenko, F.K., Efremenko, V.G. (1990) Structure and phase transformations in wrought high-manganese steel. Ibid., 2, 8-10 [in Russian].

6. (2006) TU U 27.3-26524137-1342:2006: Frogs and cores with welded-up rail ends of R65, R50 and UIC60 types. Specification [in Ukrainian].

7. (2012) DIN EN 14587-3:2012: Railway applications Track-flash butt welding of rails. Pt 3: Welding in association with crossing construction. 


\title{
DETERMINATION OF PARAMETERS OF FRICTION STIR WELDING MODE OF ALUMINUM-BASED ALLOY
}

\author{
I.O. VAKULENKO and S.O. PLITCHENKO \\ Dnipropetrovsk National University of Railway Transport named after Academician V. Lazaryan \\ 2 Lazaryan Str., 49010, Dnipro, Ukraine. E-mail: plit4enko@ukr.net
}

\begin{abstract}
A procedure is proposed for determination of parameters of process of plates joining using friction stir welding technology by the example aluminum alloy. A nature of metal heating was determined in investigation of working tool rotation at different relationships of frequencies and normal pressing to joined edges. A minimum value of temperature interval in realizing of friction stir welding technology was determined from the analysis of nature of increase of heating temperature of edges being joined. Based on the analysis of received experimental data a concept of determination of main parameters of welding process was proposed. 17 Ref., 9 Figures.
\end{abstract}

Keywords : friction stir welding, heat energy, working tool; welding mode, aluminum-based alloys, optimum temperature

Friction stir welding (FSW) relates to diffusion technologies characterized by absence of heating to metal melting temperatures (Figure 1).

The main source of heat in such a technology is a friction forces appearing between the metal surfaces being welded and working part of special tool [2-4].

With such a technology the intensity of necessary energy is determined by a complex effect of rotation frequency of the tool around its axis, pressing force and speed of its movement along the edges being joined under conditions of optimum geometry dimensions and shape of working tool [5].

At the same time high sensitivity of FSW process to insignificant changes of technological characteristics considerably complicates maintenance of the optimum welding conditions, especially when welding circuit differs from straight line. Indeed, under conditions of constant pressing force a relationship between rotation frequency and movement speed of working tool along the edges being joined allows control of the process of metal heating in a weld zone without difficulties. In contrast to this, it is more difficult to keep a stationary mode of welding only in varying pressing force when recommended temperature corresponds to narrow interval $0.8-0.95$ from melting temperature of metallic material $[5,6]$.

Taking into account that the working tool determines the process of generation and distribution of heat energy in the welding zone, dimensions of its constituents and shape (Figure 2) significantly effect the welded joint quality.
Every part of the tool ensures performance of specific functions in transformation of mechanical energy into heat one by friction. Thus, shoulder provides approximately $80-90 \%$ of necessary energy for edge heating [7], the rest is generated by pin. In such a way, the shoulder provides the main contribution in FSW under condition of necessary level of metal heating from mechanical contact.

The detailed analysis of structural transformations in the metal after FSW indicates that only specific shape of working tool guarantees the necessary distribution of heating temperature along intersection of contact surfaces $[3,8]$.

Depending on technological problems a special relief [9] can be made on the working surface of the

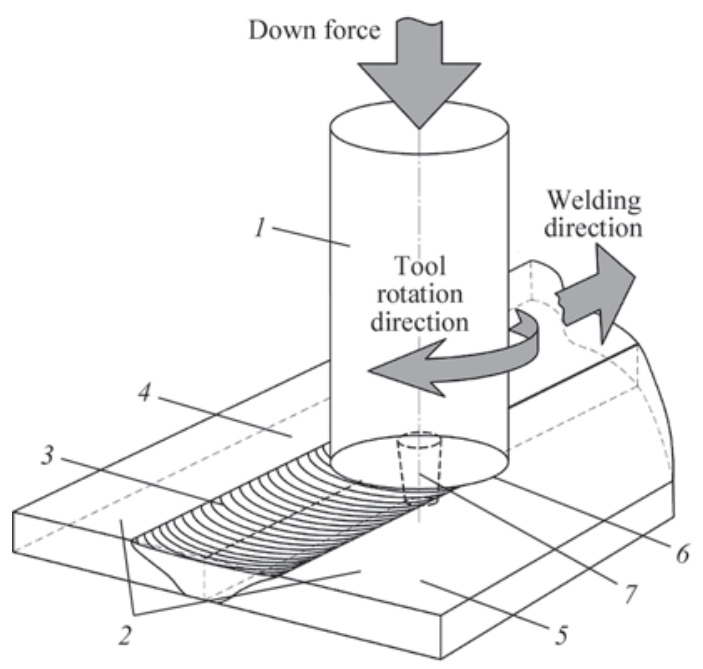

Figure 1. Process of welding of two plates [1]: 1 - tool; 2 plates; 3 - weld; 4 - advancing side; 5 - retreating side; 6 shoulder; 7 - pin 


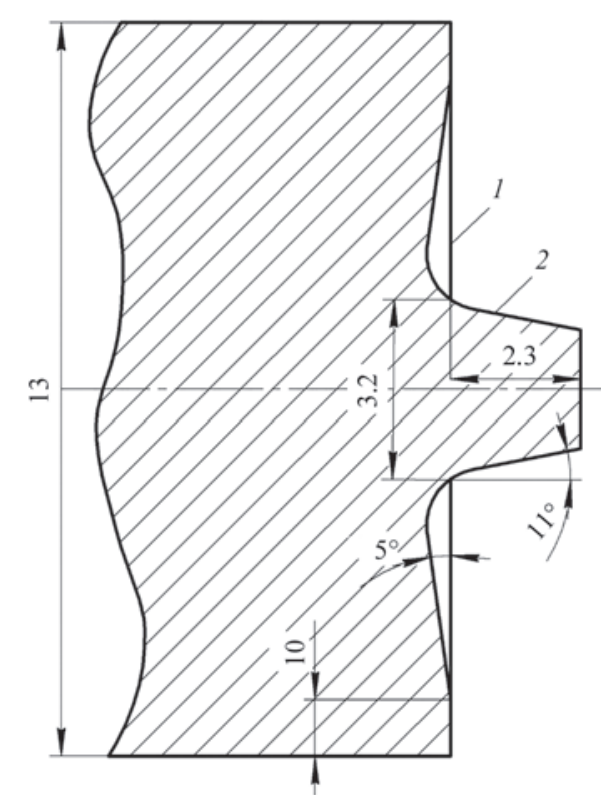

Figure 2. Schematic presentation of FSW working tool: 1 shoulder; 2 - pin

tool, for example, for breaking oxide films or increase the level of metal stirring in edges being joined. Based on the results of investigations of works $[2,4,10]$ performance of grooves enables getting increased level of complex of properties in welded joint metal.

A pin of the working tool in comparison with the shoulder has somewhat other designation. Its operation provides redistribution of heat energy sufficient for maintaining determined conditions of development of diffusion processes of metal mass transfer along the thickness of edges being joined during tool active operation.

The shape of working tool pin and its diameter have qualitative dependence on the series of factors, namely angle of its inclination in welding, thickness of the base metal, chemical composition etc. [7]. Making the grooves on pin surface in form of threads helps to control a flow of plasticized metal guiding it for compaction of some areas of the weld. Such an

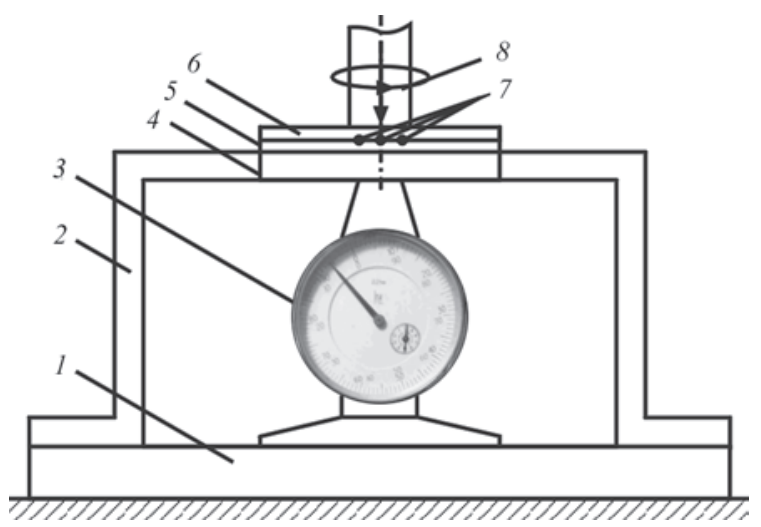

Figure 3. Scheme of bench for investigations: 1 - base plate of machine; 2 - bench framework; 3 - dynamometer; 4 - motion plate; 5 - heat insulator; 6 - sample being welded; 7 - thermocouples; 8 - working tool effect reduces the possibility of lack of penetration of weld root [8].

In comparison with the technologies of partial or complete melting an application of FSW allows considerably reducing the level of metal overheating in a weld heat-affected zone. The perspective directions of application of such technology are joining of the elements of dissimilar materials which form heterogeneous melts or chemically unstable multiphase mixtures in solidification. The joints received on traditional technologies, for example, in electric arc welding, can have unpredictable negative effect on welded joint quality.

The aim of work is improvement of the procedure for determination of radius of working tool shoulder in FSW.

Material and experiment procedure. FSW was carried out on specially designed equipment that together with selected parameters of working tool [1012] provided welded joint formation.

The FSW process (Figure 1) was performed on the following scheme, i.e. working tool 1, with specific frequency of rotation around own axis, was located under $1-3^{\circ}$ angle relatively to a plane of edges being joined. Constant normal force of the tool was necessary for deepening the shoulder at up to $10 \%$ depth of edge thickness. Appearance of friction force on the contact surfaces of shoulder 5 , pin 6 and elements being joined 3 and 4 provide necessary level of base metal heating. Action of the pin results in uniform distribution of heat along edges thickness. The metal starts stirring after reaching the necessary level of heating.

A working tool material was high-speed steel R9, which provides maintenance of shape and size of the tool at increased heating temperatures when realizing FSW technology of the most aluminum-based alloys [5]. Shape and size of the working tool (Figure 2) was determined based on analysis of known experimental data $[1,3-5]$.

The investigations of FSW technology was carried out on the plates of $1.85 \mathrm{~mm}$ thickness from aluminum alloy AMg3 with content of chemical elements within the limits of grade composition.

Change of temperature in a welding zone and level of tool pressing was performed with the help of specially developed research bench (Figure 3) which was located on a base plate 1 of milling machine. The bench consisted of framework elements 2, motion metallic plates 4 and heat insulator 5 made of mica. The pressing force of working tool to the base metal during welding was measured with the help of dynamometer of DS0.1 type with detecting head. 
The temperature of heating of edges being joined $\mathrm{T}$ was determined by deepening of thermocouples of chromel-alumel type in the metal at different distance from weld axis. The speed of rotation of the working tool $\omega$ was varied from 800 to $1600 \mathrm{~min}^{-1}$ at force of plates pressing to the surface not more than $1.45 \mathrm{kN}$. The speed of tool movement along the weld $v_{\mathrm{w}}$ was constant and made $50 \mathrm{~mm} / \mathrm{min}$.

Received results and discussion. The level of metal heating was regulated in the process of investigation at different relationships of frequency of working tool rotation and its normal pressing to the edges being joined.

Figure 4 shows the results of effect of FSW process technological parameters on metal heating temperature in zone of action of the working tool shoulder.

The optimum temperature of heating of edge metal under conditions of rapid increase of ductile properties was determined from the analysis of $P=f(T)$ relationship nature. Independent on the tool rotation speed and force of its pressing the values of the minimum temperature lied in relatively low interval $70-85{ }^{\circ} \mathrm{C}$. An average value of temperature $76^{\circ} \mathrm{C}$ that corresponded to alloy plasticization moment was taken considering possible uncontrolled deviations at maintenance of stable conditions of welding process and in order to facilitate heat balance analysis.

A comparative analysis with the absolute values of temperature of start of resolidification development $T_{\mathrm{r}}$ for different alloys on $T_{\mathrm{r}}=0.45 T_{\mathrm{m}}$ dependence, where $T_{\mathrm{m}}$ is the metal melting temperature indicating sufficiently qualitative match between them.

The detailed analysis of curve shape $P=f(T)$ (Figure 4) taking into account staging of processes of structural transformations under conditions of hot reduction [13] indicates that the processes of internal rebuilding of alloy from the moment of formation of horizontal area to rapid decrease of pressing force are caused by development of dynamic processes of cell formation and resolidification at determined relationship.

Thus, the moment of formation of horizontal area can be accepted as the minimum value of temperature interval of FSW process and rapid decrease of $T$ is the maximum allowable value.

Shape of curves and the points of qualitative substitutions of $P=f(T)$ relationship indicate the dependence of conditions of achievement of metal superplastic state on FSW parameters. Really, if temperature of plasticization start remains virtually independent on $\omega$ and $P$ relationship than achievement of superplastic state (area of pressing force fall) to the larger extent is determined by $\omega$ value.

Evaluation of heat energy $Q$ necessary for FSW realizing was carried out in order to determine the pa-

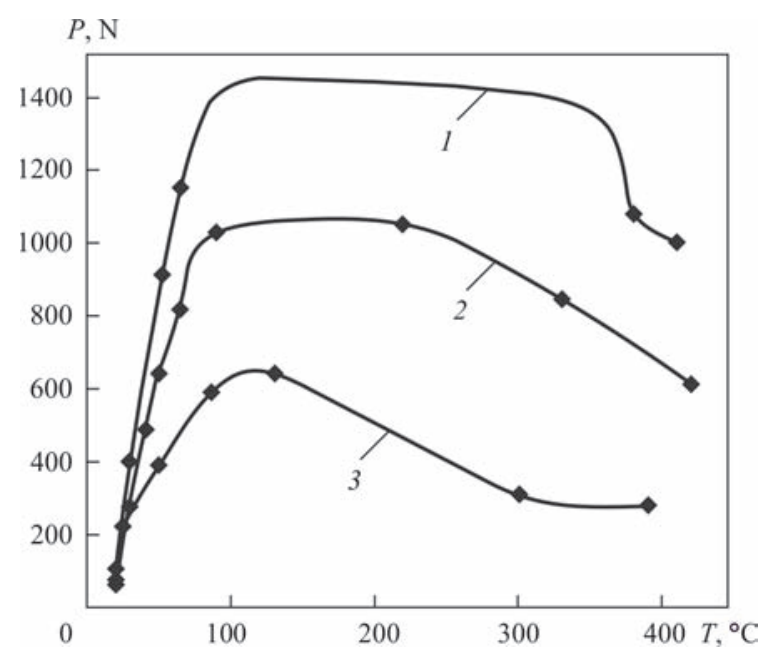

Figure 4. Experimental curves of effect of rotation speed $\omega$ and pressing force $P$ of working tool $\left(v_{\mathrm{w}}=\right.$ const) on heating temperature of alloy edges under shoulder: $1-\omega=800 ; 2-1250$; $3-1600 \mathrm{rpm}$

rameter which has the largest effect on alloy ductility for different relationships of rotation speed and pressing force of the working tool. Taking into account that achievement of metal stirring conditions is heat activated process a well-known equation was used [14] for evaluation of $Q$ :

$$
\dot{\varepsilon}=A \exp \left(-\frac{Q}{R T}\right) P^{m},
$$

where $\dot{\varepsilon}$ is the deformation rate; $A$ is the coefficient of proportionality; $R$ is the absolute gas constant; $T$ is the temperature $(\mathrm{K}) ; P$ is the force characteristic; $m$ is the level index.

Under experiment conditions, relationship (1) was transformed to the form:

$$
Q=R T(m \ln P-\ln \omega),
$$

where $\omega$ is the rotation frequency; $P$ is the working tool pressing frequency.

The basic of $Q$ calculation made the experimental data (Figure 4) of different welding modes.

For edge thickness $1.85 \mathrm{~mm}$, inserting the experimental values for steady mode in relationship (2): $\omega=13.3 \mathrm{~s}^{-1}\left(800 \mathrm{~min}^{-1}\right), P=1 \mathrm{kN} ; \omega=20.8 \mathrm{~s}^{-1}$ $\left(1250 \mathrm{~min}^{-1}\right), P=0.59 \mathrm{kN}$ and $\omega=26.7 \mathrm{~s}^{-1}\left(1600 \mathrm{~min}^{-1}\right)$, $P=0.275 \mathrm{kN}$ for temperatures in zone of welding $0.7 T_{\mathrm{m}}$, the corresponding $Q$ values were received. Figure 5 shows the nature of $Q$ dependence on $\omega$.

Provided results indicate that increased rotation frequency under conditions of constant welding speed ensures heating to necessary temperature in the welding zone at lower level of energy.

Thus, reduction of necessary energy can be reached by decrease of normal pressing force of the working tool to billets at rise of $\omega$ in process of welding that is proved by curve 3 on Figure 4 . 


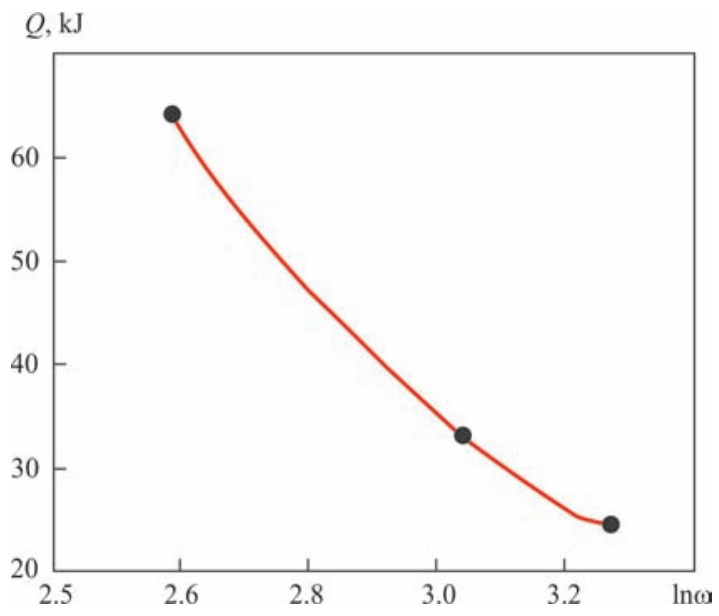

Figure 5. Dependence of value of energy $Q$ for steady welding process (at $0.7 T_{\mathrm{m}}$ ) on working tool rotation frequency $\ln \omega$ and pressing force at $v_{\mathrm{w}}=$ const

Together with this under conditions of minimum force $P(0.275 \mathrm{kN})$ another nature of change was determined, i.e. calculated using (2) amount of energy on frequency of working tool rotation (Figure 6).

Joined analysis of calculated values $Q$ (Figures 5, 6) indicates the need to determine the optimum energy for friction stir welding and possible dependence on geometry of the working tool. There was an attempt to evaluate the optimum diameter of the working tool shoulder for different thicknesses of edges being joined taking into account a contribution of the shoulder into energy balance in FSW. For this purpose a relationship of dependence of FSW process heat balance on main technological parameters [15] was used:

$$
N=\frac{2}{3} \pi \mu p \omega R_{\text {tool }}^{3} \text {, }
$$

where $N$ is the energy characteristic; $\mu$ is the friction coefficient; $p$ is the specific normal pressure of the tool; $\omega$ is the angle rotation speed; $R_{\text {tool }}$ is the tool shoulder radius.

From relationship (3), $R_{\text {tool }}$ equals

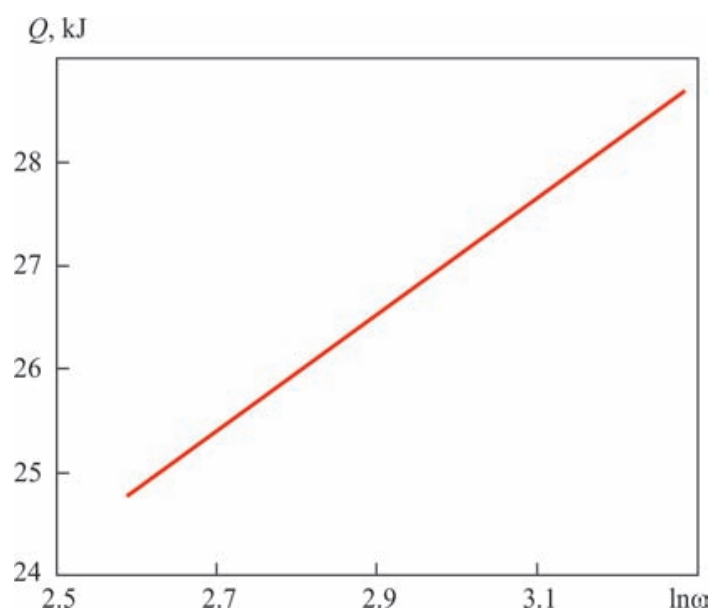

Figure 6. Dependence of amount of energy $Q$ for steady welding process on working tool rotation frequency $(\ln \omega)$ at $P=0.275 \mathrm{kN}$, $v_{\mathrm{w}}=$ const by relationship (2)

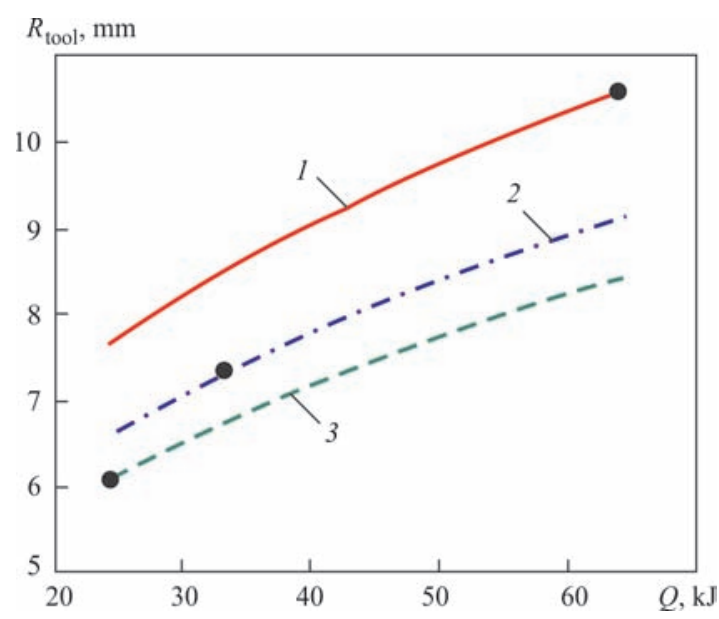

Figure 7. Diagram of selection of working tool shoulder radius $R_{\text {tool }}$ for steady welding mode at $P=0.275 \mathrm{kN}, v_{\mathrm{w}}=$ const and $\delta=$ $1.85 \mathrm{~mm}: 1-\omega=800 ; 2-1250 ; 3-1600 \mathrm{rpm} ; \bullet-Q$ value from analysis Figure 5

$$
R_{\text {tool }}=\sqrt[3]{\frac{3 N}{2 \pi \mu p \omega}} .
$$

The results of $R_{\text {tool }}$ calculation by (4) using hypothetical values of $Q$ for investigated intervals of $\mathrm{P}$ and $\omega$ change are given in Figure 7.

Evaluated values $Q$ from experiment [16] were used instead of $N$ in order to check fulfillment of dependence (4). Received results on $R_{\text {tool }}$ for the experiment conditions in FSW for $\delta=1.85 \mathrm{~mm}$ indicate sufficiently qualitative match with that calculated by (4).

The analysis of the results of experimental investigations and carried calculations prove existing dependence of value of heat energy in the welding zone, first of all, on radius of working tool shoulder, namely reduction of $R_{\text {tool }}$ results in $Q$ decrease.

In process of welding position of the tool at $1-3^{\circ}$ angle relatively to normal line of the billet provides the necessary conditions for metal compaction. Expected nonuniformity of temperature distribution along the area of contact spot (shoulder) takes place only at initial stages before coming to the optimum welding conditions. After that steady conditions of the process of heat energy emission are reached.

Designing of the working tool requires taking into account that diameter of the shoulder determines level of mechanical loads on the equipment in whole, as well as, width of heating zone. Under conditions of higher speeds of working tool rotation the excessive increase of $R_{\text {tool }}$ can result in overheating of welded joint that will have negative effect on its mechanical properties. Received qualitative dependencies are proved by the experiment, i.e. the optimum welding conditions are rather achieved at rise of $\omega$ and decrease of $P$.

At the same time it is necessary to expect specific effect on technological characteristic when reaching the optimum welding mode from the side of chemical 


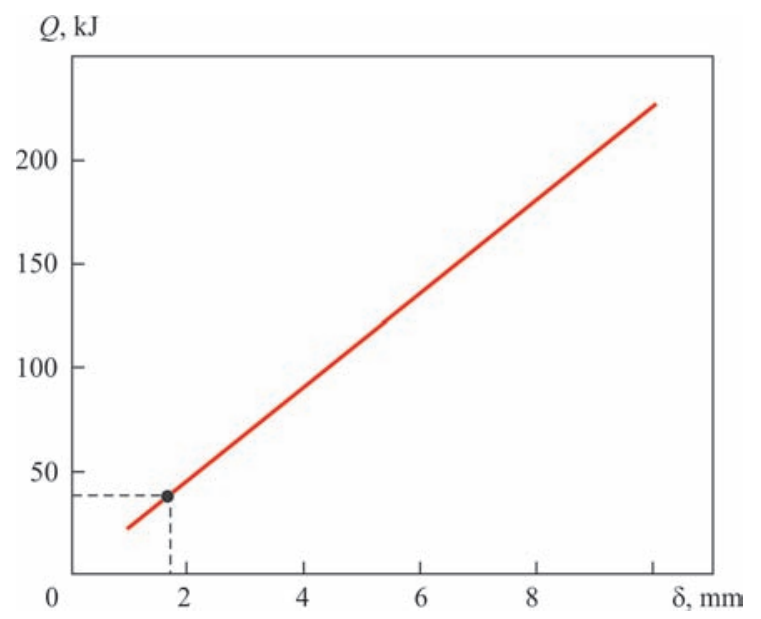

Figure 8. Dependence of necessary amount of energy $Q$ by (5) for steady welding process on metal thickness $\delta$

and phase composition of alloy. The total contribution can be evaluated through correlative relationships of heat physical properties.

Following similarity criterion $\psi$ it is possible to determine the necessary energy for welding depending on plate thickness $\delta$ [17]:

$$
\psi=\frac{N}{\lambda T \delta},
$$

where $N$ is the characteristic similar to $Q$ from (3); $\lambda$ is the heat conductivity; $\delta$ is the thickness of metal edges; $T$ is the temperature in welding zone, $\mathrm{K}$.

Based of relationship (5) for specific alloy under conditions of constant $\lambda$ and $T$ (the optimum temperature of edge heating in FSW) $\psi$ value varies in a very small range of values that is proved by the data [17] and experimentally in the work. Taking into account that thickness of metal being welded can be changed in a wide range, calculations of $R_{\text {tool }}$ are limited by thicknesses from 1 to $10 \mathrm{~mm}$ that is the most widespread in industry.

After inserting in (5) the constant characteristics $\lambda$, $T$ and $\psi$ (was taken as constant value) the relationship between $\delta$ and $Q$ was received for steady FSW mode (Figure 8). Taking into account that $Q$ of the same level can be reached by different combination of $\omega$ and $P$, the calculation of welding energy by (5) in reality provides an average value for a range of changes of $\omega$ and $P$ that has determined prove. Thus, for $\delta=$ $=1.85 \mathrm{~mm}$ thickness an obtained value of energy by relationship (5) and average $Q$ value following three modes $(40 \mathrm{~kJ})$ have sufficiently qualitative match.

Thus, provided dependence (Figure 8) allows determining the optimum FSW conditions for different thickness plates. For example, the necessary value of heat energy for $\delta=3 \mathrm{~mm}$ thickness should make the value around $70 \mathrm{~kJ}$. Then, using energy value for specific equipment with determined power the optimum

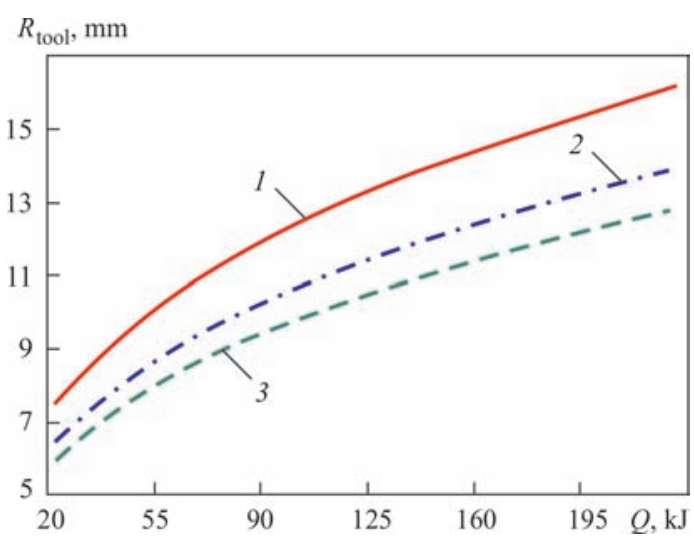

Figure 9. Diagram for determination of recommended radius of working tool shoulder $R_{\text {tool }}$ for reaching steady welding process at $P=0.275 \mathrm{kN}, v_{\mathrm{w}}=$ const: $1-\omega=800 ; 2-1250 ; 3-1600 \mathrm{rev} /$ $\min$

frequency of working tool rotation and corresponding radius of shoulder are evaluated.

Taking into account that plotted relationship $R_{\text {tool }}=$ $=f(Q)$ (Figure 7) is only referred to edge thickness 1.85 , Figure 9 provides more generalized example, when $1<\delta<10 \mathrm{~mm}$.

At the same time, plotted diagram (Figure 9) in fact refers to the conditions of constant pressing force $(0.275 \mathrm{kN})$, however, the optimum level of $Q$ for welding (FSW) is determined by combination of $\omega$ and $P$.

Verification of dependence fulfillment (Figure 9) was carried out experimentally. Thus, under conditions of constant pressing force $(0.275 \mathrm{kN})$ for welding of $3 \mathrm{~mm}$ thickness edges at $\omega=1250 \mathrm{rpm}$ the tool radius shall be in $9-10 \mathrm{~mm}$ range and for $1600 \mathrm{rpm}$ frequency it is approximately $8-9 \mathrm{~mm}$. Under conditions when proved necessity of searching the optimum welding mode is based on change of working tool pressing force, $R_{\text {tool }}$ calculation is carried out using other diagram for specific $P$ value.

Thus, provided evaluations make it possible to improve the process of searching the optimum welding parameters by friction stir welding.

\section{Conclusions}

1. The main conditions for reaching the effect of constant softening of metallic materials in FSW were determined by the example of aluminum-based alloy.

2. The minimum value of temperature interval of metal softening in FSW was determined.

3. A procedure of shoulder radius selection depending on the relationship of rotation speed and working tool pressing force in FSW was developed for different thicknesses of edges being joined.

1. Thomas, W.M., Nicholas, E.D., Needham, J.S. et al. (1991) Friction stir butt welding. Int. Pat. Appl. PCT/GB 92/02203; GB Pat. Appl. 9125978.8. Publ. 1991. 
2. Schneider, J.A. (2007) Temperature distribution and resulting metal flow: Friction stir welding and processing, 37-49.

3. Makarov, E.L., Korolyov, S.A., Shtrickman, M.M., Kashchuk, N.M. (2010) Modeling of thermal processes in friction welding. Svarka i Diagnostika, 3, 21-25 [in Russian].

4. Mishara, R.S., Mahoney, M.W. (2007) Friction stir welding and processing. Ohio, ASM International.

5. Poklyatsky, A.G., Ishchenko, A.Ya., Podielnikov, S.V. (2008) Influence of friction stir welding process parameters on weld formation in welded joints of aluminium alloys $1.8-2.5 \mathrm{~mm}$ thick. The Paton Welding J., 10, 22-25.

6. Song, M., Kovacevic, R. (2003) Numerical and experimental study of the heat transfer process in friction stir welding. In: Proc. Ins. Mech. Eng., B.J. Eng. Manuf., IMECHE, 217, $73-85$.

7. Vakulenko, I.O., Mityaev, O.A., Plitchenko, S.O. (2014) On structure transformations in friction stir welding of aluminium alloy. In: New materials and technologies in metallurgy and mechanical engineering. Zaporizhzhya, 1, 8-10 [in Ukrainian].

8. Schneider, J.A., Nunes, A.C. (2004) Characterization of plastic flow and resulting microtextures in a friction stir weld. Metall. Mater. Trans. B, 35, 777-783.

9. Colligan, K. (2003) Tapered friction stir welding tool. Int. Pat Appl. 10/140,797; US Pat. 6,669,075 B2. Publ. 30.12.2003.
10. Vakulenko, I.O., Plitchenko, S.O. Nadezhdin, Yu.L. (2012) Application of friction stir welding technology of aluminium alloy. Visnyk Dniprop. Nats. Zalizn. Transport. Univers. V. Lazaryana, 41, 230-233 [in Ukrainian].

11. Vakulenko, I.O., Plitchenko, S.O. Nadezhdin, Yu.L. (2012) Method of friction stir welding of aluminium-based alloys. Ukraine Pat. 75698, Int. Cl. B23K 1/00. Fill. 29.05.12; Publ. 10.12.12 [in Ukrainian].

12. Reynolds, A.P., Schneider, A.P. (2007) Microstructure development in aluminum alloy friction stir welds. In: Friction stir welding and processing, 51-70.

13. Vakulenko, I.A., Bolshakov, V.I. (2008) Morphology of structure and strain hardening of steel: Monography. Dnepropetrovsk, DNU [in Russian].

14. Hayes, R.W., Hayes, W.C. (1982) On the mechanism of delayed discontinuous plastic flow in an age-hardened nickel alloy. Acta Metallurgica, 30, 1295-1301.

15. Vill, V.I. (1970) Friction welding of metals. Leningrad, Mashinostroenie [in Russian].

16. Vakulenko, I.O., Plitchenko, S.O. (2017) Determination activation energy of friction stir welding. In: Proc. of $9^{\text {th }}$ Intern. Conf. of Young Scientists on Welding and Related Technologies (23-26 May 2017, Kyiv, Ukraine). Kyiv, 54-58.

17. Erokhin, A.A. (1973) Fundamentals of fusion welding. Physical-chemical principles. Moscow, Mashinostroenie [in Russian].

Received 23.02.2018 


\title{
AUTOMATIC SUBMERGED-ARC WELDING OF BRIDGE SPANS OF HIGH-QUALITY STEELS 10KhSNDA AND 15KhSNDA IN FIELD
}

\author{
D.P. CHEPRASOV ${ }^{1}$, Yu.A. KUZNETSOV ${ }^{2}$ and E.A. LEDNIKOV ${ }^{3}$ \\ ${ }^{1}$ Polzunov Altai State Technical University \\ 46 Lenina Ave., 656038, Barnaul, Russia. E-mail: ar gac@mail.ru \\ ${ }^{2}$ OJSC «SIBMOST», Mostootryad-96 \\ 119a Lenina Ave., 656011, Barnaul, Russia \\ ${ }^{3} \mathrm{LLC}$ «GATs AR NAKS» \\ 71 Krasnoarmeyskii Ave., 656000, Barnaul, Russia
}

\begin{abstract}
Presented are the results of optimization of technology of automatic submerged-arc welding performed in assembly at construction of bridge spans of steels 10KhSNDA and 15KhSNDA (TU 14-1-5120-2008) under conditions of West-Siberian region. Taking into account local climatic and temperature conditions, the designations of metal structures, principle of steel alloying and thickness of welded sheets it is determined that welding shall be carried out using the modes providing heat input in the limits of 30-35 thou $\mathrm{J} / \mathrm{cm}$ in two passes, on glass substrate with reduced by $20-30 \%$ height of filling of metal-chemical filler. Necessary toughness and strength of welded joints on this technology is explained by favorable conditions for phase transformations and formation of homogeneous structure in weld metal and HAZ. 9 Ref., 4 Tables, 3 Figures.
\end{abstract}

Ke yw ord s : bridge structures, automatic submerged-arc welding, heat input, fusion zone, embrittlement

10KhSND, 15KhSND (GOST 6713-91) steel grades and 10KhSNDA and 15KhSNDA (TU 14-1-51202008) grades are used as a main material for manufacture of bridge structures of North implementation according to [1]. The main difference of steel produced by TU from standard ones is presence in their content of strong carbide-forming elements and somewhat decreased content of carbon, manganese, chromium, nickel and detrimental impurities (Tables 1 and 2).

The first experience of application of these steel grades, produced still by TU 14-1-5120-91, showed [2, $3]$ that butt welded joints of $12-16 \mathrm{~mm}$ thickness, received by one-sided single- and two-pass submerged-arc welding using metal-chemical filler (MCF) and copper forming substrates are susceptible to low-temperature embrittlement, particularly along fusion zone.

In new TU [4] chemical composition is corrected to the side of reduction of carbon equivalent. However, elimination of increased sensitivity of field weld-

Table 1. Chemical composition, wt.\% ed joints to low-temperature embrittlement in single-pass automatic submerged-arc welding was not successful [5]. Therefore, present work is dedicated to optimization of automatic submerged-arc welding necessary for construction of bridge spans of steels 10KhSNDA and 15KhSNDA (TU 14-1-5210-2008) under temperature conditions of a region.

Materials and investigation procedure. Following the requirements of design documentation for construction of bridges of North implementation the rolled plates of category 2 and 3 in normalized or thermally improved state after quenching and high-temperature tempering with carbon equivalent value not more than $0.45 \%$, determined by formula [4], were used in the work.

Welding of long-length longitudinal and transverse joints of flooring of orthotropic and back plates of $12 \mathrm{~mm}$ thickness without groove preparation using MCF on copper and glass substrates was carried out under conditions of Mostootryad-96 in different time of the year. Flux AN-47 in combination with wire Sv-

\begin{tabular}{|c|c|c|c|c|c|c|c|}
\hline Steel grade & $\mathrm{C}$ & $\mathrm{Si}$ & $\mathrm{Mn}$ & $\mathrm{Cr}$ & $\mathrm{Ni}$ & $\mathrm{Cu}$ & $\mathrm{Nb}$ \\
\hline 10KhSND & $<0.12$ & $0.8-1.1$ & $0.5-0.8$ & $0.6-0.9$ & $0.5-0.8$ & $0.4-0.6$ & - \\
\hline 15KhSND & $0.12-0.18$ & $0.4-0.7$ & $0.4-0.7$ & $0.6-0.9$ & $0.3-0.6$ & $0.2-0.4$ & - \\
\hline 10KhSNDA & $<0.12$ & $0.8-1.1$ & $0.65-0.95$ & $0.3-0.6$ & $0.2-0.5$ & $0.4-0.6$ & $0.03-0.06$ \\
\hline 15KhSNDA & $0.1-0.15$ & $0.4-0.7$ & $0.6-0.9$ & $0.3-0.6$ & $0.2-0.5$ & $0.2-0.4$ & $0.03-0.06$ \\
\hline
\end{tabular}

Note. Amount of sulfur and phosphorus in steels $10 \mathrm{KhSND}$ and $15 \mathrm{KhSND}$ not more than $0.035 \mathrm{wt} . \%$. Amount of sulfur in steels $10 \mathrm{KhSNDA}$ and $15 \mathrm{KhSNDA}$ not more than $0.010 \mathrm{wt} . \%$, phosphorus $-0.015 \mathrm{wt} . \%$. Replacement of niobium by vanadium in the amount $0.08-0.12 \mathrm{wt} . \%$ is allowed. 
Table 2. Mechanical properties of steel

\begin{tabular}{|c|c|c|c|c|c|c|}
\hline \multirow{3}{*}{ Steel grade } & \multirow{3}{*}{$\begin{array}{l}\text { Ultimate strength } \\
\qquad \sigma_{\mathrm{t}}, \mathrm{MPa}\end{array}$} & \multirow{3}{*}{$\begin{array}{c}\text { Yield limit } \\
\sigma_{\mathrm{y}}, \mathrm{MPa}\end{array}$} & \multirow{3}{*}{$\begin{array}{c}\text { Relative } \\
\text { elongation } \delta_{\mathrm{s}}\end{array}$} & \multicolumn{3}{|c|}{$\begin{array}{c}\text { Impact toughness } K C U, \mathrm{~J} / \mathrm{cm}^{2} \text { for rolled metal of categories at } \\
\text { temperature, }{ }^{\circ} \mathrm{C}\end{array}$} \\
\hline & & & & 1 & 2 & 3 \\
\hline & & & & -40 & -60 & -70 \\
\hline 10KhSND & $530-670$ & 390 & 19 & 29 & 29 & 29 \\
\hline $15 \mathrm{KhSND}$ & $490-670$ & $335-345$ & $19-21$ & 29 & 29 & 29 \\
\hline 10KhSNDA & $510-670$ & $390-495$ & 19 & 29 & 29 & 29 \\
\hline $15 \mathrm{KhSNDA}$ & $470-685$ & $335-450$ & $19-21$ & 29 & 29 & 29 \\
\hline
\end{tabular}

10NMA of $4 \mathrm{~mm}$ diameter on the modes necessary for practical purposes were used for welding.

A quality control of welded joints was carried out systematically in the process of welding performance using destructive and non-destructive methods for detection of external and internal defects and determination of mechanical properties. The samples were made with the help of run-on plates, used for welding mode adjustment. In a series of cases for specification of received data the samples were manufactured directly from regular welded joints.

The samples of XIII type of GOST 6996-66 were subjected to static tension on rupture-test hydraulic machine. Impact toughness at normal and reduced temperatures were determined on samples of VI type on GOST 6996-66. Structure of weld metal and near-weld zone (NWZ) were examined applying optical microscope Neophot 32 at up to 500 magnification. Phase composition, fine structure, qualitative and quantitative analyses of morphological and structural constituents of austenite decay products in NWZ metal and fusion zone were examined using X-ray images on difractometer DRON-2.0, transmission electron microscopy applying diffraction light- and dark-field image.

Results and their discussion. It is determined that welded joints of orthotropic plates of steel 10KhSNDA and $15 \mathrm{KhSNDA}$ produced by single- and two-pass automatic submerged-arc welding with MCF on copper forming substrates have necessary strength and ductile properties, which lie at the level of base metal properties (Figure 1). At the same time these welded joints received by single-pass submerged-arc welding under summer as well as winter conditions at heat input more than 50 thou $\mathrm{J} / \mathrm{cm}$ was found to be sensitive to low-temperature embrittlement, in particular, in a fusion zone. To a greater degree the embrittlement at $-60{ }^{\circ} \mathrm{C}$ was observed in welding under winter conditions at environment temperature $-15-20{ }^{\circ} \mathrm{C}$ using copper forming substrates (Table 3, variants 1, 3). Application of multipass automatic submerged-arc welding at reduced heat input using steel substrates with inserted strips of sheet glass on GOST 111-2014 of 4-5 mm thickness provides formation of quality welded joints in welding under summer as well as winter conditions (Table 3, variants 2 and 4).

The experience shows that welding with increased heat input on copper substrates results in boiling of molten metal with its further splashing through slag crust, pore appearance, overlaps and other weld defects.

Investigations of structure of samples cut out directly from standard butt joints determined that automatic submerged-arc welding of these steels at increased heat input (Table 3, variants 1 and 3) provokes formation in NWZ of coarse grain with fine plates of $\alpha$-phase. The latter penetrate the grains with the products of intermediate austenite decay that indicates presence of intense overheating which resulted in formation of unfavorable Widmanstatten pattern (Figure 2).

In fusion zone period of $\alpha$-phase lattice is more than in ferrite included in base metal structure. Scalar
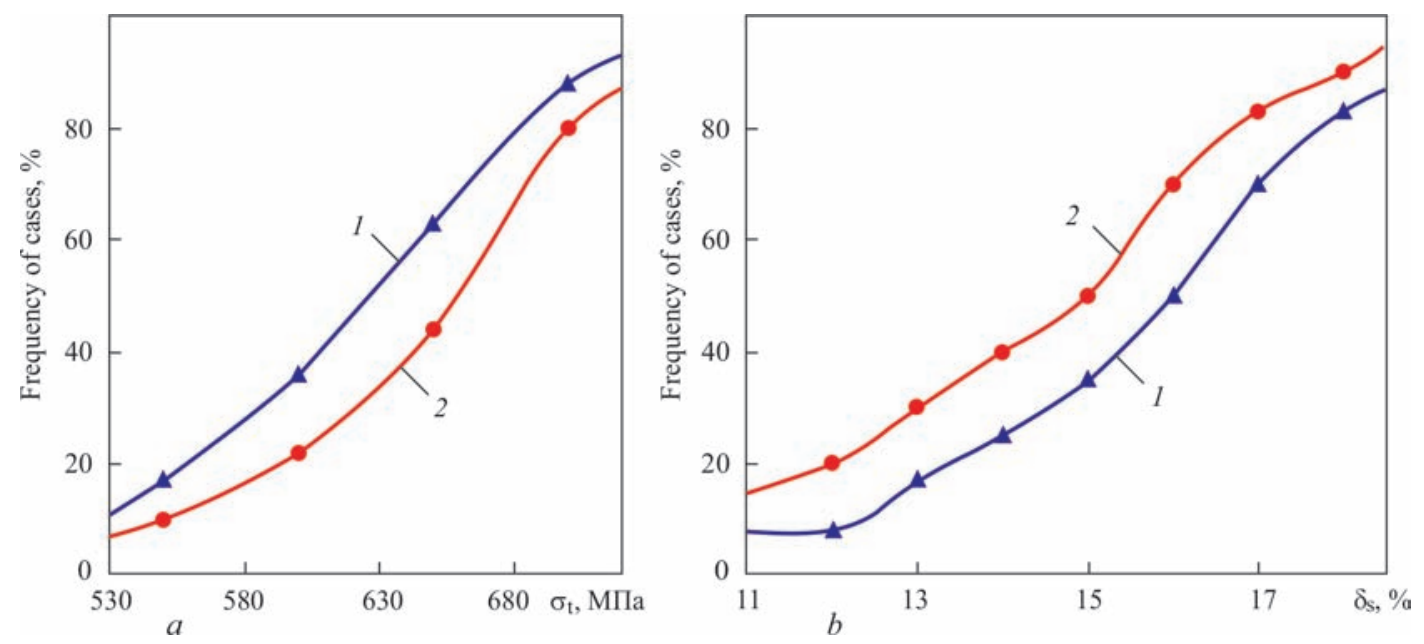

Figure 1. Frequency curves of distribution of ultimate tensile strength $(a)$ and relative elongation $(b)$ of welded joints of steel $10 \mathrm{KhSNDA}(1)$ and $15 \mathrm{KhSNDA}(2)$ 
Table 3. Impact toughness of metal of single- and two-pass butt welded joints of steels

\begin{tabular}{|c|c|c|c|c|c|c|c|c|}
\hline \multirow{2}{*}{$\begin{array}{l}\text { Number } \\
\text { of variant }\end{array}$} & \multirow{2}{*}{$\begin{array}{c}\text { Steel grade of } \\
\text { welded joint }\end{array}$} & \multirow{2}{*}{$\begin{array}{c}\text { Wall thickness } \\
\text { of butt joint, mm }\end{array}$} & \multirow{2}{*}{$\begin{array}{c}\text { Number of } \\
\text { passes }\end{array}$} & \multirow{2}{*}{$\begin{array}{c}\text { Average value } \\
\text { of welding heat } \\
\text { input of pass, } \\
\mathrm{J} / \mathrm{cm}\end{array}$} & \multirow{2}{*}{$\begin{array}{l}\text { Average value } \\
\text { of time of metal } \\
\text { staying at tem- } \\
\text { perature more } \\
\text { than } 1300^{\circ} \mathrm{C}, \mathrm{s}\end{array}$} & \multicolumn{3}{|c|}{$\begin{array}{c}\text { Impact toughness } K C U \\
\text { at }-60{ }^{\circ} \mathrm{C}, \mathrm{J} / \mathrm{cm}^{2}\end{array}$} \\
\hline & & & & & & Base metal & Weld metal & Fusion zone \\
\hline 1 & 10KhSND & 12 & 1 & 63000 & 56.0 & $90 \ldots 110$ & $35 \ldots 50$ & $15 \ldots 25$ \\
\hline 2 & $15 \mathrm{KhSND}$ & 12 & 2 & $\frac{45000}{40000}$ & $\frac{28.5}{24.0}$ & $90 \ldots 110$ & $55 \ldots 70$ & $40 \ldots . .50$ \\
\hline 3 & 10KhSNDA & 12 & 1 & 63500 & 57.0 & $80 \ldots 100$ & $35 \ldots 40$ & $10 \ldots 15$ \\
\hline 4 & 15KhSNDA & 12 & 2 & $\frac{44000}{40000}$ & $\frac{28.0}{24.0}$ & $80 \ldots 100$ & $50 \ldots 60$ & $35 \ldots 45$ \\
\hline
\end{tabular}

density of defects of crystalline structure is at the level of scalar density of defects of crystalline structure of martensite $\alpha$-phase forming in austenite decay in the field of martensite transformation (Table 4). There are coarse as well as fine carbides of mainly lamellar shape (Figure 3) in the joints, inside the grains and on boundaries of ferrite crystals. Amplitude of torsion curvature of crystal lattice reaches $950-1000 \mathrm{~cm}^{-1}$ and by its value approximates to the maximum value marked as martensite $\alpha$-phase (Table 4).

It is determined that no Widmanstatten pattern was present in multilayer welding at reduced heat input (Table 3, variants 2 and 4) using glass substrate. Ferrite-pearlite structure with grain numbers 6 and 5 on GOST 5640-68 was formed in NWZ. Ferrite $\alpha$-phase has significantly smaller period of its crystal lattice in comparison with $\alpha$-phase formed in welding at increased heat input (Table 4). The scalar density of defects of crystalline structure lies in the limits of scalar density of defects of crystalline structure in proeutectoid ferrite of base metal of category 2 rolled stock delivered after normalizing. No carbides were observed in the crystal field and along $\alpha$-phase boundaries.

Additional prove of data received from electron microscopy on presence of carbide and carbonitride inclusions in the fusion zone can be the results of microchemical analysis made on «MAR-1» device (X-ray microanalyser) on a procedure proposed in work [6]. The phosphorescent flashes were clearly registered in the samples received in one-sided single-pass automatic submerged-arc welding with in- creased heat input at electron beam passing along the fusion zone when carbide and carbonitride inclusions of niobium, vanadium and other carbide-forming elements included in 10KhSNDA and 15KhSNDA steel composition enter the electron beam. In microchemical analysis of the samples welded by multilayer welding with reduced heat input, amount of phosphorescent splashes rapidly decreased when carbide and carbonitride inclusions entered the electron beam. Their amount in fusion zone does not exceed similar indices in the base metal.

Received data as well as data stated in work [2] allowed making a conclusion that welding with increased (above 50 thou $\mathrm{J} / \mathrm{cm}$ ) heat input of $10 \mathrm{KhSNDA}$ and 15KhSNDA steels, microalloyed with strong carbide-forming elements, results in longterm stay of weld metal and NWZ in the field of high (above $1300{ }^{\circ} \mathrm{C}$ ) temperatures. This provokes more complete solution of carbides and carbonitrides in liquid phase and austenite, austenite grain growth. Further cooling promotes formation of unfavorable Widmanstatten pattern, precipitation from austenite and melt of carbonitrides of vanadium, niobium and chromium, which in opinion of $[7,8]$ promote local distortion of crystal lattice of $\alpha$-phase, reduction of dislocation mobility, in particular at negative temperatures and, as a result, complication of sliding process in deformation.

Thus, the main reason of low impact load resistance at negative temperatures of welded joints of bridge structures from steels $10 \mathrm{KhSNDA}$ and $15 \mathrm{KhSN}-$ DA, received by one-sided automatic submerged-arc

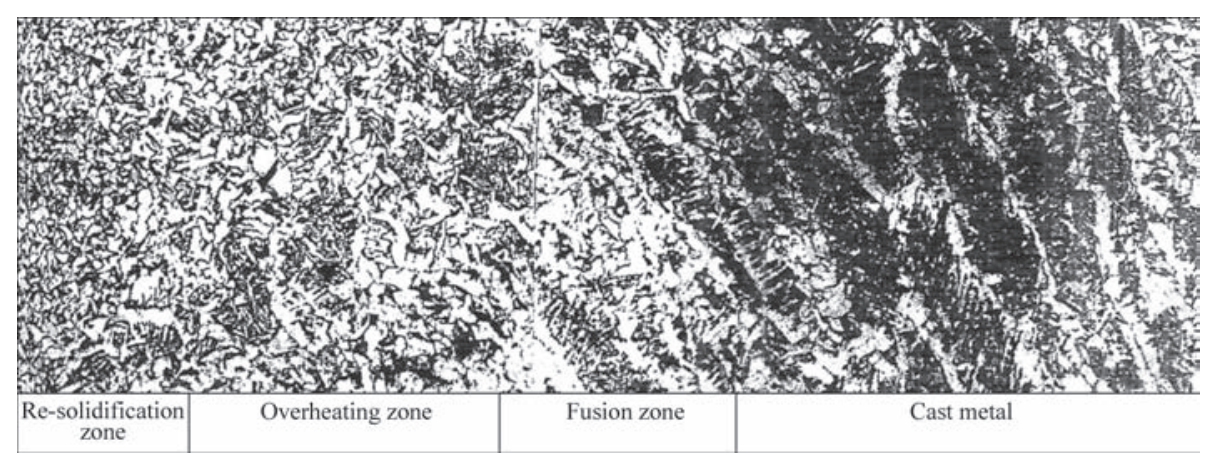

Figure 2. Microstructure $(\times 250)$ of weld of steel $15 \mathrm{KhSNDA}$ produced by one-sided single-pass automatic submerged-arc welding at increased heat input (Table 3 , variant 3 ) 

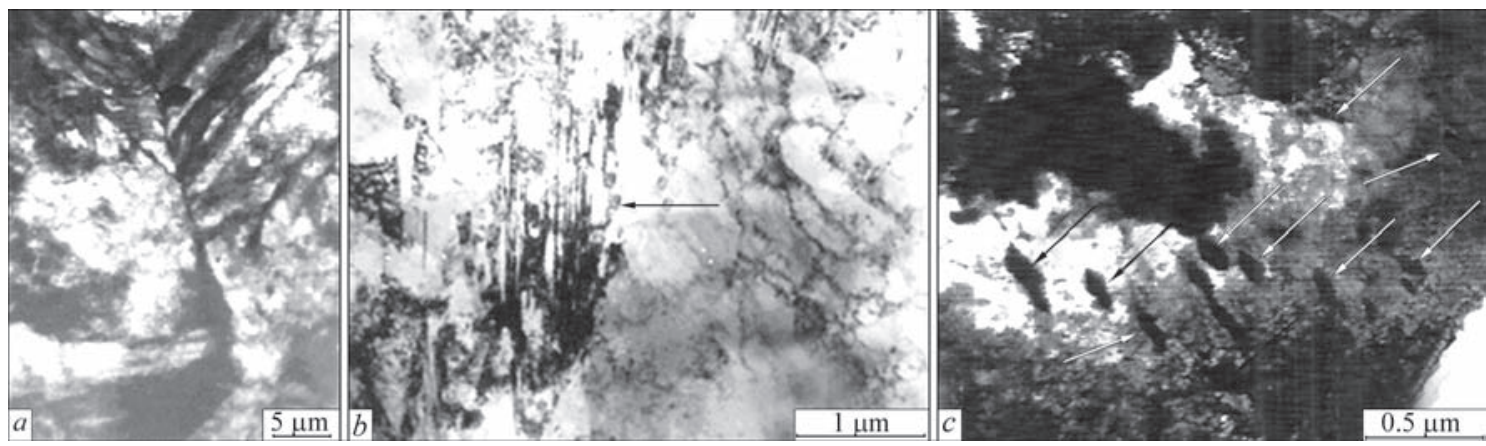

Figure 3. Fine structure in local areas of fusion zone of welded joint from steel 15KhSNDA: $a$ - fragment of fusion line; $b-$ accumulations of lamellar shape carbides; $c$ - plates of $\alpha$-phase with unidirectional carbide particles (indicated by arrows)

Table 4. Physical characteristics of $\alpha$-phase

\begin{tabular}{|l|c|c|c|}
\hline \multicolumn{1}{|c|}{ Designation } & Period of crystal lattice, $\mathrm{nm}$ & $\begin{array}{c}\text { Scalar density of dislocations } \\
\rho, 10^{9}, \mathrm{~cm}^{-2}\end{array}$ & $\begin{array}{c}\text { Amplitude of torsion curvature } \\
\text { of crystal lattice, } \mathrm{cm}^{-1}\end{array}$ \\
\hline Table value for $\alpha$-phase Fe [6] & 0.28664 & - & - \\
\hline Steel 15KhSNDA in normalized state & 0.28720 & $1.55-2.15$ & $450-550$ \\
\hline Martensite $\alpha$-phase & 0.28860 & $6.40-7.60$ & $1350-1400$ \\
\hline Welded joint (fusion zone). Table 3, variant 1 & 0.28770 & $5.60-6.70$ & $950-1000$ \\
\hline Welded joint (fusion zone). Table 3, variant 2 & 0.28735 & $2.10-3.20$ & $560-640$ \\
\hline $\begin{array}{l}\text { Note. Accuracy of determination of lattice period } \pm 0.00005 \mathrm{~nm} \text {, scalar dislocation density } \pm 0.2 \cdot 10^{9} \mathrm{~cm}^{-2}, \text { torsion curvature of crystal lattice } \\
50 \mathrm{~cm}^{-1} \text {. }\end{array}$ \\
\hline
\end{tabular}

welding using solid wire with granulated filler at increased (above 50 thou $\mathrm{J} / \mathrm{cm}$ ) heat input applying copper forming substrates shall be considered a very nonuniform structure formed in fusion zone, which consists of dislocated ferrite saturated with carbide and carbonitride inclusions. They serve original stress concentrators promoting joint embrittlement. Authors of work [9] prove the appropriateness of application of glass substrate in automatic submerged-arc welding of steel bridge structures.

In the conclusion it can be noted that present results and earlier experience of performance of welding works under extreme climatic conditions of West Siberia requires optimizing the commercial conditions of automatic submerged-arc welding in the field. It is turned into welding in two passes at reduced heat input and application of glass substrates. At that, as a rule, the first pass in carried out with 30-35 thou $\mathrm{J} / \mathrm{cm}$ input energy at $20-30 \%$ reduced height of grit filling that provides ensured root weld penetration. The second pass, at $12-14 \mathrm{~mm}$ thickness of edges being welded forms more «accurate» on height weld since the first pass does not fill the whole gap volume. Welding on glass substrates reduces the cooling rate of the weld in the area of temperatures of phase transformations. This prevents formation of intermediate (bainite) and quenching structures. Welding works under autumn-winter conditions require particular control of preheating temperature and welding on preheated steel substrates with inserted glass strips of 4-5 mm thickness in their slots. Taking into account local climatic conditions and peculiarities of structure of bridge span in order to get quality welded joints at each new object it is necessary perform thoughtful adjustment of technology of automatic submerged-arc welding and apply for this so called technological probes delivered to construction site together with metal structures.

1. STO-GK Transstroj-005-2007: Standard of organization. Steel bridge structures. Technology of field welding [in Russian].

2. Cheprasov, D.P., Ivanajsky E.A., Platonov, A.S. et al. (1998) Properties of field welded joints of bridge structures from steels $10 \mathrm{KhSNDA}$ and 15KhSNDA. Svarochn. Proizvodstvo,6, 16-18 [in Russian].

3. Cheprasov, D.P., Petrov, V.P., Ivanajsky E.A. et al. (2003) Hydrogen brittleness of field welded joints of bridge structures from steels $10 \mathrm{KhSNDA}$ and 15KhSNDA. Ibid., 3, 12-16 [in Russian].

4. TU 14-1-5120-2008: Rolled plate from high-quality low-alloy steel for bridge engineering [in Russian].

5. Lednikov, E.A., Cheprasov, D.P., Konnik, D.A. (2017) Cold resistance of welded joints of steel bridge structures from high-quality steels $10 \mathrm{KhSNDA}$ and $15 \mathrm{KhSNDA}$. Polzunovsky Almanakh, 1, AltGTU [in Russian].

6. Gorelik, S.S., Rastorguev, L.N., Skakov, Yu.A. (1970) X-ray and electro-optical analysis. Practical guide on radiography, electronography and electron microscopy of metals, semiconductors and dielectrics. Moscow, Metallurgiya [in Russian].

7. Dobrotina, Z.A., Litvinenko, S.P., Rozanova, G.A. (1979) Cold resistance of welded joints of 09G2SBF steel. Svarochn. Proizvodstvo, 1, 25-27 [in Russian].

8. (1988) Embrittlement of structural steels and alloys. Ed. by K.L.Bryant et al. Moscow, Metallurgiya [in Russian].

9. Muzalev, V.N., Semukhin, B.S. (2015) Peculiarities of welding of metal bridge spans. Vestnik TGASU, 2, 184-193 [in Russian] 


\title{
SELECTION OF WELDING TECHNOLOGY IN MANUFACTURE AND RESTORATION REPAIR OF SPIRALS OF HIGH-PRESSURE HEATERS OF NPP POWER UNITS
}

\author{
N.M. MAKHLIN ${ }^{1}$, V.E. VODOLAZSKY ${ }^{1}$, A.E. POPOV ${ }^{1}$, A.E. KOROTYNSKY ${ }^{2}$ and S.I. LAVROV ${ }^{3}$ \\ ${ }^{1} \mathrm{SE}$ «Scientific and Engineering Center of Welding and Control in Nuclear Engineering of Ukraine (SEC WCNPE) \\ of the E.O. Paton Electric Welding Institute of the NAS of Ukraine» \\ 11 Kazimir Malevich Str., 03150, Kyiv, Ukraine. E-mail: electro@paton.kiev.ua \\ ${ }^{2}$ E.O. Paton Electric Welding Institute of the NAS of Ukraine \\ 11 Kazimir Malevich Str., 03150, Kyiv, Ukraine. E-mail: office@paton.kiev.ua \\ ${ }^{3} \mathrm{SE}$ «Atomenergomash» of the SE NNEGC «Energoatom» \\ 71503, Energodar, Zaporizhzhia Region, Ukraine. PO Box 306. E-mail: lavrov@aem.zp.ua
}

\begin{abstract}
The high-pressure heaters are the fundamentally necessary links of the second circuit of power units of nuclear power plants with light-water WWER-type reactors. They represent single-plane or two-plane pipe spirals of carbon steel. The paper presents the results of selection and mastering the mechanized welding technology for applying in the manufacture and restoration repair of high-pressure heaters. 20 Ref., 2 Figures.
\end{abstract}

Keywords: high-pressure heaters, spirals of high-pressure heaters, automatic welding, consumable electrode, electrode wire, mixture of shielding gases, technological equipment, rotary joints of pipelines, welding rotator

The light-water reactors on heat neutrons (of the PWR and BWR type), in which water is used as a coolant and a moderator, found the widest application in the world nuclear power engineering. The share of power units with such reactors amounts to at least $87 \%$ of the power units of nuclear power plants (NPP) in the world $[1,2]$.

The high-pressure preheaters (HPH), which are the most important and critical components of the second circuit of pressurized water reactors (PWR), are designed for heating the feed water to the required temperature with its further supply to heat exchanger - steam generator (SG). The steam, produced in $\mathrm{SG}$, enters the turbine, which sets into motion the electric generators of the NPP power unit [1-3].

The PWR-type reactors also include the casing water-cooled (-moderated) power reactors (WWER) operated at all 15 power units of four currently operating NPP in Ukraine. The same reactors are expected to be used in future when creating new power units of the Ukrainian NPP.

The characteristic features of HPH spirals consist in the presence of welded joints of pipe elements of spirals and their tail pieces, as well as in the parameters of the medium (feed water), which is supplied at a nominal pressure of $12.0 \mathrm{MPa}$ into a spiral, where the feed water is heated up to the $235^{\circ} \mathrm{C}$ temperature, as a result of which during the operation of HPH the welded joints of their spirals are subjected to corro- sion-erosion wear. Therefore, the designing, manufacturing and restoration repair of HPH spirals have their own specifics [3-5], which determines the technical requirements to the material, design and welded joints of HPH.

The appearance of one of the most widespread variants of the HPH spiral is shown in Figure 1.

By the design, the HPH spiral consists of three pipe elements joined together by two butt welds. The semi-products for these elements are the long sections of a pipe of carbon steel 20, having a nominal diameter of $32 \mathrm{~mm}$ and a nominal wall thickness of $4.0 \mathrm{~mm}$. The length of one of the straight sections («central»), used as the semi-products for pipe elements of the HPH spiral, amounts to $7000 \mathrm{~mm}$, the

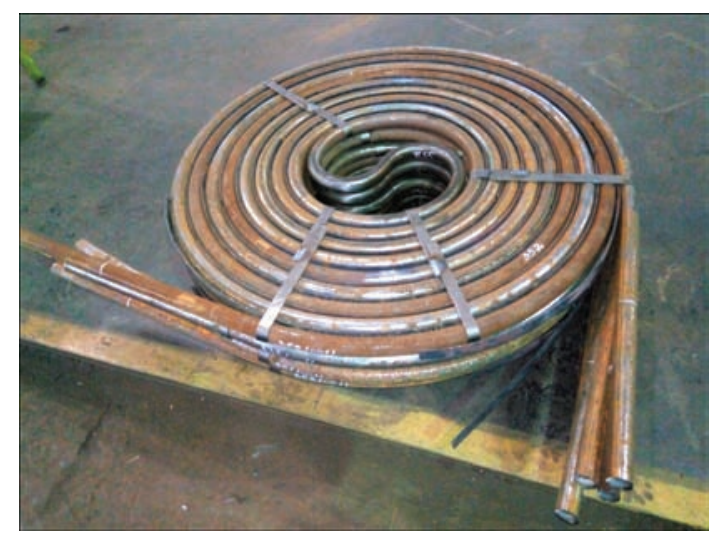

Figure 1. General appearance of HPH spiral 
other two straight sections are 5980 and $5403 \mathrm{~mm}$, respectively. All the mentioned sections on the side of their edges have V-shaped groove 1-24-1 (C-24-1), which is formed with the help of previous machining. After producing welded joints of pipe elements, their heat treatment and nondestructive testing, the spiral design itself is formed from the pipe section produced in this way by a special device. To the straight entrance and exit lengths of this structure, the tail pieces are welded-on and a nondestructive testing of their welded joints is performed, which, according to many year experience, HPH are the most susceptible to corrosion-erosion damages during service. Taking this into account, during restoration repair of HPH spirals, the failed tail pieces of steel 20 are replaced by the tail pieces of chrome-nickel steel of austenitic class (mainly of steel 12Kh18N10T).

Until now, during manufacture and repair of $\mathrm{HPH}$ spirals, in domestic practice even in the factory conditions, only the method of manual multipass argon-arc welding (TIG) is used for making the welded joints of these spirals, the main disadvantages of which are a low welding efficiency, inability to keep the stability of welded joints quality because of its dependence on the «human» factor, the need to invite the experienced highly qualified welders. Therefore, an increase in efficiency of welding and providing stability of welded joints quality of HPH spirals during their manufacture and restoration repair by using automatic or mechanized arc welding are an urgent task in the domestic enterprises.

For its solution, the capabilities of using different methods of arc welding, including automatic orbital welding by a non-consumable electrode in the inert gas (GTAW), manual and automatic orbital welding by a non-consumable electrode in the inert gas with activating fluxes (ATIG and GTAW-A, respectively) and mechanized (automatic) welding with a consumable electrode in shielding gases, were experimentally tested.

According to the Rules and Norms of Nuclear Engineering and other standard documents, being in force in Ukraine, the welded joints of the pipe elements of HPH spirals should be produced with a full penetration with a force limit of $2.0 \pm 1.0 \mathrm{~mm}$ and a convexity of the root weld of not more than $1.5 \mathrm{~mm}$ or its concavity, not exceeding $0.6 \mathrm{~mm}$. In this case, the edge displacement of pipe elements of HPH spirals should not exceed $0.4 \mathrm{~mm}$, and the welded joints of these pipe elements can be classified as the category III (subcategory IIIc) according to PN AE G-7010-89.

The welded joints of pipe elements of their spirals are subjected to $100 \%$ nondestructive and selective destructive testing. Among nondestructive methods of testing, the application of visual-instrumental control (VIC) and radiographic control (RGC) is envisaged [6]. At a selective destructive testing of welded joints of HPH spirals of pipe elements, the chemical composition of weld metal is checked and the mechanical properties of welded joints are determined, and the metallographic examinations are also carried out.

While performing experimental and technological works and investigations, the specimens-simulators of pipe elements of HPH spirals of steel 20 with a nominal outer diameter of $32 \mathrm{~mm}$ and a nominal wall thickness of $4.0 \mathrm{~mm}$ were used, the edges of which were machined in accordance with the requirements of PN AE G-7-009-89, PN AE G-7-010-89 and OST 24.125.02-89.

The E.O. Paton Electric Welding Institute together with the SEC WCNPE carried out investigations on determination of the possibility to use GTAW by methods of auto-pressing or successive penetration, developed at the Research and Design Institute of Site Technologies (RDIST) in 1970-1980 [7, 8]. It was experimentally established [9] that it is not possible to achieve the stable required quality of welded joints of HPH spirals in use of GTAW by methods of auto-pressing or successive penetration because of physical properties of the material of the pipe of HPH spiral and its geometric dimensions. Even at an allowable reduction in the thickness of the pipe wall to $3.6 \mathrm{~mm}$, the penetration of the wall along its entire perimeter was nonuniform in all the cases, and its depth did not exceed 0.8 times of the nominal thickness. This is explained by the fact that, firstly, carbon steels (to which the steel 20 belongs), as compared to the steels of the austenite class, have a much lower coefficient of linear expansion and a substantially higher thermal conductivity, and this does not allow providing the sufficient compressive forces for necessary thermoplastic deformations. Secondly, the nominal wall thickness of the HPH spiral of the pipeline is $4.0 \mathrm{~mm}$, and the ratio of the wall thickness $S$ to the nominal outer diameter of the pipeline $D_{\mathrm{p}}$ is only 0.125 , i.e. close to the lower limit of GTAW applying by the methods of auto-pressing or successive penetration. It was experimentally established, that in case of GTAW method application the totality of these factors in combination with real conditions of heat removal does not allow providing neither complete penetration of welded joints of HPH spirals regulated by normative and design documentation, nor the stability of quality of formation of their welded joints.

It is known [10-14] that in TIG or GTAW methods of welding it is possible to increase the penetration depth by $2-3$ times by using activating fluxes. How- 
ever, the disadvantages peculiar to the welding methods ATIG and GTAW-A, connected with the lack of means for mechanized application of activating flux layer, difficulty in control of uniformity of the deposited layer, and also with the possible use of fluxes in the form of aerosols, are the reason of the fact that until now, ATIG and GTAW-A in the domestic nuclear engineering are almost not used.

One of the most widespread and demanded technological processes at different types of production is the mechanized consumable electrode welding in the active gases (MAG), mainly in $\mathrm{CO}_{2}[15,16]$.

It is known that as compared to the manual methods of arc welding by coated or nonconsumable electrodes, the MAG process has significant advantages, but at the same time this method of welding has a number of drawbacks, among which the greatest negative influence for welded joints of pipe elements of HPH spirals has a relatively low quality of the weld surface, i.e. the irregularity and coarse rippleness and a relatively low stability of welding process at a significant number of arc gap short-circuits.

As a result of experiments carried out at the SEC WCNPE, it was established that during welding of rotary joints of HPH spirals, the MAG method provides a high efficiency of welding process and the required penetration depth, however, the proper weld formation can not be achieved in principle, and therefore there are all grounds to assume that to produce welded joints of HPH spirals, the MAG process is almost not profitable in practice.

At the same time, in all industrialized countries and in Ukraine, the mechanized welding in mixtures of argon-based shielding gases [17-19] found the wide spreading, in which where a small amount of oxygen or other oxidizing gas (most often $\mathrm{CO}_{2}$ ) is added to argon, amounting to $80-95 \%$ of the total volume of the mixture, which significantly improves the stability of arc burning, greatly improves the quality of welds formation and almost excludes the region of welding modes with arc gap short-circuits. In this case, there are regions of welding modes, characterized by either drop or spray (fine-drop) transfer of the electrode metal. As compared to MAG, such nature of mass transfer provides a number of technological advantages. And although in this case, as compared to MAG, the penetration capacity of the arc is by 10-20\% reduced and to obtain the same penetration depth it is necessary to increase the welding current, during welding with consumable electrode in the mixtures of shielding gases, a more quality weld formation is provided (smooth surface with a smooth transition to the base metal); reduction of losses of electrode metal for spattering by not less than 3-4 times; decrease in the labor consumption for cleaning of base metal from spatters by not less than 8-10 times; creation of favorable conditions for use of pulsed processes $[18,19]$; the possibility of welding at direct current of straight polarity and with extended stickout; higher mechanical properties of weld metal.

Taking into account the advantages, typical to the method of welding with a consumable electrode in mixtures of shielding gases, as well as the results of the search and experimental-technological works, carried out by the E.O. Paton Electric Welding Institute of the National Academy of Sciences of Ukraine and the SEC WCNPE, it should be noted that automatic arc welding with consumable electrode in mixtures of shielding gases is one of the most efficient and promising ways for producing welded joints of pipe elements of HPH spirals. At the same time the most rational is the use of rotary joints.

To carry out experimental and technological works for making the rotary welded joints of pipe HPH elements using MAG and welding with a consumable electrode in the mixtures of shielding gases, the mock-up of the welding installation was created at the SEC WCNPE, which includes a welding rectifier VS-300B, semi-automatic machine A-547 with experimental models of control panel and torch, designed for feeding the electrode wire with a nominal diameter of 1.0-1.2 mm, as well as a rotator mock-up. The main parameters of the rotator mock-up are given below.

\section{Basic parameters of the rotator mock-up}

Nominal diameter of pipe elements of HPH spirals, $\mathrm{mm} \ldots 32$ Nominal wall thickness of pipe elements

of HPH spirals, $\mathrm{mm} \ldots \ldots \ldots \ldots \ldots \ldots \ldots \ldots \ldots . \ldots \ldots$ Limits of rotation speed control (welding speed) of workpiece welded, rpm, not less than . . . . . . 1.0-7.0 Rated voltage of single-phase supply mains

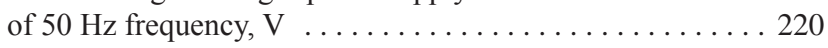
Power of supply unit (converter AC-DC)

of rotator reversible electric drive, $W$, not less than ..... 200 Nominal output voltage of the direct current of rotator reversible electric drive, $\mathrm{V} \ldots \ldots \ldots \ldots \ldots \ldots \ldots \ldots \ldots$

The specimens-simulators of pipe elements of HPH spirals of steel 20 with V-shaped groove, prepared for welding according to the requirements of normative documents and the Design Documentation, were subjected to mechanized welding: MAG and consumable electrode welding in the mixtures of shielding gases. Preliminary, TIG method was applied to make two or three tack welds for each joint in an argon at welding current of 80-100 A, for which an experimental sample of a specialized power source ITs 617 UZ.1 for TIG was used. According to the results of several series of experimental welding, it was established: 
- welded joints, which were produced by MAG method with forced short-circuits of a thin electrode wire, provided the necessary penetration depth, but required a careful selection of welding mode and maintenance of parameters of this mode during welding process with an accuracy of not worse than $\pm 5 \%$, moreover, in some specimens-simulators of the pipe elements of HPH spirals, the welds defects were observed, the most characteristic of which are weld sagging, undercuts, absence of a smooth transition to the base metal, coarse rippleness of finishing surface;

- welded joints, which were produced by consumable electrode welding in shielding gas mixtures, not only provided the necessary penetration depth, but also almost did not have inadmissible defects, moreover, in this case a favorable transfer of electrode metal was observed, in which there was almost no spattering of a workpiece welded, and the quality of welded joints fully meets the requirements of PNAE G-7-009-89.

Also, the main requirements to the technological equipment for mechanized welding of joints of pipe elements of HPH spirals (by method of consumable

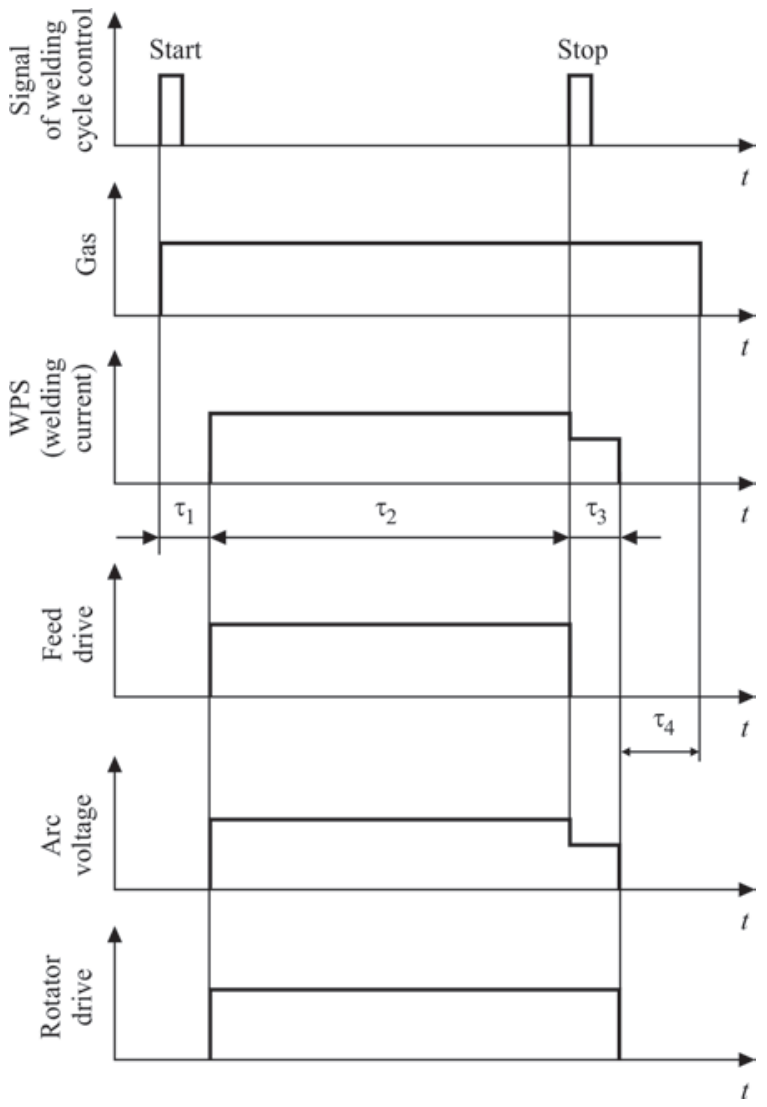

Figure 2. Cyclogram of the welding process of pipe elements of HPH spirals: $\tau_{1}$ — time interval «gas before welding»; $\tau_{2}$ - time interval during which the welding proper takes place without a break between the first and second passes of the arc ; $\tau_{3}$ - time interval during which «stretching» of welding arc occurs until the moment of its complete break and the «crater' rewelding; $\tau_{4}$ time interval «gas after welding» electrode welding in the shielding gas mixtures) were determined and optimized. The values of the main optimized parameters of the technological equipment for mechanized welding with consumable electrode in mixture of shielding gases of joints of pipe elements of HPH spirals are given below.

The main optimized parameters of technological equipment for mechanized welding of joints of pipe elements of HPH spirals by a consumable electrode in a mixture of shielding gases

Nominal diameter of pipe elements of HPH spirals, $\mathrm{mm} \ldots 32$ Nominal wall thickness of pipe elements of $\mathrm{HPH}$

spirals, $\mathrm{mm} \ldots \ldots \ldots \ldots \ldots \ldots \ldots \ldots \ldots \ldots \ldots .4 .0 \ldots \ldots$

Range of welding current control, A . . . . . . . . 110-130

Range of operating arc voltage control, V . . . . . . . 20-24

Nominal diameter of consumable electrode (electrode wire)

predominantly of grade Sv-08GS or Sv-08G2S), mm . . . . 1.0

Range of control of rotation speed of workpiece welded

(welding speed), rpm ..................... 1-7

Range of control of feed speed of consumable electrode

(electrode wire predominantly of grade Sv-08GS

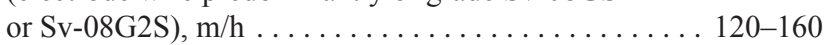

Displacement of axis of consumable electrode (electrode

wire) relative to the vertical («zenith»), angular deg . . . . 15-20

Displacement of axis of consumable electrode (electrode

wire) relative to the vertical («zenith»), $\mathrm{mm} \ldots \ldots \ldots \ldots$. 10-15 Number of full-circumferential passes of arc while producing one welded joint, not more than $\ldots \ldots \ldots \ldots \ldots \ldots \ldots 2$ Duration of cycle of one joint welding, s, not more than . . 5.0 Torch cooling $\ldots \ldots \ldots \ldots \ldots \ldots \ldots \ldots \ldots \ldots \ldots \ldots \ldots \ldots \ldots \ldots$

It was established in the course of experimental and technological investigations, that in addition to meeting the requirements, the technological equipment for mechanized welding of pipe elements of HPH spirals should provide the stability of welding parameters such as welding current, operating voltage of welding arc, speed of rotation (welding) at an accuracy of not worse than $\pm 4 \%$, the speed of consumable electrode (electrode wire) feed at an accuracy of not worse than $\pm 5 \%$, duration of welding cycle at an accuracy of not worse than $\pm 10 \%$, and also a reliable clamping and aligning of both pipe elements to be welded together in order to perform their synchronous rotation and exclude the need in applying preliminary tacks.

Proceeding from this, the innovative technical proposals on construction of the main parts of such technological equipment were developed by the SEC WCNPE. One of the most important basic components of the complex of technological equipment for mechanized welding of pipe elements of HPH spirals is its horizontal rotator.

According to the technical proposals developed at the E.O. Paton Electric Welding Institute together with the SEC WCNPE, the welding part of the complex of technological equipment for mechanized welding of pipe elements of HPH spirals should at least contain a welding cycle control unit (WCCU), welding power 
source (WPS), mainly of an inverter type, with rigid or flat falling external volt-ampere characteristics (VAC), MIG/MAG torch with gas cooling and a unit of start-protective equipment (USPE).

WCCU is intended for controlling the welding process, the cyclogram of which is shown in Figure 2. WCCU provides two ways for control of the work of the components and executive mechanisms of technological equipment for mechanized welding of pipe elements of HPH spirals - «manual» and «automatic» at two types of operation of this equipment — «setting up» and «welding», as well as smooth regulation and preliminary presetting the values of electrode wire feed rate, duration of the gas before welding time intervals, of the welding process itself (before the moment of coming the leading edge of the signal (pulse) «stop», «gas after welding» and automatic stabilization of these values during the process of setting up or welding.

As a result of experimental and technological investigations, it was determined that in order to produce high-quality multipass welded joints of pipe elements of HPH spirals by welding with a consumable electrode in shielding gases based on argon, the optimum region of welding modes should have the following values of parameters: welding current 110-130 A; operating arc voltage - 21-23 V; welding speed $-1-6 \mathrm{rpm}$, and as a consumable electrode, the electrode wire (preferably of grade Sv-08GS or Sv-08G2S) should be used with a nominal diameter of $1.0 \mathrm{~mm}$, and its feeding rate should be in the ranges of $120-160 \mathrm{~m} / \mathrm{h}$.

It was also established that among many inverter-type WPS offered by the domestic market, the most rational for meeting the above-mentioned requirements is the use of inverter-type WPS MIG/MAG/ TIG/MMA 303 designed and produced by «Tesla Weld» and widely spread in Ukraine, which contains in a single casing WPS and a device for automatic feeding of electrode wire MIG 303 with a standard four-roller feeding mechanism. The basic technical characteristics and VAC of this WPS are suitable for meeting the specified technical requirements with the exception of the durations of the time intervals «gas before welding» and «gas after welding». In addition, in accordance with the algorithm of operation of this WPS, the natural burning-out of the electrode wire at the completion of welding cycle and the automatic switching off of the welding current, the termination of the electrode wire feed and the switching-off of the gas cut-off (gas valve) occur almost simultaneously. To eliminate the mentioned drawbacks of WPS of the type MIG/MAG/TIG/MMA 303 (peculiar also to other analogues offered by the Ukrainian market) the de- velopment of WCCU and modernization of a control system for this WPS were made at the SEC WCNPE.

The manufacture and testing of the mock-ups of WCCU units and modernization of WPS control system of the type MIG/MAG/TIG/MMA 303 allowed establishing that in such variant, this modified WPS, preserving all the technical characteristics peculiar to it, is capable to provide the execution of the welding cycle shown in Figure 2. Here the range of control of the duration of the "gas before welding» time interval amounts at least from 1.0 to $10.0 \mathrm{~s}$, and the range of control of the duration of the «gas after welding» time interval is not less than from 10.0 to $30.0 \mathrm{~s}$.

In order to simplify the connection of the components of technological equipment for mechanized (automatic) welding of pipe elements of HPH spirals to the power mains, providing the ability of executing the mode «emergency stop» at the operator's command or automatically with almost instantaneous and complete deenergizing of all these components without exception, and introduction of their additional automatic protection against long-term overload by current consumption and from a stable short-circuiting, USPE was developed and designed at the SEC WCNPE.

\section{Conclusions}

1. The mechanized arc welding in a mixture of gases is the most efficient and rational method of multipass welding, i.e. with consumable electrode for use in manufacture and restoration repair of $\mathrm{HPH}$.

2. The basic requirements to technological equipment for mechanized welding of butt joints of pipe elements of HPH spirals, and also the region of basic optimized parameters of welding mode with a consumable electrode in a mixture of shielding gases (with solid electrode wire of predominantly grade $\mathrm{Sv}-08 \mathrm{GS}$ or Sv-08G2S with a nominal diameter of $1.0 \mathrm{~mm}$ ). At the same time, it was established that two welding passes are enough to produce quality welded joints of pipe elements of HPH spirals.

3. The technical proposals for creation of a complex of the technological equipment for mechanized (automatic) welding of rotary joints of pipe elements of HPH spirals were developed.

1. Efimov, O.V., Pylypenko, M.M., Potanina, T.V. et al. (2017) Reactors and steam generators of power generating units of NPP: schemes, processes, materials, structures, models. Ed. by O.V. Efimov. Kharkiv, TOV «V spravi» [in Ukrainian].

2. Buongiomo, J. (2010) PWR Description. Massachusetts Institute of Technology.

3. Voronin, L.M. (1980) Peculiarities of design and construction of NPP. Moscow, Atomizdat [in Russian].

4. (2003) P-45-3: Regulations of arrangement and safe operation of steam and hot water line for facilities of nuclear power 
consumption. Moscow, NTTs YaRB Gosatomnadzor Rossii [in Russian].

5. Marushkin, V.M., Ivashchenko, S.S., Vakulenko, B.F. (1985) High-pressure heaters of TPP and NPP turbo installations. Moscow, Energoatomizdat [in Russian].

6. Troitsky, V.A. (2006) Concise manual on quality control of welded joints. Kiev, Feniks.

7. Bukarov, V.A. (2002) Technology of automatic arc shieldedgas welding. In: Welding in nuclear industry and engineering: Transact. NIKIMT, Vol. 1, 149-210 [in Russian].

8. Ishchenko, Yu.S. (2002) Physical-technological fundamentals of weld formation in arc welding process. Ibid., Vol. 2, 204-240 [in Russian].

9. Makhlin, N.M., Korotynsky, A.E., Bogdanovsky, V.A. et al. (2011) Single- and multioperator systems for automatic welding of position butt joints of nuclear power plant piping. The Paton Welding J., 11, 28-36.

10. Savitsky, M.M., Kushnirenko, B.M., Olejnik, O.I. (1999) Peculiarities of tungsten electrode welding of steels with activating fluxes (ATIG-process). Avtomatich. Svarka, 12, 20-28 [in Russian].

11. Bajic, D.R., Savitsky, M.M., Melnichuk, G.M. et al. (2002) A-TIG welding of structural steels for power engineering applications. The Paton Welding J., 9, 30-34.
12. Bajic, D.R., Melnichuk, G.M., Lupan, A.F. et al. (2002) Procedure and parameters of A-TIG welding of structural steels. Ibid., 10, 31-34.

13. Gordon, J.R. (1995) Perspectives on welding research and development in the USA. Weld. Review Int., 9, 95-108.

14. Stankevich, I.Ya., Dmitriev, V.I., Korida, V.L. et al. (1982) Application of activating flux in automatic welding of pipelines. Energeticheskoe Stroitelstvo, 10, 19-20 [in Russian].

15. Potapievsky, A.G. (1974) Consumable electrode shielded-gas welding. Moscow, Mashinostroenie [in Russian].

16. Kononenko, V.Ya. (2007) Consumable and nonconsumable electrode shielded-gas welding. Kiev, TOV Nika-Print [in Russian].

17. Svetsinsky, V.G., Rimsky, S.T., Galinich, V.I. (1994) Welding of steels in shielding gas mixtures on argon base in industry of Ukraine. Avtomatich. Svarka, 4, 41-44 [in Russian].

18. Rimsky, S.T., Svetsinsky, V.G., Shejko, P.P. et al. (1993) Consumable electrode pulsed arc welding in mixture of argon with carbon-dioxide gas. Ibid., 2, 38-41 [in Russian].

19. Aichele, G. (1990) Use of the pulsed technique-active gas metal-arc welding. Schweissen und Schneiden, 4, E62-E63.

20. Lobanov, L.M., Vodolazsky, V.E., Makhlin, N.M., Korotynsky, O.E. et al. (2017) Horizontal manipulator for arc welding of tubular structure parts. Ukraine, Applic. A2017 11752 [in Ukrainian].

Received 10.01.2018 


\title{
INFLUENCE OF SURFACING MODES USING FLUX-CORED STRIPS ON CHEMICAL COMPOSITION AND HARDNESS OF DEPOSITED METAL
}

\author{
A.P. VORONCHUK, A.P. ZHUDRA, A.V. PETROV and V.V. FEDOSENKO \\ E.O. Paton Electric Welding Institute of the NAS of Ukraine \\ 11 Kazimir Malevich Str., 03150, Kyiv, Ukraine. E-mail: office@paton.kiev.ua
}

\begin{abstract}
The influence of surfacing modes with an open arc using flux-cored strips of different types on chemical composition and hardness of the deposited metal was studied. PL-AN 101 and PL-AN 179 flux-cored strips manufactured on the base of steel strip-sheath, as well as PL-AN 111 strip on the base of nickel sheath were selected as the objects of investigations. Surfacing was performed in A-874N machine with VDU-1201 power source and AD-167 attachment in a wide range of modes. The dependencies of the change of chemical composition of the deposited metal on the value of current, voltage and deposition rate were established. At the same time, change of current values in the range of 600-1100 A has little effect on chemical composition of metal deposited with PL-AN 101 and PL-AN 111 strips, and in surfacing with PL-AN 179 strip it results in increase of the content of almost all alloying elements. Increase of voltage and deposition rate leads to decrease of the degree of alloying for all the types of flux-cored strips and to decrease of deposited metal hardness, and increase of current leads to its growth. 8 Ref., 1 Table, 4 Figures.
\end{abstract}

Keywords : flux-cored strip, surfacing modes, chemical composition, hardness

When obtaining data characterizing the influence of the modes of open-arc surfacing with flux-cored strip on geometrical dimensions of the deposited beads published in [1], the influence of surfacing modes on chemical composition and hardness of the deposited metal was studied in parallel. Investigation of these parameters is an important task, as change of surfacing modes essentially influences the processes of alloying element transition into the weld pool that, in its turn, affects the hardness values and deposited layer performance. This data is required for calculation of flux-cored strips at prediction of the deposited metal compositions.

Known are works [2,3], in which deposited metal composition was considered in interrelation with transition of alloying components in submerged-arc surfacing, depending on current, voltage and deposition rate. It was shown $[4,5]$ that in a number of cases an increase of carbon content is observed at increase of welding current, while manganese and silicon content in the deposited metal decreases.

The authors of works $[6,7]$ note that in flux-cored strip surfacing situations are possible when part of the powder filler passes into the weld pool, bypassing the drop stage. However, as shown by additional studies $[6,8]$, this is characteristic not for all the flux-cored strip designs. So, one-lock design of flux-cored strip with a tight lock allowed practically totally eliminating spillage of filler powder into the weld pool. There- fore, the industry has now switched to application of mainly this type of flux-cored strips.

Three grades of flux-cored strips were selected for investigations: PL-Np-300Kh25S3N2G2 (PL-AN 101), PL-Np-500Kh40N40S2RTs (PL-AN 111) and PL-Np-400Kh20B7M6V2F (PL-AN 179) of one-lock design of type B to GOST $26467-85$ of $16.5 \times 3.8 \mathrm{~mm}$ cross-section. Such selection of consumables allowed studying a rather wide range of deposited metal compositions, as PL-AN 101 and PL-AN 179 flux-cored strips are manufactured on the base of steel stripsheath, and PL-AN 111 strip on the base of nickel strip. Experiments were performed in surfacing machine A-874N, fitted with VDU-1201 power source and AD-167 attachment. Surfacing was performed by separate beads in one layer at reverse polarity direct current (RPDC) at unchanged extension of $50 \mathrm{~mm}$, and rigid external characteristic of the power source. Plates of St 3 steel $30 \mathrm{~mm}$ thick of $300 \times 400 \mathrm{~mm}$ size were used as base metal. Six beads of $200-250 \mathrm{~mm}$ length each were deposited on each of the plates. To eliminate the influence of preheating each subsequent bead was deposited after complete cooling of the previous one. Anode-mechanical cutting was used to cut out samples from bead middle portions, which after grinding were used to determine the composition and hardness of the deposited metal. Modes of surfacing with all the mentioned strips are given in the Table. 
Surfacing modes

\begin{tabular}{|c|c|c|}
\hline$I, \mathrm{~A}$ & $U, \mathrm{~V}$ & $v, \mathrm{~m} / \mathrm{h}$ \\
\hline $600 \pm 25$ & $32 \pm \mathrm{I}$ & $32 \pm 1$ \\
\hline $750 \pm 25$ & $32 \pm \mathrm{I}$ & $32 \pm 1$ \\
\hline $900 \pm 25$ & $32 \pm \mathrm{I}$ & $32 \pm 1$ \\
\hline $1150 \pm 25$ & $32 \pm \mathrm{I}$ & $32 \pm 1$ \\
\hline $1200 \pm 25$ & $32 \pm \mathrm{I}$ & $32 \pm 1$ \\
\hline $900 \pm 25$ & $24 \pm \mathrm{I}$ & $32 \pm 1$ \\
\hline $900 \pm 25$ & $28 \pm \mathrm{I}$ & $32 \pm 1$ \\
\hline $900 \pm 25$ & $36 \pm \mathrm{I}$ & $32 \pm 11$ \\
\hline $900 \pm 25$ & $40 \pm \mathrm{I}$ & $32 \pm 1$ \\
\hline $900 \pm 25$ & $32 \pm \mathrm{I}$ & $19 \pm 1$ \\
\hline $900 \pm 25$ & $32 \pm \mathrm{I}$ & $40 \pm 1$ \\
\hline $900 \pm 25$ & $32 \pm \mathrm{I}$ & $48 \pm 1$ \\
\hline $900 \pm 25$ & $32 \pm \mathrm{I}$ & $55 \pm 1$ \\
\hline
\end{tabular}

Chemical composition of the deposited layer was assessed by the spectral method, and deposited metal hardness was determined to GOST 9013-59 as arithmetic mean from not less than 20 measurements. Obtained results are given in the graphic form.
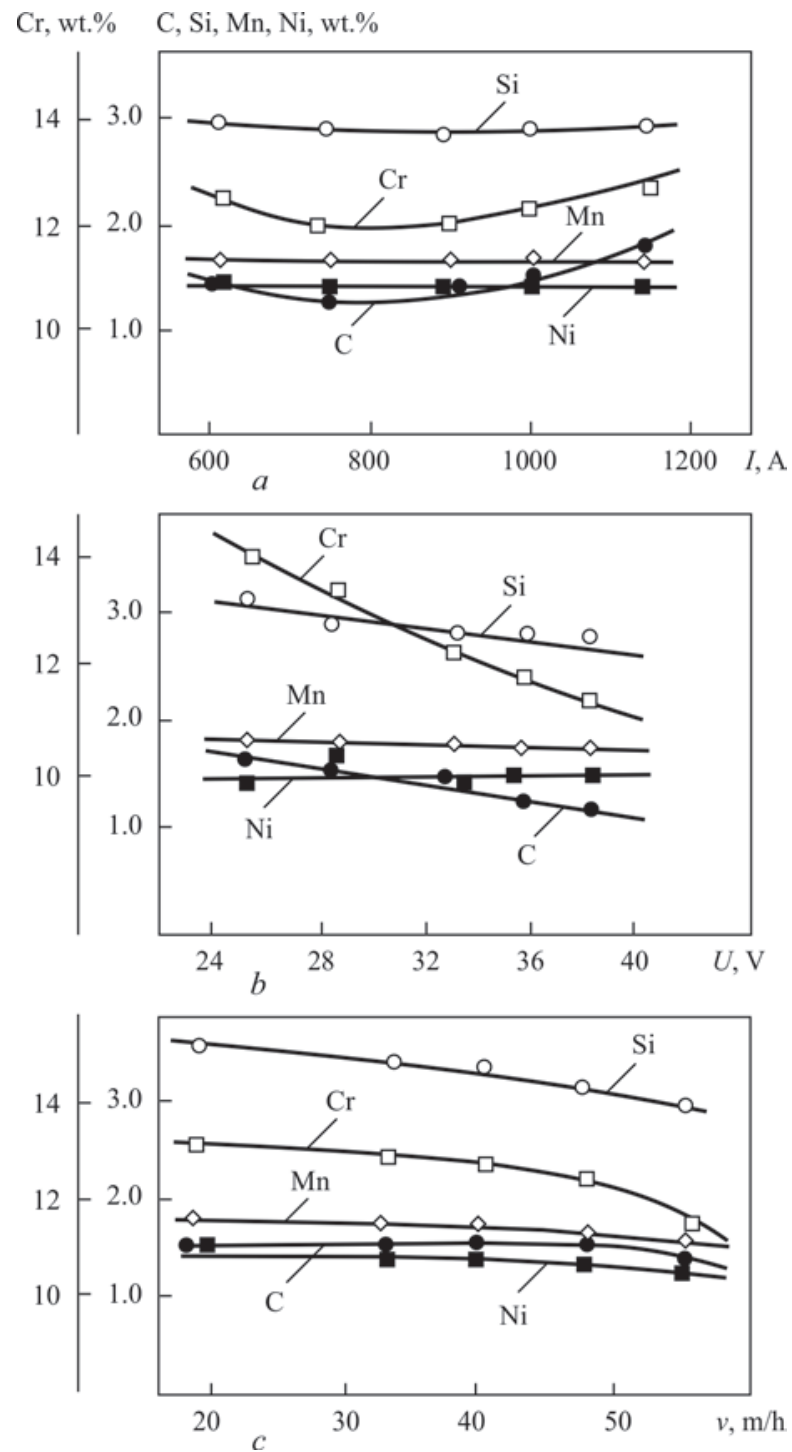

Figure 1. Chemical composition of metal deposited with PL-AN 101 flux-cored strip, depending on surfacing current $(a)$, voltage (b) and rate (c)
Figure 1 gives the data on chemical composition of the bead deposited with PL-AN 101 flux-cored strip, depending on current, voltage and deposition rate, respectively. At current increase from 600 up to $1200 \mathrm{~A}$, deposited metal composition changes only slightly (Figure 1, a). At voltage rise from 24 to $38 \mathrm{~V}$, a noticeable lowering of carbon and chromium content is observed. Silicon content in the deposited layer also decreases. Manganese and nickel content practically does not change here (Figure 1, b). Noted lowering of carbon and chromium content is, obviously, related to increase of the fraction of base metal in the deposited metal and greater loss of these elements at the drop stage and in the weld pool, as a result of increase of arc length.

At increase of deposition rate, the content of all the elements in the deposited layer decreases that is, obviously, related to greater spattering losses (Figure 1,c).

Figure 2 gives the composition of metal deposited with PL-AN 111 strip, depending on surfacing pa-
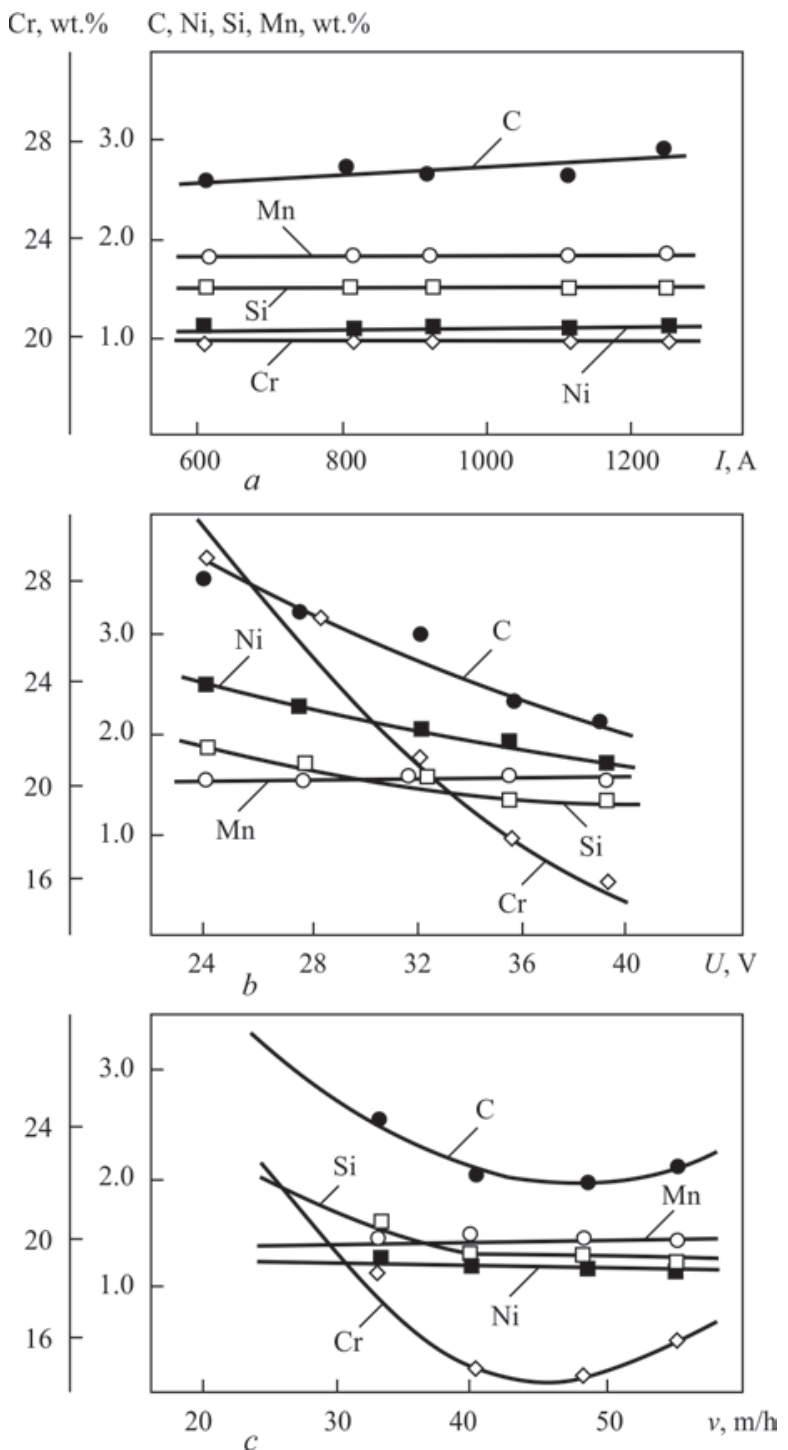

Figure 2. Composition of metal, deposited with PL-AN 111 fluxcored strip, depending on surfacing current $(a)$, voltage $(b)$ and rate $(c)$ 
rameters. Change of current in the range from 600 to $1200 \mathrm{~A}$ also practically does not influence the composition (Figure 2, a). Voltage rise from 24 to $38 \mathrm{~V}$ leads, mainly, to lowering of carbon and chromium content that is related to increase of base metal fraction in the deposited metal and alloying element loss (Figure 2,b). Minimum carbon and chromium content in the deposited metal corresponds to deposition rate of $40-50 \mathrm{~m} / \mathrm{h}$ (Figure 2, c).

Figure 3 gives chemical composition of metal deposited with PL-AN 179 flux-cored strip, depending on surfacing parameters. Increase of welding current values in the range from 600 up to $1200 \mathrm{~A}$ leads to increase of all the alloying elements content in the deposited metal, except for manganese, the content of which somewhat decreases (Figure 3,a). Voltage increase leads to lowering of the degree of alloying
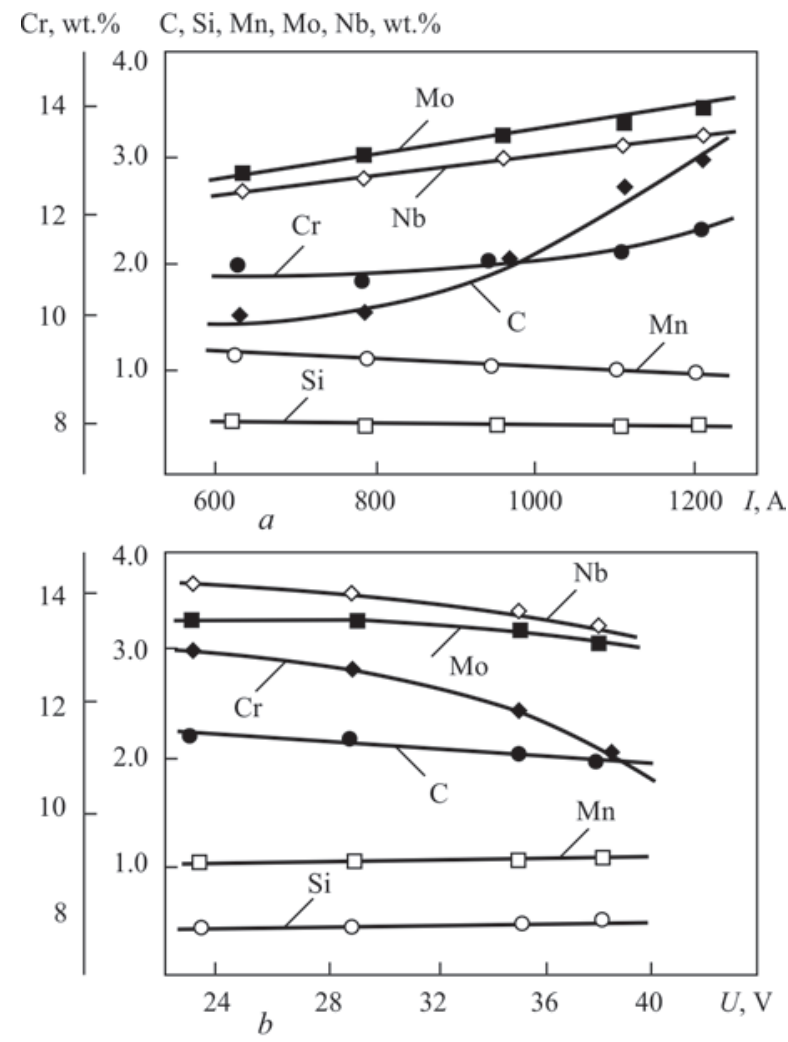

Cr, wt.\% $\quad \mathrm{C}, \mathrm{Si}, \mathrm{Mn}, \mathrm{Mo}, \mathrm{Ni}$, wt.\%

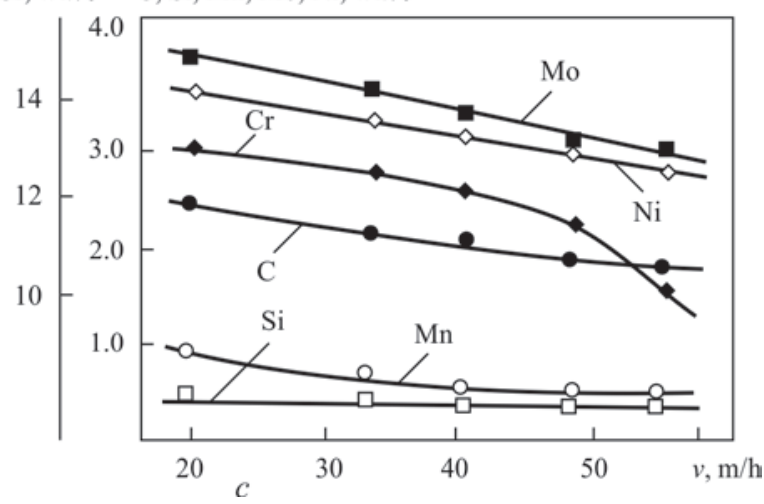

Figure 3. Composition of metal deposited with PL-AN 179 fluxcored strip, depending on surfacing current $(b)$ and rate with carbon, chromium, molybdenum and niobium in the entire considered range from 24 up to $38 \mathrm{~V}$. Manganese and silicon content remains practically unchanged (Figure 3, b). Increase of the rate from 19 to $55 \mathrm{~m} / \mathrm{h}$ leads to lowering of the content of practically all the alloying elements in the deposited layer (Figure 3,c).

Figure 4 gives the dependencies of the deposited layer hardness on deposition rate, arc voltage and welding current. One can see from the presented graphs that increase of deposition rate (Figure 4,c) and voltage (Figure $4, b$ ) lead to lowering of deposited layer hardness, and current increase (Figure 4, a) leads to its slight increase.

Considering the obtained results as a whole, the following should be noted. In addition to surfacing modes, the composition of powder-filler and material of sheath-strip have a significant influence on the characteristics of flux-cored strip melting, and, therefore, chemical composition and hardness of the deposited metal. So, in surfacing with PL-AN 111 flux-cored
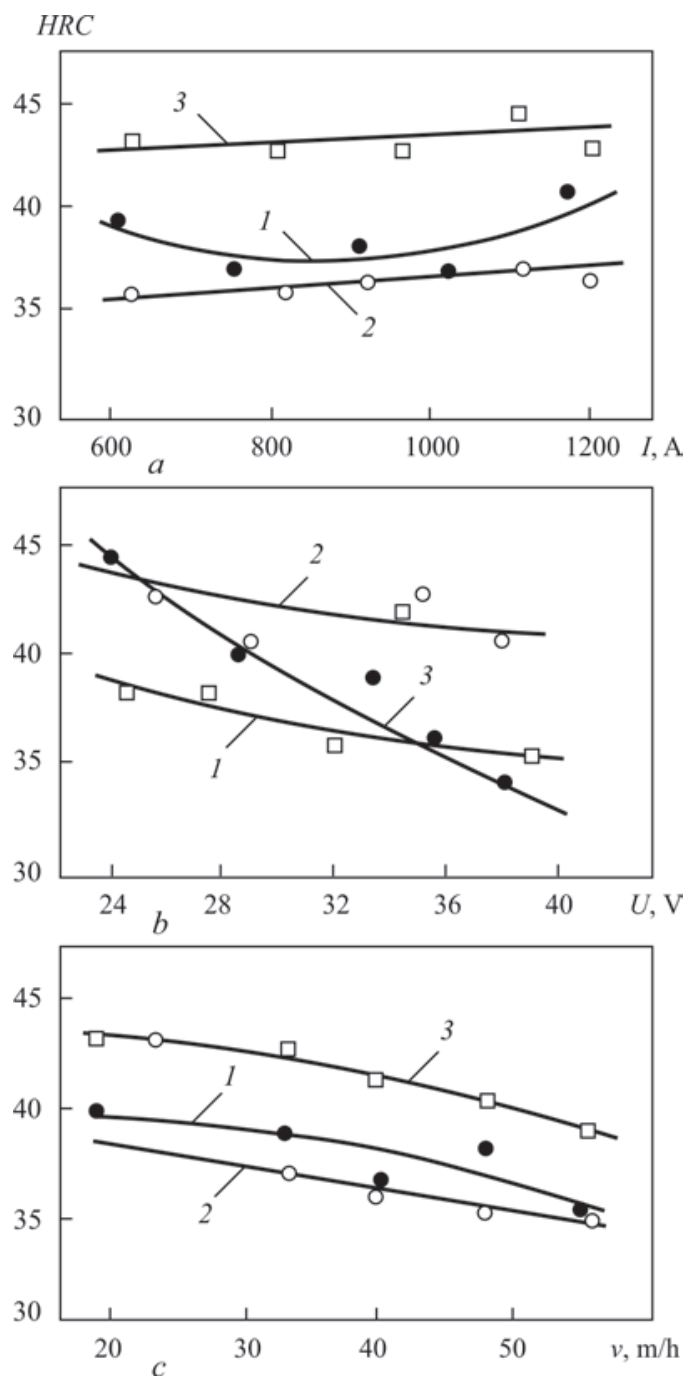

Figure 4. Deposited metal hardness, depending on surfacing current $(a)$, voltage $(b)$ and rate $(c)(1$ - PL-AN 101; 2 - PL-AN $111 ; 3$ - PL-AN 179) 
strip, manufactured on the base of nickel strip-sheath, all the studied characteristics differ considerably from the data obtained in surfacing with PL-AN 101 and PL-AN 179 flux-cored strips, manufactured from steel strip-sheath. In our opinion, this is related to lower, by approximately 1.5 times, ohmic resistance of nickel, compared to low-alloyed steel.

In surfacing with PL-AN 101 flux-cored strip, current rise leads to a slight change of the deposited metal composition, and voltage rise - to a significant reduction of the content of chromium, carbon, and silicon at stable values of the content of manganese and nickel. Voltage increase usually leads to larger arc gap that causes greater loss of the main alloying components at the drop stage.

Current increase in surfacing with PL-AN 179 fluxcored strip leads to increase of the content of all alloying elements and carbon at a stable content of manganese and silicon. Voltage increase only slightly influences the alloying element content, but markedly lowers carbon content. In this case, we observed a similar, but less pronounced effect, as in the previous case.

In surfacing with PL-AN 111 flux-cored strip, change of current values only slightly influences the deposited metal composition, and increase of voltage values leads to a considerable lowering of the content of chromium, carbon and nickel at stable values of silicon and manganese that is also related to increase of alloying element losses at the drop stage.

Increase of deposition rate does not influence the content of silicon and manganese for all the types of flux-cored strips. Here, lowering of alloying for PLAN 179 strip and to a smaller degree for PL-AN 101 strip is observed. For metal deposited with PL-AN 111 strip, increase of the rate leads to reduction of carbon and chromium, that is the consequence of increase of base metal fraction in the deposited layer.

Some inconsistency of the results of the influence of surfacing mode parameters on chemical composition of the deposited metal, produced with application of PL-AN 101 and PL-AN 179 flux-cored strips in our opinion is also attributable to considerable differences between the compositions of powder filler of the above strips. The base of the charge of PL-AN 101 strip is complex-alloyed master alloy, characterized by a lower melting temperature, than that of PL-AN 179 strip, consisting of refractory element components, such as tungsten, niobium, vanadium, and molybdenum.

Hardness of metal deposited with the studied fluxcored strips, correlates well with its chemical composition.

1. Zhudra, A.P., Voronchuk, A.P., Kochura, V.O. et al. (2017) Effect of flux-cored strip surfacing modes on geometric parameters of deposited beads. The Paton Welding J., 1, 36-40.

2. Kravtsov, T.G. (1978) Electric arc surfacing with electrode strip. Moscow, Mashinostroenie [in Russian].

3. Kudelya, E.S., Subbotovsky, V.P. (1954) Examination of composition and homogeneity of high-alloy deposited metal by spectral method. Avtomatich. Svarka, 3, 4-81 [in Russian].

4. Frumin, I.I. (1960) Automatic wear-resistant surfacing. Moscow, Mashinostroenie [in Russian].

5. Frumin, I.I. (1961) Automatic electric arc surfacing. Kharkov, Metallurgizdat [in Russian].

6. Yuzvenko, Yu.A., Gorpenyuk, B.N., Shimanovsky V.P. et al. (1977) Chemical macroheterogeneity of metal deposited by open arc with flux-cored strip. In: Theoretrical and technological principles of surfacing, 21-29 [in Russian].

7. Patskevich, I.R., Fejfets, L.A. (1971) About chemical heterogeneity of layer deposited with flux-cored strip in carbon-dioxide gas. Avtomatich. Svarka, 11, 66-67 [in Russian].

8. Zhudra, A.P., Voronchuk, A.P. (2012) Cladding flux-cored strips (Review). The Paton Welding Journal, 1, 39-44.

Received 14.02.2018 


\title{
APPLICATION OF NON-CONDUCTING CONSUMABLE BILLETS AT ELECTROSLAG SURFACING IN CURRENT-SUPPLYING MOULD
}

\author{
Yu.M. KUSKOV, V.G. SOLOVIOV, P.P. OSECHKOV and V.A. ZHDANOV \\ E.O. Paton Electric Welding Institute of the NAS of Ukraine \\ 11 Kazimir Malevich Str., 03150, Kyiv, Ukraine. E-mail: office@paton.kiev.ua
}

\begin{abstract}
The effect of increasing the distance from the processed surface to the current-conducting section of the current-supplying mould on base metal penetration, deposition rate and specific power consumption was studied at electroslag surfacing of end faces with application of non-conducting billets. Comparison of this effect on the quality of bimetal produced in electroslag surfacing with electrodes and non-conducting billets of the same cross-section was performed. It is found that application of optimal electric power to the slag pool through current-conducting section of current-supplying mould and of consumable billets allows achieving the set penetration of base metal, good formation of the deposited layer and process efficiency, commensurate with those obtained at surfacing with electrode of the same cross-section, only in the case of optimum distance from the melted edge of the consumable billet to the processed surface of the item. 13 Ref., 1 Table, 2 Figures.
\end{abstract}

Ke y word s : electroslag surfacing of end faces, non-conducting large-section consumable billet, current-supplying mould, power sources, processed surface, base metal penetration, surfacing quality

In addition to penetration, the most important parameters of electroslag surfacing (ESS) include the quality of deposited layer metal and its formation, and certainly, one of the main advantages of the electroslag process - increased surfacing efficiency, compared to other methods of producing bimetal by welding processes.

A large number of methods and engineering solutions of ESS performance have been proposed to produce sound bimetal products [1]. One of the simple, but at the same time effective methods is application of non-conducting filler, most often wire, alongside consumable electrodes in the electroslag process. This technique of addition of two melting welding consumables to the slag pool has become the most widely accepted in electroslag welding (ESW). Here, plates or electrode wires are used as electrodes [2-5], and the filler is additionally fed in the form of extruded or flux-cored wire and strips [6-8].

Application of additional filler results in improvement of the shape and dimensions of the metal pool, micro- and macrostructure of the deposited metal, as well as its mechanical properties; welding process efficiency is increased and power consumption is lowered. However, as noted in [5], further addition of cold filler to the slag pool cannot essentially change the amount of heat, coming to base metal from the metal pool. This is related to the fact that heat content of the metal pool is determined, mainly, by the temperature of drops falling into it from the molten electrode tip. Therefore, in ESS practice, unlike ESW, another direction of improvement of all the surfacing parameters has been developed. This is simultaneous application of both large-section consumable electrodes, and non-consumable electrodes at ESS [9-11]. In this case, however, although electric power applied to the consumable electrodes, can be decreased, nonetheless, the influence of overheated drops of electrode metal on metal pool temperature and on heating of the item processed surface, respectively, is preserved.

The work had the objective of achieving minimum and uniform penetration of base metal at good formation of the deposited metal by changing various process parameters (both electric, and geometrical) of ESS with ring-type non-consumable electrode, i.e. current-supplying mould (CSM), with application of non-conducting large-section billets instead of electrodes of the same size. It is of interest to compare the results obtained at ESS in CSM at alternating and direct currents, using large-section electrodes, with different electric connection circuits $[12,13]$, with the results of surfacing in CSM of the same size at melting of non-conducting consumable billets. Procedure of experiment performance is similar to that given in [13].

Figure 1 gives the electric connection circuit during performance of experiments on surfacing. Five experiments have been conducted at direct current $(33 \mathrm{M}$, $35 \mathrm{M}, 36 \mathrm{M}, 37 \mathrm{M}$ and $39 \mathrm{M}$ ) and one experiment at al- 


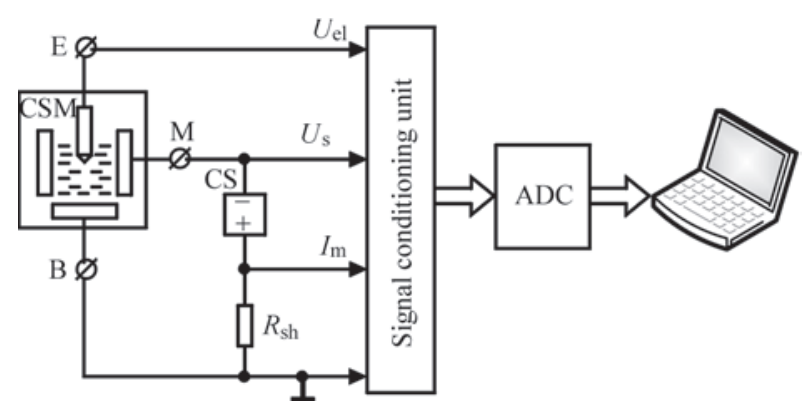

Figure 1. Diagram of electrical connections at performance of surfacing experiments $(\mathrm{E}, \mathrm{M}$, and $\mathrm{B}$ are the terminals of connection of the electrode, mould current-conducting section, and bottom plate with the item, respectively; CS is the direct current source; $R_{\mathrm{sh}}$ is the measuring current shunt; $U_{\mathrm{s}}, U_{\mathrm{el}}, I_{\mathrm{m}}$ are the signals proportional to current source voltage, supplied electrode voltage and mould (bottom plate) current, respectively; ADC is analog-digital converter)

ternating current $(6 \mathrm{M})$. In some experiments, position of the processed surface of the item relative to lower edge of current-conducting section of the mould was changed, namely this distance $h$ was equal to 110 , 70 and $44 \mathrm{~mm}$. Experiments were performed with non-conducting consumable billets of two diameters of 90 and $115 \mathrm{~mm}$. Longitudinal macrosections were cut out of all the surfaced samples for assessment of penetration depth and its uniformity over the fusion zone.

The Table gives the parameters of ESS modes and evaluation of the quality of bimetal samples, obtained during performance of these experiments.

Analysis of the results given in the Table, shows that indexes of surfacing quality for experiments, in which the distance from the processed surface to current-conducting section was large, namely 110 and $70 \mathrm{~mm}(6 \mathrm{M}, 33 \mathrm{M}$, and $35 \mathrm{M}$ experiments), were better, than for $36 \mathrm{M}, 37 \mathrm{M}$ and $39 \mathrm{M}$ experiments, in which $h=44 \mathrm{~mm}$. This is, supposedly, related to the fact that in the first case the slag pool volume and its heat capacity were greater, and it allowed ensuring fast heating of non-conducting billet edge to melting temperature at relatively low current value in the mould current-conducting section, and not overheat-

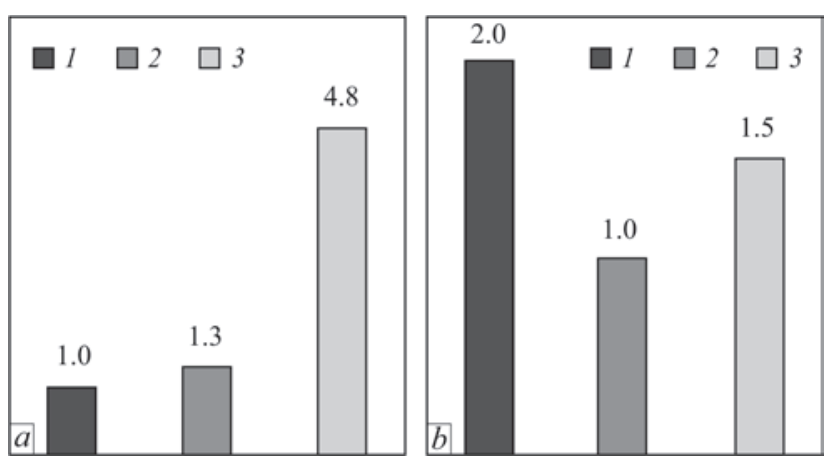

Figure 2. Histogram of comparison of minimum values of specific power consumption, $\mathrm{kW} \cdot \mathrm{h} / \mathrm{kg}(a)$ and minimum values of average penetration depth, mm (b) obtained during performance of surfacing experiments in CSM (1 - alternating current, for $a-D_{\mathrm{el}}=130 \mathrm{~mm} ; b-90 ; 2-$ direct current $D_{\mathrm{el}}=90 \mathrm{~mm} ; 3-$ non-conducting billet, $D_{\mathrm{b}}=115 \mathrm{~mm}$ )

ing the item around the periphery near the forming section walls. Moreover, at greater depth of the slag pool there are wider possibilities for selection of consumable billet edge position in the slag. At small value $h$ in practice it is difficult to «keep» the consumable billet edge at the required distance from the processed surface, and higher current in the mould current-conducting section increases the near-anode voltage drop on the item, and leads to deep penetration of its peripheral zone.

It follows from here that at technological schematic of surfacing with non-conducting billet, which offers much less possibilities for controlling the surfacing process, than the schematic with the consumable electrode, it is not rational to position the processed surface at a small distance from the mould current-conducting section.

Figure 2, $a$ shows the histogram of minimum values of specific power consumption and minimum values of average penetration depth (Figure 2, b), obtained at performance of experiments on ESS in CSM at alternating [12] and direct [13] currents, as well as at application of non-conducting billet. Quality indexes of bimetal of $33 \mathrm{M}, 35 \mathrm{M}$ and $6 \mathrm{M}$ samples give grounds to assert that the process of surfacing by

ESS parameter values and assessment of the quality of bimetal samples produced in CSM

\begin{tabular}{|c|c|c|c|c|c|c|c|c|c|c|c|}
\hline $\begin{array}{c}\text { Experiment } \\
\text { number }\end{array}$ & $\begin{array}{c}\text { Billet } \\
\text { diameter, } \\
\mathrm{mm}\end{array}$ & $\begin{array}{c}\text { Current, } \\
\mathrm{kA}\end{array}$ & $\begin{array}{c}\text { Voltage, } \\
\mathrm{V}\end{array}$ & $\begin{array}{c}\text { Power, } \\
\mathrm{kW}\end{array}$ & $\begin{array}{c}V_{\mathrm{b}}, \\
\mathrm{mm} / \mathrm{min}\end{array}$ & $\begin{array}{c}G, \\
\mathrm{~kg} / \mathrm{h}\end{array}$ & $\begin{array}{c}h, \\
\mathrm{~m}\end{array}$ & $\begin{array}{c}Q, \\
\mathrm{~kW} \cdot \mathrm{h} / \mathrm{kg}\end{array}$ & $\begin{array}{c}H_{\mathrm{av}} \\
\mathrm{mm}\end{array}$ & $\begin{array}{c}\Delta_{\mathrm{av}} \\
\mathrm{mm}\end{array}$ & $\begin{array}{c}\text { Surfacing quality } \\
\text { PSQ }\end{array}$ \\
\hline $33 \mathrm{M}$ & 90 & 1.81 & 31.3 & 56.7 & 2.14 & 6.4 & 110 & 8.9 & 1.6 & 1.2 & Satisfactory \\
\hline $35 \mathrm{M}$ & 90 & 1.65 & 46.1 & 76.1 & 2.0 & 6.0 & 110 & 12.8 & 1.8 & 1.3 & Same \\
\hline $36 \mathrm{M}$ & 90 & 2.59 & 36.5 & 94.5 & 0.5 & 1.6 & 44 & 60.3 & 8.4 & 7.2 & $»$ \\
\hline $37 \mathrm{M}$ & 90 & 2.57 & 35.3 & 90.7 & 0.42 & 1.2 & 44 & 73.1 & 8.1 & 7.2 & $»$ \\
\hline $39 \mathrm{M}$ & 90 & 2.52 & 35.6 & 89.7 & 3.8 & 14.9 & 44 & 8.0 & 7.6 & 7.0 & Good \\
\hline $6 \mathrm{M}^{*}$ & 115 & 2.2 & 36 & 79.2 & 6 & 16.5 & 70 & 4.8 & 1.5 & 1.0 & Same \\
\hline
\end{tabular}


the schematic with non-conducting billet can compete with ESS by consumable electrode both at alternating and at direct currents (Figure 2, b). In any case, however, it is necessary to take into account the position of consumable billet edge in the slag pool relative to the processed surface, as this parameter has a great influence on $H_{\text {av }}$ and $\Delta_{\text {av }}$ values. This fact is confirmed by the results of experimental ESS (36M, 37M and $39 \mathrm{M}$ experiments) (see Table). All the three samples were obtained as a result of melting of $90 \mathrm{~mm}$ billets at practically the same currents and voltages and the same distance from the processed surface to CSM current-conducting section $(44 \mathrm{~mm})$, as in this case the specific power consumption values differ considerably. This is attributable to uncontrolled change of the position of consumable billet edge in the slag relative to the processed surface. Frequent removal of the billet from the slag pool (for assessment of the position of the billet edge in slag) had a certain influence on the results, promoting lowering of the values of average speed of billet movement.

It is also obvious that ESS with application of non-conducting consumable billets cannot compete with ESS with consumable electrode as to deposition rate and specific power consumption. Electrode melting rate in CSM is higher a priori, than that of non-conducting billet, and ESS efficiency is higher, respectively. In its turn, heating of non-conducting billet to melting temperature through heating of the slag pool at passage of just mould current through it (unlike ESS with consumable electrode), leads to reduction of the concentration of applied power near the billet, that increases the specific power consumption in ESS with non-conducting billet (Figure 2,a).

Data obtained from $6 \mathrm{M}$ experiment show that at sufficient power applied to CSM, and optimum position of the edge of non-conducting consumable billet relative to the processed surface, good values of base metal penetration at high power efficiency of the surfacing process can be achieved.

Apparently, it rational to apply surfacing with non-conducting consumable billet in those cases, when, despite an increased power consumption, achieving minimum penetration is a mandatory condition for joining metals with markedly differing properties and definitely forming brittle structures in the fusion zone even at their slight mixing. Such a technology allows more reliably achieving minimum penetration, than in surfacing with large-section electrode by the schematic with the same potentials on the electrode and CSM current-conducting section.

In conclusion it should be noted that at ESS with non-conducting consumable billets sound bimetal joints can be obtained at relatively small distances from CSM current-conducting section to the processed surface, determined by surfacing modes and chemical composition of the applied flux. Here, the position of its edge in the slag pool relative to the processed surface should be taken into account, as this parameter has a great influence on base metal penetration values.

1. Artamonov, V.L., Sushchuk-Slyusarenko, I.I. (1988) Electroslag surfacing. Avtomatich. Svarka, 11, 41-46 [in Russian].

2. Benua, F.F., Katler, A.I. (1960) Technical-economic indexes of melting in automatic slag welding with plate electrode. Ibid., 10, 19-22 [in Russian].

3. Yakushin, B.F., Bashev, L.F. (1982) Study of the electroslag welding with filler metal. Izv. Vuzov, 7, 97 [in Russian].

4. Yakushin, B.F., Bashev, L.F., Tikhonov, V.P. et al. (1989) Improvement of technological strength of welded joint in electroslag welding. Avtomatich. Svarka, 10, 51 [in Russian].

5. Sushchuk-Slyusarenko, I.I., Shabalin, N.N., Andrianov, G.G. et al. (1974) Some means for improvement of electroslag welding efficiency. Ibid., 2, 46-48 [in Russian].

6. Gulida, V.P., Semenov, V.M., Yakovleva, L.I. et al. (1987) Electroslag welding with additional filler wire of parts from 09G2S steel of 60-140 mm thickness. Svarochn. Proizvodstvo, 2, 15-18 [in Russian].

7. Burkatsky, A.A., Durkin, V.E., Sushchuk-Slyusarenko, I.I. (1984) Electroslag welding with additional flux-cored wire feed. Avtomatich. Svarka, 6, 67 [in Russian].

8. Medovar, B.I., Saenko, V.Ya., Nagaevsky, I.D. et al. (1984) Electroslag technology in mechanical engineering. Kiev, Tekhnika [in Russian].

9. Ponomarenko, V.P., Stojko, V.P., Valits, K.A. et al. (1988) Electroslag surfacing using consumable and nonconsumable electrodes. In: Theoretical and technological principles of surfacing. Surfacing in metallurgical and mining industries. Kiev, PWI, 30-32 [in Russian].

10. Ermantraut, M.M., Malimonov, V.I. (1968) Application of nonconsumable electrode in electroslag surfacing. Svarochn. Proizvodstvo, 2, 16-18 [in Russian].

11. Kuskov, Yu.M., Soloviov, V.G., Zhdanov, V.A. (2017) Electroslag surfacing of end faces with large-section electrode in current-supplying mould. The Paton Welding J., 12, 29-32.

12. Kuskov, Yu.M., Soloviov, V.G., Osechkov, P.P. et al. (2018) Electroslag surfacing of billet end faces with application of consumable and nonconsumable electrodes. Ibid., 2, 38-41.

13. Kuskov, Yu.M., Soloviov, V.G., Osechkov, P.P. et al. (2018) Electroslag surfacing with large-section electrode at direct current in current-supplying mould. Ibid., 3, 32-35. 


\section{VISIT OF SPECIALISTS OF THE LANZHOU UNIVERSITY OF TECHNOLOGY (PRC) TO THE PWI}

In the period of March 18-25, 2018, on the official invitation of the PWI authority, a delegation of welding specialists of the Lanzhou University of Technology (LUT) as well as the enterprise Lanshi visited the PWI. That was already a repeated visit followed after the earlier visit of the PWI by the LUT management. The delegation included Dr. Yu Shi and Dr. Ding Fan, the wellknown scientists in China in the field of welding.

At the beginning of the meeting L.M. Lobanov, the Deputy Director of the Institute, Academician of the NASU, acquainted the guests with the history, achievements and main directions in the activities of the E.O. Paton Electric Welding Institute. Then the delegation visited the demonstration hall of the Institute, where
- development and creation of automatic expert systems for technical diagnostics of loaded parts, objects and structures (supervisor - A.Ya. Nedoseka);

- mathematical modeling in the field of evaluation of the residual life of welded structures operating under the conditions of static and dynamic loads (supervisor O.V. Makhnenko);

- development of new welding consumables (supervisor - V.V. Golovko);

- development of plasma welding technologies, hybrid and combined processes, as well as plasma cutting (supervisor - V.N. Korzhik);

- development of equipment and technologies for welding of live tissues (supervisor - G.S. Marinsky).

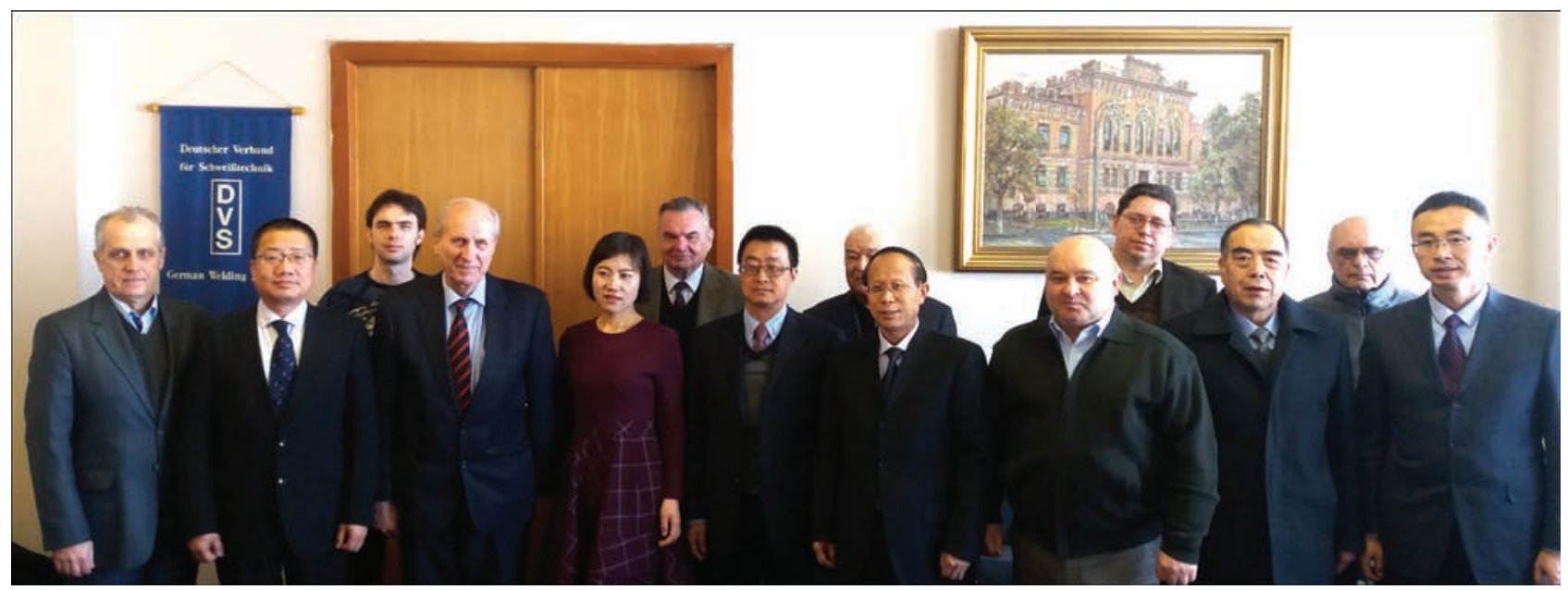

During the meeting at the E.O. Paton Electric Welding Institute

it studied the main directions of the Institute research works and the results of their practical application.

Further, the Chinese specialists were offered an extensive program of a deeper acquaintance with the scientific and practical activities of the Institute in separate areas. The presentations on the following directions were heard:

- development, mathematical modeling and application of highly effective processes of activated TIG and plasma welding, including welding over the active flux layer and welding with high-frequency modulation of welding current by programmed pulses. The demonstration of welding equipment and technologies was carried out (supervisor of the works - I.V. Krivtsun);

- development and application of highly effective processes for welding titanium alloys, including a narrow gap welding (supervisor - S.V. Akhonin);

- development of detonation spraying equipment and technology (supervisor — Yu.N. Tyurin);
The Chinese specialists were provided with information about the publishing activities of the E.O. Paton Electric Welding Institute, which was presented by A.T. Zelnichenko.

At the final meeting with the specialists of the People's Republic of China, a closing conversation was held with the participation of I.V. Krivtsun, Deputy Director, Academician of the NASU, at which the supervisors of the works on the directions were also present. As a result of joint discussions, the Protocol on the visit of the Chinese experts to the E.O. Paton Electric Welding Institute, as well as the Agreement on joint cooperation (exchange of specialists, joint research projects, search for customers by the Chinese part and support for the PWI developments implemented at the industrial enterprises in China) were signed.

On the invitation of the Chinese part in October of 2018, a delegation of specialists of the E.O. Paton Electric Welding Institute will visit the Lanzhou University of Technology.

D.V. Kovalenko 


\section{METHOD OF ASSESSMENT OF METAL STATE OF WWER-1000 REACTOR WELDED BODY}

The reactor body is a welded structure. The safe service of the reactor unit depends on many factors and is defined mainly by the reliability of the reactor body (RB), which has to preserve the integrity at a normal service, violation of service conditions and at design accidents.

The effect of service factors (neutron irradiation, increased temperature, cyclic loading) on metal of RB (base metal and weld metal) leads to change in metal properties, first of all, to reduction in the brittle fracture resistance. Therefore, the data about the developing of the radiation embrittlement process of RB metal are important from the point of view of safe service of the NPP.

The control of RB metal state is realized by testing the witness specimens (WS), mounted into the reactor, using the nondestructive and destructive methods. The results of the WS testing are representative for the assessment of RB metal properties only in that case, if the conditions of irradiation of specimens in the reactor and RB itself are known with a necessary accuracy, which requires making a thorough dosimetry of the neutron irradiation.

Test results of WS are the main source of information about RB metal state. Using the witness specimens the change in mechanical properties and characteristics of brittle fracture resistance is controlled. This information is required for justification of safe service life of the nuclear power unit.

\section{Basic materials}

In the nuclear power engineering of Ukraine 13 reactor units of WWER-1000 type are in service. Rated heat power of the reactor is $3000 \mathrm{MW}$, pressure of working medium (borated water) at the output of active zone is $160 \mathrm{kgf} / \mathrm{cm}^{2}$, temperature is $320^{\circ} \mathrm{C}$, consumption of a coolant is $84000 \mathrm{~m}^{3} / \mathrm{h}$. The bodies of reactors WWER-1000 are manufactured of low-carbon low-alloy steel of ferrite-pearlite class of chrome-nickel-molybdenum-vanadium composition. The nickel-free steel 15Kh2MFA, used earlier for bodies of the WWER440 reactors, was not suitable for manufacture of RB of WWER-1000 by strength and technological properties. In particular, it was necessary to decrease the temperature of preliminary and concurrent heating in welding, as well as to eliminate subsequent tempering after completion of welding works with account for possibility of some lowering the tempering temperature. In this connection the bodies of reactors WWER-1000 are manufactured of 15Kh2NMFA grade steel. To manufacture the upper and bottom shells, located opposite the active zone, steel 15Kh2NMFA-A of the same composition is used, but with more strict requirements as to content of harmful impurities (phosphorus, copper and sulphur).

The reactor body consists of 7 shells, welded together by the circumferential welds. For each element of RB, an ingot of a definite weight is produced by casting, from which a proper forging is manufactured. Weight of forgings for RB of WWER-1000 is from 70 up to 115 tons. The thick-walled shells are manufactured from ingots in the hydraulic presses. An ellipsoid segment for a bottom is manufactured by a stamping method. Forgings for $\mathrm{RB}$ are subjected to hardening and tempering. After full heat treatment of initial billets a sample is cut out from each of them for mechanical and technological tests. Then billets are subjected to the preliminary mechanical treatment and edge preparation for welding of circumferential welds.

\section{Welding consumables}

In manufacture of RB of WWER-1000 different welding consumables are used for welding of circumferential welds: wire Sv-08KhGNMTA with flux 48NF-18M or wire Sv-10KhGNMAA and Sv-12Kh2N2MAA with flux FTs-16A. As the use of these consumables was permitted by the valid standard documentation, then the plant-manufacturers (Izhora and Atommash) performed welding of circumferential joints on the same type of $\mathrm{RB}$ by using different technological variants. Later, to reduce the radiation embrittlement factor, the solution was taken to refuse the applying of welding consumables with nickel content of more than $1.5 \%$ for welds, located opposite the active zone. However, this was not already important for the power units of the NPP of Ukraine, as the bodies of reactors were manufactured earlier. 
After the completion of welding of each circumferential weld the heat treatment by a high tempering mode is performed. The anti-corrosion surfacing is made inside by the automatic welding with a strip electrode of Sv-07Kh25N13 grade (first layer) and Sv-08Kh19N10G2B (second and third layers) under the flux layer at rotation of $\mathrm{RB}$ in a special tilter. This operation requires also the post heat treatment (additional tempering), therefore, the tempering after welding is performed together with a tempering after surfacing.

\section{Manufacture of witness specimens}

WS of base metal (BM) of RB are manufactured at the plant-manufacturer of the reactor bodies from tolerances of one of the shells, located opposite the active zone, for which the content of harmful impurities by a sum $(10 \mathrm{P}+\mathrm{Cu})$ is highest, and in case of an equality of this value it is manufactured from a shell for which the content of arsenic, antimony and tin $(\mathrm{As}+\mathrm{Sb}+\mathrm{Sn})$ is highest.

WS of weld metal (WM) and heat-affected zone (HAZ) are manufactured of an industrial reference welded joint, made at the same groove preparation, the same modes and methods of welding, using the welding consumables of the same batch as the welded joints of RB shells, located in the active zone region, passed the complex of heat treatments, as the RB itself.

In accordance with the requirements of PNAE G-7-002 and PNAE G-7-008 the control of change in properties of BM, WM and HAZ is envisaged in specimens of Charpy, Charpy with a crack and tensile specimens, namely:

- proportional ten-fold cylindrical specimens of $3 \mathrm{~mm}$ diameter test part for the tensile tests (T);

- test specimens for impact bending of type II by GOST 9454 for BM and type IX by GOST 6996 for WM and HAZ ( Charpy specimens) (Ch);

- specimens of COD type for determination of crack resistance (Charpy with a crack) (C).

The witness specimens are placed into airtight containers, manufactured from stainless steel 08Kh18N10T. Heat removal from WS, heated by a neutron flux and gamma-irradiation, is provided by means of fillers and gaskets of aluminium of aluminium alloys. At the present time, two types of containers are used. The regular container is a cylindrical container with thick walls, withstanding the operating medium pressure without deformations. These containers are supplied by a plant-manufacturer in a set with RB. The main drawback of regular container assemblies (CA) with cylindrical containers is the high scattering of value of neutrons fluence on the WS test parts due to a high gradient of the neutron flux around the perimeter and height of regular CA. In the updated programs it is rational to use plane containers, which allow decreasing greatly the gradient of neutron flux to WS test parts, irradiated in the same container, at optimum orientation of CA.

At all the power units of WWER-1000 of the NPP of Ukraine the container assemblies with irradiated WS are mounted into a space between the upper edge of a compartment and the lower edge of a block of protective pipes into special pipes, welded-on to the upper edge of the compartment. Containers with WS are arranged into container assemblies which are mounted at the upper and lower tiers.

Results of the WS testing are representative for evaluation of RB metal properties only in that case, if the conditions of specimens irradiation in reactor and RB itself are known at a required precision. To determine the conditions of WS irradiation (fluence of rapid neutrons of energy $E \geq 0.5 \mathrm{MeV}$ and irradiation temperature) in the container with WS, the neutron-activation indicators (NAI) and irradiation temperature indicators (ITI) are mounted. NAI represent foils (thin discs) or wires of metals (chemically pure iron, niobium, copper), which are placed into the aluminium alloy capsule. As ITI, the indicators on the base of a diamond powder and fusion-type monitors of temperature, based on fusible eutectics with a melting temperature, close to a temperature of the coolant, are used. The indicators are placed in holes, made in WS or in the fillers.

Arrangement of containers with WS in CA provides the irradiation of containers of the upper tier by the neutron flux, approximately equal to the neutron flux to the inner surface of RB, and that of the lower tier is irradiated by the neutron flux of approximately 2.5 times higher, which allows determining the metal properties at the present moment and predicted period until the fuel unloading.

The terms of withdrawal of sets of witness specimens are determined from the results of investigations of specimens of the previous sets of WS, analysis of accumulated fluence of rapid neutrons at the inner surface of RB 
since the service beginning and value of a critical temperature of brittleness for the predicted period. Evaluation of results of WS investigations are carried out by the comparison of predicted properties of RB materials, obtained during the WS testing, with limited admissible values, established in RB design documentation. From the results of this comparison the conclusion is made about the feasibility of safe service of RB before the unloading and testing the next set of WS or about the need in carrying out the compensating measures in case, if it is expected that during the period of time, for which the prediction is made, the controllable values of base and weld metals will come out beyond the safe limits.

In case of emergency stop of the reactor operation and its filling with a cold water (at thermal shock), the high stresses are occurred in RB. The state of RB metal is evaluated mainly by a critical temperature of brittleness $T_{\mathrm{cr}}$ at which the body integrity is provided. In some cases, to avoid the brittle fracture the constant preheating of a water container up to temperature above the critical one is used.

If it is revealed during the process of reactor service that RB is subjecting to embrittlement more intensively that the metal of other similar bodies, then it is possible either to decrease the neutron flux in a preset point of RB due to, for example, change in procedure of fuel loading, or to perform a special heat treatment of the body («annealing»). In this case a powerful programmable heat source (based usually on electric heaters and filament lamps) is used. The body is heated slowly approximately up to $500{ }^{\circ} \mathrm{C}$, held at this temperature not less than 20-40 h and then cooled slowly. Time of heating and cooling is not less than 4-20 h, maximum heating temperature is determined by the strength of concrete and structures of the reactor support elements. The cooling rate is usually lower than that in heating for decreasing stresses in the anti-corrosion inner surfacing of the body.

During metal irradiation with a neutron flux the defects are formed in a crystalline lattice. The value of defects depends on energy of the moving neutron. During decay of uranium nuclei the neutrons emission is occurred with a wide energy spectrum. At metal annealing the defects of the crystalline lattice are annihilated («dissolved») due to energy of heating, and the energy spectrum of lattice atoms is comparatively narrow and determined by the metal heating temperature. It is evident, that the probability of annihilation is higher in small defects, formed by neutrons with a low energy. Consequently, during heating the low-energy defects are most intensively dissolved in the lattice, and the defects from neutrons with a high energy are preserved. Thus, the annealing purifies the lattice mainly from low-energy defects. Moreover, the total density of defects is decreased and the values of metal ductility are increased.

Effect of brittleness decrease as a result of annealing can occur to be comparatively short. At the above-mentioned parameters of annealing the brittle fracture resistance is not recovered completely up to the initial state of the non-irradiated metal. From the system point of view, during the process of reactor operation the annealing is a comparatively short-time disturbance and the system is gradually returned into a normal state.

It should be noted that the metal heating during annealing contributes also to decrease in concentration of atoms of harmful impurities, in particular, phosphorus at the grain boundaries and increases the metal resistance to the brittle fracture.

The definite difficulties in control of the reactor body properties may be connected with insufficient number of WS, in particular, for doubling the measurements in evaluation of current and accumulated fluence of rapid neutrons. In this case, it is possible to apply the method of specimens reconstruction. It consists in the following. To the fragments (halves) of irradiated specimens after tests for impact and three-point static bending the tail pieces are welded-on, they are cut by a required size and a proper notch is made in the middle of the obtained specimen. As a result we have a specimen with a notch in the test part of the irradiated material. The main requirement to welding is a minimum power of welding to avoid the specimen overheating and violation of its properties. The electron beam welding is usually used.

In general, the accepted system of control of metal properties of the reactor body and its welds allows evaluating and predicting their properties at an acceptable accuracy and reliability. The certain drawback is the WS arrangement in the reactor. It would be more logic to place them on the body inner wall, however, it is connected with the change in design and sizes of the reactor body.

O.G. Kasatkin 
Developed in the PWI

\section{HYBRID LASER-ARC DEPOSITION OF DIAMOND AND DIAMOND-LIKE COATINGS}

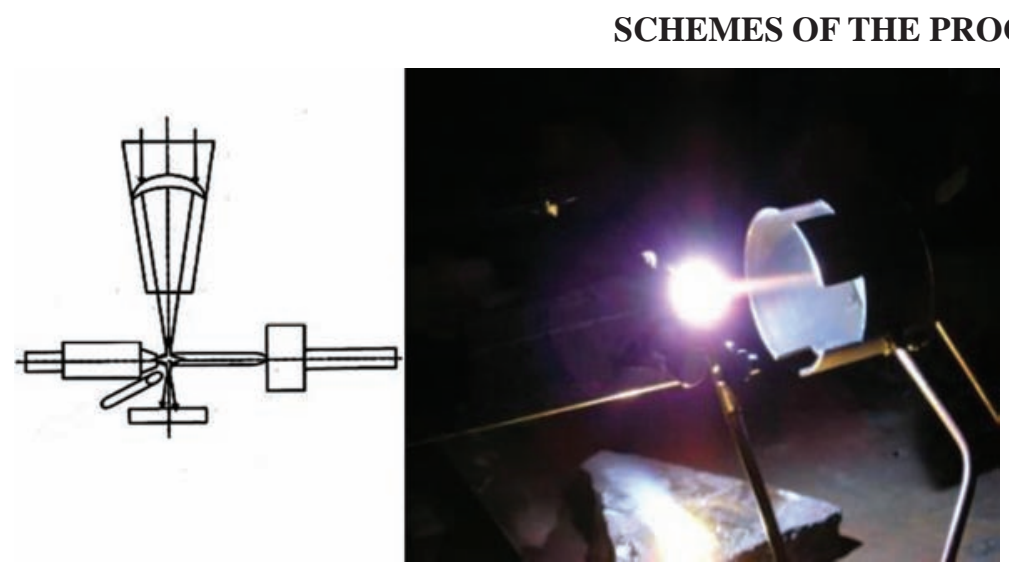

Intercoupling of plasma jet with laser radiation: $\mathrm{CO}_{2}$-laser $(2 \mathrm{~kW})$, plasmatron MP-03 (2 kW)

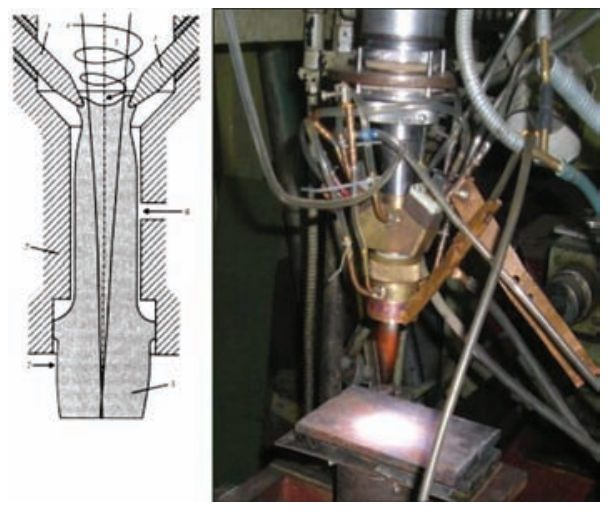

Coaxial interaction of plasma jet with laser radiation: $\mathrm{CO}_{2}$-laser $(2 \mathrm{~kW})$, plasmatron ILDP-01 $(2 \mathrm{~kW})$

Parameters of the processes

\begin{tabular}{|c|c|c|c|c|c|}
\hline Types of coatings & $\begin{array}{c}\text { Duration of treatment, } \\
\text { min }\end{array}$ & $\begin{array}{c}\text { Treatment distance, } \\
\mathrm{mm}\end{array}$ & $\begin{array}{c}\text { Working gas (composi- } \\
\text { tion, consumption, } \\
1 / \mathrm{min})\end{array}$ & $\begin{array}{c}\text { Material } \\
\text { of base }\end{array}$ & $\begin{array}{c}\text { Temperature of base, } \\
{ }^{\circ} \mathrm{C}\end{array}$ \\
\hline Diamond & $5-15$ & $40-75$ & $\begin{array}{c}95 \mathrm{H}_{2}+\mathrm{CH}_{4} \\
0.8-2.3\end{array}$ & $\mathrm{Mo}, \mathrm{Si}$ & $600-950$ \\
\hline Diamond-like & $7-15$ & $50-180$ & $\begin{array}{c}95 \mathrm{H}_{2}+5 \mathrm{CH}_{4} \\
0.6-1.4\end{array}$ & Steel 45, titanium alloy & $100-250$ \\
\hline
\end{tabular}

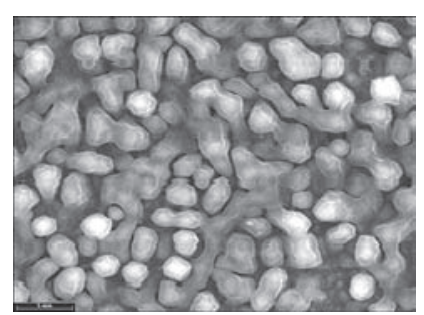

Diamond coating based on mo- Diamond-like coating on steel lybdenum
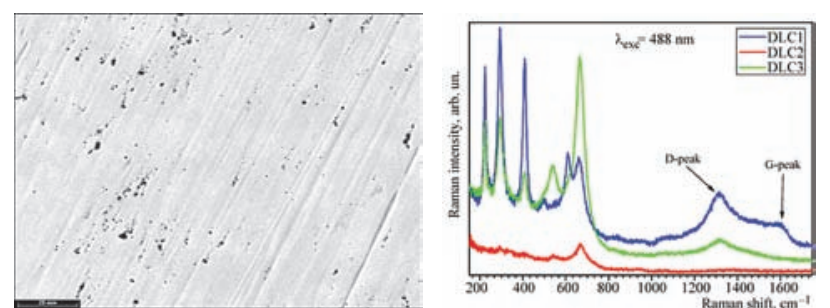

Raman spectroscopy of diamond-like coatings

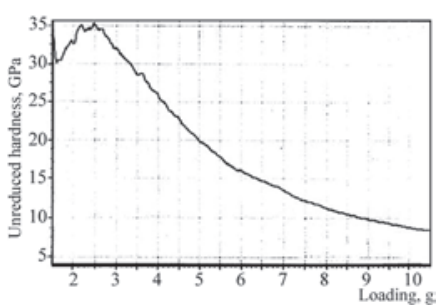

Hardness of diamond-like coatings on steel 45 at $T<250{ }^{\circ} \mathrm{C}$, $\Delta_{\text {coat }}=0.5-7 \mu \mathrm{m}$

PROPERTIES OF DIAMOND-LIKE COATINGS

Coating thickness, $\mu \mathrm{m}-0.3-3$

Hardness/ GPa:

- on steel surface - 12-35 (hardness of base makes 2.0-2.6)

- on surface of titanium alloy - 15-30

Deposition rate, $\mu \mathrm{m} / \mathrm{h}-2-25$

\section{RESULTS}

- physical-mathematical model of plasma jet, which is generated by integrated laser-arc plasmatron, was developed;

- an integrated laser-arc plasmatron ILDP-01 of up to $5 \mathrm{~kW}$ power for coating deposition was developed;

- a process of laser-plasma coating deposition under conditions of intercoupling and coaxial interaction of plasma jet with laser beam was investigated;

- conditions of formation of diamond and diamond-like coatings were investigated;

- structure of diamond coatings on the bases from Mo and Si and structure and properties of diamond-like coatings on the bases from steel 45 and titanium alloy were investigated. 


\section{EQUIPMENT FOR PRODUCTION OF 3D METALLIC PARTS}

\section{USING PLASMA-ARC TECHNOLOGY METHODS}

Automatic versatile complex was developed for additive plasma-arc and microplasma deposition of volumetric metallic products with head movement working zone $900 \times 900 \times 900 \mathrm{~mm}$. Joint development of PWI and «PLAZER» Company.

$>$ Automatic complex allows producing the volumetric metallic products using powder and wire materials.
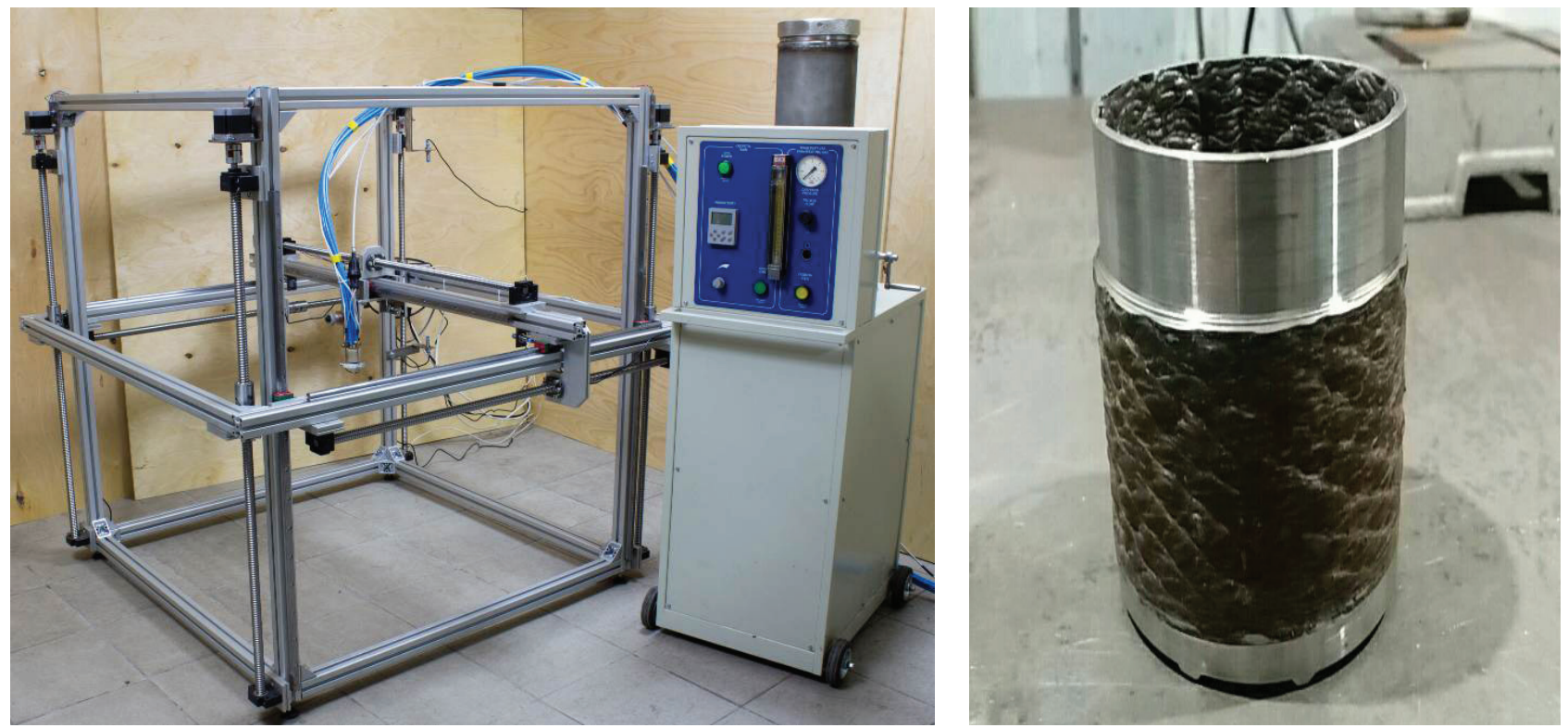

Block-modular structure of the equipment allows realizing additive production of the parts with following methods:

$>$ MIG-MAG surfacing

$>$ Plasma surfacing

$>$ Microplasma surfacing

$>$ Hybrid plasma-MIG surfacing 


\section{REVERSE POLARITY PLASMA-AIR CUTTING}

Universal technological complex was developed for reverse polarity plasma cutting of metals, for severing of stainless steels, ferrous and non-ferrous metals of 5-200 mm thickness with direct current plasma arc. Joint development of PWI and «PLAZER» Company.
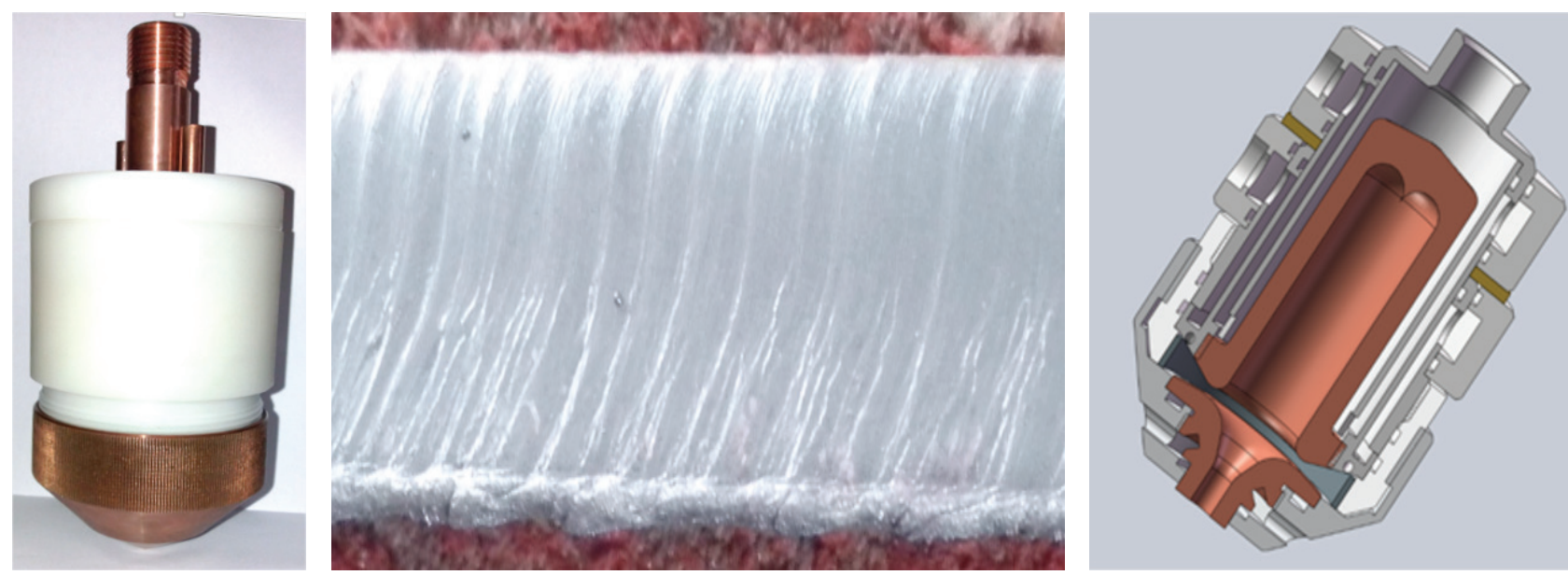

\section{UNIT FOR}

PLASMA-ARC WIRE SPRAYING OF COATINGS

The unit realizes a process of plasma-arc wire spraying in argon arc with intensive concurrent air blowing.

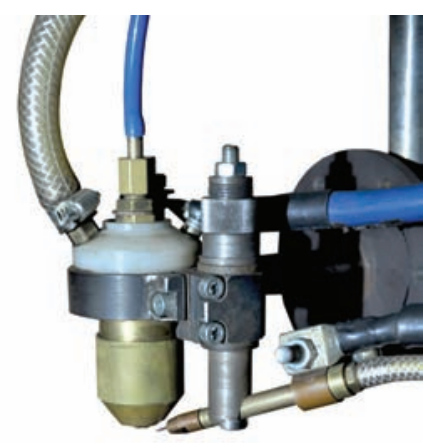

Plasmatron of plasma-arc unit

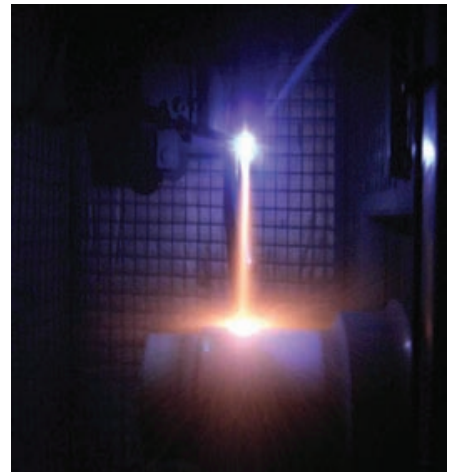

Process of plasma-arc spraying with current-carrying wire

The unit is designed for deposition of wear resistant, corrosion resistant and special coatings by means of spraying of current-conducting materials in form of powder and compact wires of $1.6-1.8 \mathrm{~mm}$ diameter. Thickness of deposited coatings is $0.05-5 \mathrm{~mm}$ (and more). Compressed air and argon are used as working gases. Joint development of PWI and «PLAZER» Company. 